\title{
Murburn precepts for redox dynamics in glycolysis, Cori cycle and Warburg effect: Is lactate dehydrogenase a murzyme?
}

\author{
Kelath Murali Manoj ${ }^{1 *}$, Vijay Nirusimhan ${ }^{l}$, Abhinav Parashar ${ }^{l}$, Jesucastin $E^{l}$, Daniel Andrew Gideon ${ }^{{ }^{*}}$ \\ ${ }^{1}$ Satyamjayatu: The Science \& Ethics Foundation, \\ Shoranur-2 (PO), Palakkad District, Kerala, India-679122. \\ KMM-satyamjayatu@yahoo.com; (ORCID: 0000-0003-4515-994X) \\ DAG-dnlndrwster@gmail.com (ORCID: 0000-0003-2470-550X)
}

\begin{abstract}
Physiological redox conversion of alpha-hydroxy/keto acids is believed to be reversibly carried out by (de)hydrogenases, employing nicotinamide cofactors. With lactate dehydrogenase (LDH) as example, we point out that while the utilization of NADH for the reduction of pyruvate to lactate (the post-glycolytic reaction) can be mediated via the classical Michaelis-Menten mechanism, the oxidation of lactate to pyruvate (with or without the uphill reduction of $\mathrm{NADH}$ ) necessitates alternative physiological approaches. This reaction could be more efficiently coupled/catalyzed with/by murzyme activities, which employ diffusible reactive (oxygen) species (DRS/DROS/ROS). Such a scheme would enable the cellular system to tide over the unfavorable energy barriers of the forward reaction $(\sim 450 \mathrm{~kJ} / \mathrm{mol}$; earlier considered to be $\sim 25 \mathrm{~kJ} / \mathrm{mole}$ !), and give kinetically viable conversions. Further, the new mechanism does not necessitate any 'smart decision-making' by the pertinent redox isozyme(s). For LDH, the new theory explains its multimeric nature, non-variant structure of the isozymes' active sites and accounts for why lactate is transported to the liver for further utilization within the physiological purview of Cori cycle. The theoretical insights, in silico evidence and analyses of literature herein also enrich our understanding of 'lactic acidosis' (in clinical context), Warburg effect and approach for cancer therapy.
\end{abstract}

Keywords: murburn concept; lactate dehydrogenase; lactate; pyruvate; Gibbs free energy of reaction in water; Warburg effect; Cori cycle; murzyme 


\section{Contents}

\section{INTRODUCTION}

Unresolved aspects of LDH function

\section{MATERIALS AND METHODS}

2.1. The alpha hydroxyl/keto acid dehydrogenase system of $\mathrm{LDH}$

2.2. In silico strategies

\section{RESULTS AND DISCUSSION}

3.1. Application of corrected thermodynamic approach in LDH system

3.2. The murburn model for lactate oxidation in liver/cancer

3.3. Analysis and extrapolation to other alpha-hydroxy acid oxidations

3.4. Understanding $\mathrm{pH}$ dynamics in glycolysis

3.5. LDH mediated conversions of pyruvate-lactate and nicotinamide nucleotides

3.5a. Classical structure-function correlations of monomers/multimers of LDH

3.5b. Analysis of the classical mechanism for the forward and backward reactions

3.5c. Explorations of LDH isozyme structures (human, rat, rabbit and pig)

Binding of ligands

Binding of inhibitors

3.5d. Predictability and validation of new proposals

\section{CONCLUSION}




\section{INTRODUCTION}

Alpha hydroxy-/keto- acids form key metabolic junction points for divergent pathways of two to six carbon-backboned molecules of various classes of biomolecules like carbohydrates and amino acids. The 3-carbon organic anions of lactate-pyruvate are salient intermediates of this class of molecules in animal physiology. About five decades back, Keith L. Manchester, an erudite Professor of Biochemistry from University of Witwatersrand, had written a one-page essay on lactate dehydrogenase (LDH) that catalyzed pyruvate-lactate inter-conversions, titled"Kinetics of lactate dehydrogenase: A textbook problem" (Manchester, 1977). The write-up presents thought-provoking pointers regarding the functioning of, a highly studied redox enzyme of clinical relevance. In the initial parts, he points out the disagreement of theoretical concepts advocated by reputed textbooks of Lehninger and Stryer, vis a vis the published literature regarding how the different isozymes are supposed to function in situ (at various tissues like skeletal muscles, heart and liver). In the last two paragraphs, he discusses the distinct conditions employed for assays in vitro, in contrast with the actual physiological premises. We reproduce (verbatim) his words from the middle portion of the insightful article:

"If we turn to skeletal muscle the role of A4 appears to be mainly that of a pyruvate reductase. In a tissue less well oxygenated and with a lower mitochondrial content than heart then the capacity for oxidation of pyruvate is likely to be less in relation to the glycolytic flux. However it is uneconomical to convert pyruvate to lactate if capacity for oxidation of pyruvate exists. The relatively high $K_{M}$ of the A4 isozyme towards pyruvate may tent to limit its function until pyruvate begins to accumulate. The erythrocyte seems to confuse the picture since it is a lactate producer yet in a number of species including man it possesses mainly B4 isozyme. It could be argued that, lacking any respiratory chain, it is desirable for the erythrocyte to get rid of pyruvate and NADH as rapidly as possible and thus a high affinity isozyme may be an advantage. The isozyme spectrum of the liver is more difficult to rationalise. It is primarily A4 in man, and presumably works in the direction of lactate oxidation, but as with the red cell, there appears to be considerable species variation in the hepatic spectrum."

Although decades have gone by, we believe that the issues are still unresolved. Further, while some consensus exist that lactate oxidation occurs in mitochondria, there are disagreements regarding the roles of cytoplasmic/mitochondrial LDH, the modality/necessity of transfer of pyruvate/lactate across the mitochondrial membrane, and the dynamics of lactate within the context of Warburg effect (Glancy et al., 2021). In conjunction to the issues identified above, we present an even more intriguing conundrum on the subject of Cori cycle. Since both muscles and liver have a high density of the same LDH isozyme or monomer (1/A4/M4) (Read et al., 2001), 
it is inexplicable with current awareness as to why lactate formed in muscles should be transported to the liver for recycling as pyruvate. Particularly, when muscle cells have $\sim 4$ fold higher expression of LDH (Fountain et al., 1970)! The current work explores if LDH could serve as a murzyme (an enzyme which utilizes diffusible reactive species for catalyzing a reaction) under the purviews of murburn concept (a new explicatory paradigm in redox metabolism/physiology), within the context of Cori cycle (Figure 1). (For a brief background on murzymes/murburn concept, alpha-hydroxyacid metabolism and the pertinent enzymes like LDH, please refer Item 1, Supplementary Information.) We propose that coupling the energetically unfavorable proton releasing reactions with murzyme activity could enable viable turnovers in the forward reaction, which would otherwise be limited by thermodynamic and kinetic considerations. (In this manuscript, we adopt the conventional terminology of the lactate $\rightarrow$ pyruvate conversion as the forward reaction and the reverse as the backward reaction.)

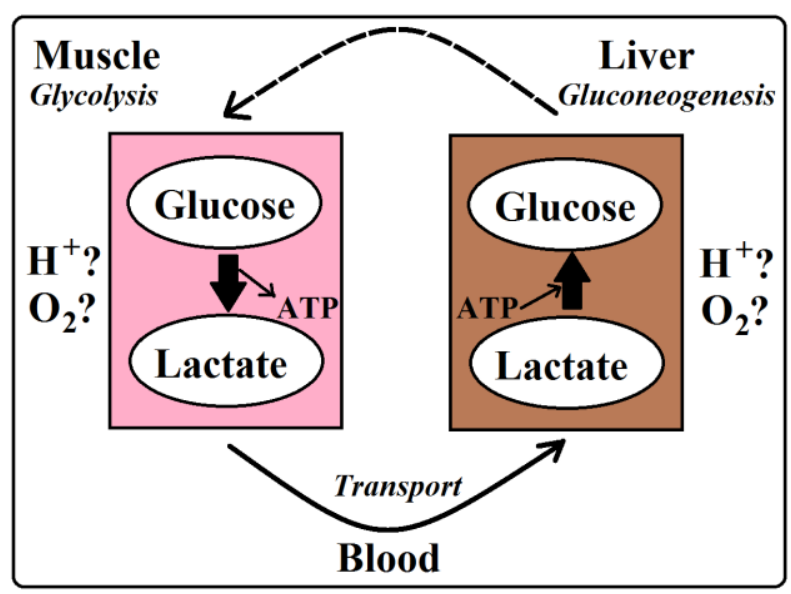

Figure 1: A schematic representation of Cori cycle. The backward reaction (lactate formation) in muscle generally occurs under anaerobic conditions (either due to lowered supply or by depletion of oxygen by accelerated mitochondrial function or both). The forward reaction (utilization of lactate) in liver is inexplicable because the same enzyme of LDH1/A/M4 is present there too. The role of protons and oxygen in the overall physiology is also under investigation in the current theoretical exploration. This is because lactate production is supposed to recycle the nicotinamide nucleotide equivalents, which must also result in $\mathrm{pH}$ homeostasis (see Figure 2). Then, it is not clear why production of lactate leads to acidosis. Further, while lactate formation occurs under anaerobic conditions, cancerous cells show enhanced lactate production even with oxygen (called the Warburg effect), with concomitant respiratory metabolism. So, the role of oxygen in the overall dynamics needs to be explored.

Based on evidence, we had recently postulated that the tetrameric hemoglobin could serve as an ATP synthase in erythrocytes (Parashar et al., 2021), as glycolytic ATP synthesis may not be adequate to serve the needs of RBC (Figure 2). In this connection, it can be seen that the pathway classically charted for lactate production from glucose does not explain at the outset why/how 
lactate production could be accompanied by (or attributed!) to acidosis. Though lactic acid accumulation in itself could lead to acidosis (as the $\mathrm{pK}_{\mathrm{a}}$ is 3.9; the alcoholic proton has a high $\mathrm{pK}_{\mathrm{a}}$ of 15.1), its precursor of pyruvic acid is even stronger $\left(\mathrm{pK}_{\mathrm{a}}=2.45\right)$. Further, the formation of lactate should only serve to $\mathrm{pH}$-stat the proton-releasing step 6 of glycolysis (mediated by glyceraldehyde-3-phosphate dehydrogenase), as the LDH-mediated step (reaction 11 of Figure 2) consumes a proton from the solvent. While higher LDH expression and activity is correlated with hypoxia and lactic acidosis (Koukourakis et al., 2003), lactate accumulation has also been noted to occur without significant acidosis (Davenport et al., 1994; Lewis et al., 2014). We shall attempt to shed some light on such long-standing confusions (which have significant impact on clinical conditions such as acidosis seen in sepsis) (Bakker et al., 2013). We shall also focus on other interesting aspects of lactate metabolism (Liberti and Locasale, 2017; Seheult et al, 2017; Rabinowitz and Enerback, 2020), as exemplified by the Warburg effect (a highly intriguing observation in cancer research within animal cells, now documented for a century).

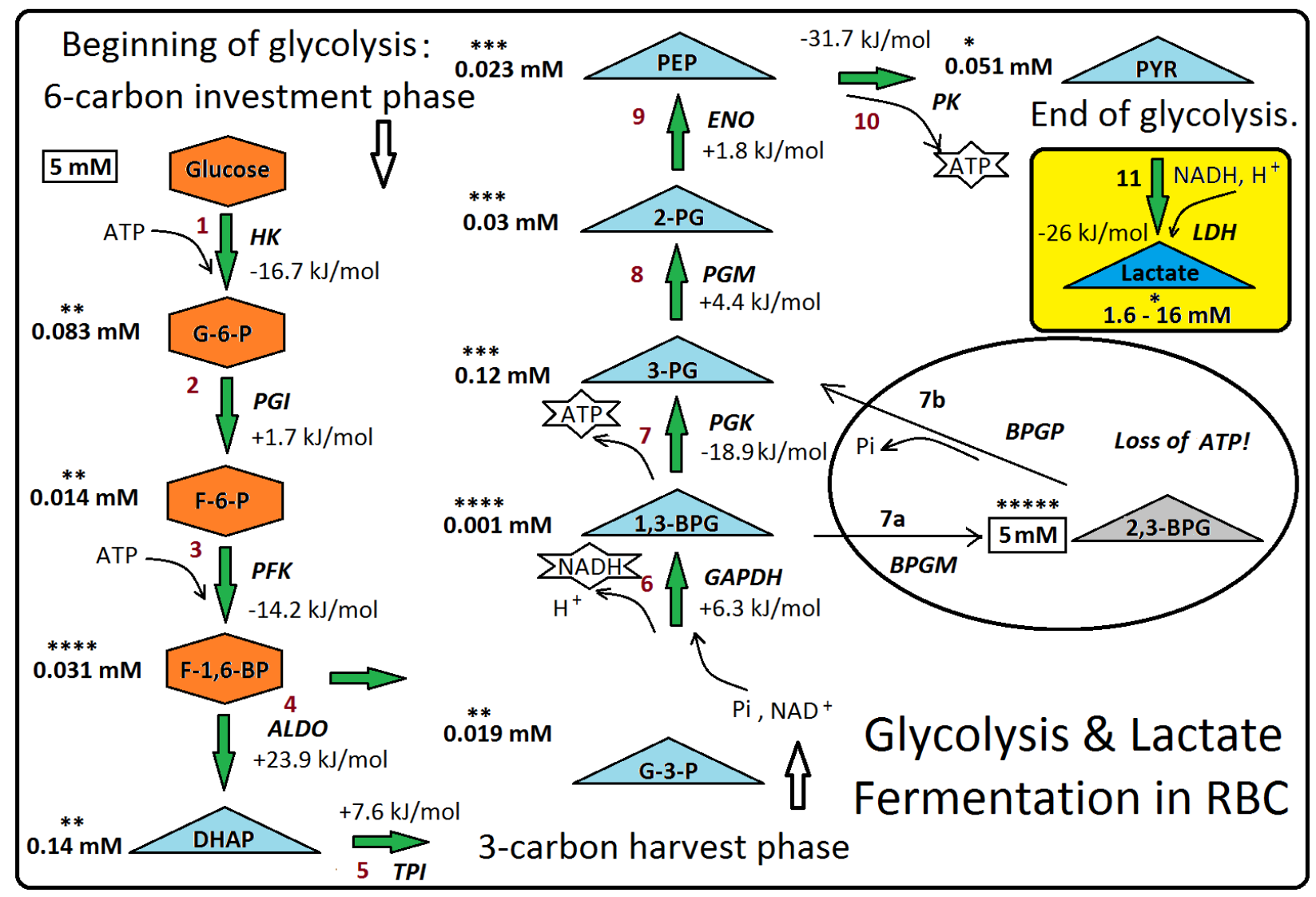

Figure 2: A view of the metabolic dynamics of the classical glycolytic scheme, leading to lactate production in erythrocytes. In this system devoid of mitochondria, the production of lactate increases upon anaerobic activity (e.g. a period of intense exercise). The asterisks indicated above the physiological concentrations of intermediates 
indicate the number of negative charges on the molecule at physiological $\mathrm{pH}$. ATP bears four negative charges and phosphorylation of an intermediate would impart the latter 2 negative charges of the phosphate moiety. The lactate formation step (which could increase from a resting concentration of $1.6 \mathrm{mM}$ to $16 \mathrm{mM}$ !) should theoretically increase or stabilize $\mathrm{pH}$ (as per the premises of the charted pathway). This image is discussed in greater detail in a later section of the manuscript.

\section{APPROACH / METHODOLOGY}

\subsection{Choice of LDH as a salient example of alpha-hydroxy/keto acid conversion enzyme}

Since LDH is a well-studied enzyme with lots of literature available on structure/function aspects and also happens to be a clinically important biomarker (indicated in a plethora of maladies like liver disease, heart attack, cancer, anaemia, and infections like encephalitis and HIV) and cancer therapy target, we chose this system as a salient representative for the alpha-hydroxy acid metabolism. Although there are four types of monomers reported for LDH over the ages, two types (A/B) are more well-known/prevalent and we shall stick to these alone in our discussions, with particular attention to the muscle/liver isozyme. This is because the LDH-A/M is supposedly involved in Cori cycle and Warburg effect (cancer). In this study, LDH proteins listed in Table 1 were employed for in silico explorations.

\subsection{In silico exploration strategy}

Receptor structures were obtained from the PDB complexes by selecting a single protein subunit and removing all waters and co-factors. AutoDockTools was used to add hydrogens, calculate Gasteiger charges, and generate PDBQT files. There is one thumbwheel that interactively adjusts the spacing between the grid points. For the flexible residue method, dockings on the whole dataset were run with default LGA settings, for 50 iterations. Spacing was 0.375 A and grid points (detailed in Table 1) in XYZ dimensions were 60-110 each. The dissociation constants $\left(\mathrm{K}_{\mathrm{d}}\right.$ values) were calculated with the following equation provided in the Autodock 4.2.6 source

code, $\mathrm{K}_{d}=\exp \left[\frac{\Delta G_{\text {Bind }}}{R * T}\right]$, where gas constant $\mathrm{R}=1.987 \mathrm{cal} / \mathrm{K} / \mathrm{mol}$, absolute temperature $\mathrm{T}=$ 298.15 K. Active site cavity was explored using POCASA server online with probe radius and grid size of 2 and 1 Angstrom(s), respectively. 
Table 1: Grid coordinates selected for docking of various molecules with pdb files of LDH isozymes from diverse sources.

\begin{tabular}{|c|c|c|c|}
\hline \multirow[t]{2}{*}{ Protein (pdb) } & \multicolumn{3}{|c|}{ Center Grid Box Co-ordinates } \\
\hline & $\mathrm{X}$ & $\mathrm{Y}$ & Z \\
\hline human heart (1IOZ) & 20.505 & 32.536 & 55.908 \\
\hline human muscle (1I10) & 11.580 & -17.482 & 151.211 \\
\hline Rabbit muscle (3H3F) & 7.421 & -13.650 & -22.994 \\
\hline Rat muscle (5ES3) & 2.843 & -27.149 & -68.642 \\
\hline Pig heart (5LDH) & 18.282 & 19.835 & 1.94 \\
\hline Pig muscle (5YTA) & -4.965 & -60.352 & -8.394 \\
\hline
\end{tabular}

\section{RESULTS AND DISCUSSION}

We shall first address the theoretical aspects and present our assessments; as we find it more important to re-address the thermodynamics of redox enzyme mediated reactions and clarify upon some conceptual terms. Before perusing our analysis on thermodynamics of the LDH reaction, it would benefit the reader to avail a critical write-up on some pertinent concepts and errors seen in earlier literature, as presented in Item 2, Supplementary Information. We believe that this approach would better prepare the reader for our findings/discussions that follow.

\subsection{Application of corrected thermodynamics calculation in LDH system}

For the LDH reaction, consider the half cell reactions:

$\mathrm{NAD}^{+}+2 \mathrm{H}^{+}+2 \mathrm{e}^{-} \rightarrow \mathrm{NADH}+\mathrm{H}^{+}\left(\mathrm{E}_{0}^{\prime}=-320 \mathrm{mV}\right)$

Pyruvate $+2 \mathrm{H}^{+}+2 \mathrm{e}^{-} \rightarrow$ Lactate $\left(\mathrm{E}_{0}^{\prime}=-185 \mathrm{mV}\right)$

The $\Delta \mathrm{G}^{\circ}$ calculated from redox potentials for the reacting couples of the 2e reactions mediated by dehydrogenase (with $\Delta \mathrm{G}=-n \mathrm{~F} . \Delta \mathrm{E}$ ) is $-26 \mathrm{~kJ} / \mathrm{mol}$ (Lehninger, 2004). The experimental $\Delta \mathrm{G}^{\circ}$ value from equilibrium constant $\left(\Delta \mathrm{G}=-\mathrm{RT} \ln \mathrm{K}_{\mathrm{eq}}\right)$ is $-66 \mathrm{~kJ} / \mathrm{mol}$ (Hakala et al., 1956). There isn't any agreement between the $\Delta \mathrm{G}$ values as seen from the traditional viewpoint. Calculation of the overall transformed standard free energy of reaction in aqueous phase ab initio from the $\Delta_{\mathrm{f}} G^{\prime \mathrm{O}}$ aq values of the reactants and products for the classical LDH reaction (via approach 1) is:

$\mathrm{CH}_{3}(\mathrm{CO}) \mathrm{CO}_{2}^{-}(-350.8)+\mathrm{NADH}(1120.1)+\mathrm{H}^{+}(452.5) \leftrightarrow \mathrm{CH}_{3}(\mathrm{HCOH}) \mathrm{CO}_{2}^{-}(-313.7)+\mathrm{NAD}^{+}(1059.1)$

$$
\Delta_{\mathrm{r}} G^{\prime \mathrm{o}}{ }_{\mathrm{aq}}=-\mathbf{4 7 6 . 4} \mathrm{kJ} / \mathbf{m o l} ; \mathrm{K}_{\mathrm{eq}} \sim \mathbf{1 0}^{83} \mathrm{M}^{-1}
$$


The literature $\Delta \mathrm{G}$ values give corresponding $\mathrm{K}_{\mathrm{eq}}$ of only $10^{4}$ to $10^{12}$, which would enable significant possibilities for backward reaction rates. We affirm that the values in literature are quite low because of the erroneous assumptions of contribution of the proton term/activity to the overall energetics (quite like the treatment in mOxPhos literature that we have pointed out already) (Manoj \& Bazhin, 2021). It would be evident that while electrons can spontaneously move from the NADH system to lactate system, the reverse would be uphill. Further, in physiology, protons are available for reaction at a premium $\left(<10^{-7} \mathrm{M}\right)$ and heterolytic dissociation of water is uphill, requiring energy consumption (>79 kJ/mol). Therefore,

$10^{83}=\left([\right.$ Lactate $\left.] \times\left[\mathrm{NAD}^{+}\right]\right) /\left([\right.$Pyruvate $\left.] \times[\mathrm{NADH}] \times\left[\mathrm{H}^{+}\right]\right)$

For the nicotinamide nucleotides, the experimental ratio of oxidized and reduced species varies with respect to the locale of measurement in liver cells (Williamson et al., 1967). The maximal $\left[\mathrm{NAD}^{+}\right] /[\mathrm{NADH}]$ ratio is $\sim 725$ in cytoplasm whereas it is $\sim 8$ in mitochondria. So, the oxidized to reduced nicotinamide ratio ranges from $10^{1}$ to $10^{3}$ in liver cells. Now, let us substitute the maximal values in the equilibrium expression above:

$10^{76}=10^{3} \times[$ Lactate $] /[$ Pyruvate $]$

The relation shows that the reaction system will tend to yield a phenomenally high [Lactate]/[Pyruvate] ratio $\left(\sim 10^{73}\right.$ !). Rewording- only if $\left[\mathrm{NAD}^{+}\right] /[\mathrm{NADH}]$ ratio is very high $\left(\sim 10^{75}\right.$ !), the pyruvate concentration will approach $1 / 10$ of the lactate concentration. From the experimental studies reported in literature, we know that the intra-hepatic ratio of [Lactate]/[Pyruvate] can vary from 10 to 30 (von Platen et al., 2019); with the actual concentration of lactate ranging from 0.5 to $5 \mathrm{mM}$ and pyruvate being 0.05 to $0.2 \mathrm{mM}$. Considering the extreme values of [Lactate $=0.5 \mathrm{mM}] /$ [Pyruvate $=0.2 \mathrm{mM}$ ], we can even get a ratio of 2.5 for the 3-carbon substrates. That is, we can have the [Lactate]/[Pyruvate] ratios ranging from $10^{0}$ to $10^{2}$ ! Clearly, the reality seen in liver cells (regeneration of high concentration of pyruvate from lactate) is beyond the purview of the simple equation governing LDH activity. In this context, changing the specificity of the enzyme by having a different isozyme can affect the $\mathrm{K}_{\mathrm{M}}$ and $\mathrm{V}_{\max }$ of the same, but cannot effect reversibility in the reaction scheme. Therefore, a new approach is needed to explain why physiology mandates that lactate is transported to liver in the Cori cycle. 


\subsection{A new hypothesis for $\mathrm{LDH}$, featuring murburn concept:}

We propose that lactate is transported to liver because there is a high amount of ROS produced by the cytochrome P450-reductase system and the reaction also generates hydroxide ions. The backward reaction of LDH generates protons, and this can enable a coupled synthesis of water, driving the equilibrium towards the oxidation of lactate (or pyruvate synthesis). Let us now consider two thermodynamic alternatives, involving the intermediacy of DROS, as would be available with the presence of CYP+CPR microsomal membrane (cytoplasmic) or even within the mitochondrial respiratory system:

(1) $\mathrm{CH}_{3}(\mathrm{HCOH}) \mathrm{CO}_{2}^{-}(-313.7)+\mathrm{O}_{2}(16.4) \rightarrow \mathrm{CH}_{3}(\mathrm{CO}) \mathrm{CO}_{2}^{-}(-350.8)+\mathrm{H}_{2} \mathrm{O}_{2}(-52.5)$

$$
\Delta_{\mathrm{r}} G^{\prime \mathrm{O}}{ }_{\mathrm{aq}}=-106 \mathrm{~kJ} / \mathrm{mol} ; \mathrm{K}_{\mathrm{eq}} \sim 10^{19}
$$

In this scenario,

$\mathrm{K}_{\mathrm{eq}}=10^{19}=\left([\right.$ Pyruvate $\left.] \times\left[\mathrm{H}_{2} \mathrm{O}_{2}\right]\right) /\left([\right.$ Lactate $\left.] \times\left[\mathrm{O}_{2}\right]\right)$

We know that concentrations of the metabolites of oxygen and peroxide are minimally $10 \mu \mathrm{M}$ and $0.01 \mu \mathrm{M}$ (Sies, 2014), respectively. Plugging in the most unfavorable scenario for this reaction (equivalent presence of oxygen and peroxide), we still get a good propensity for pyruvate formation:

$\left(10^{19} \times 10^{-5}\right) / 10^{-5}=10^{19}=[$ Pyruvate $] /[$ Lactate $]$

This is a simplistic presentation of a way in which the liver cells could regenerate pyruvate, in spite of the presence of LDH5 in them. In spite of the lower yield (compared to the LDH reaction equation), the above reaction would be kinetically more viable due to the bimolecular reactions mediated by oxygen-centered radicals.

(2) Let's consider that a xenobiotic like diclofenac or camphor is metabolized (to hydroxydiclofenac or hydroxycamphor, respectively) by the CYP+CPR mixed function oxidase system. The minimal mass-charge balanced reaction is represented by the membrane-interface equation (Parashar \& Manoj, 2021):

$\mathrm{RH}+\mathrm{O}_{2}+\mathrm{NAD}(\mathrm{P}) \mathrm{H} \rightarrow \mathrm{ROH}+\mathrm{NADP}^{+}+\mathrm{OH}^{-}$

Via the intermediacy of DROS, the above can be coupled with the endergonic reaction of pyruvate synthesis in free cytoplasm: 
Lactate $+\mathrm{NAD}^{+} \rightarrow$ Pyruvate $+\mathrm{NAD}(\mathrm{P}) \mathrm{H}+\mathrm{H}^{+}$

The sum total reaction in milieu would enable redox recycle and redox/phase homeostasis:

\section{$\mathrm{RH}+$ Lactate + NADPH $/ \mathrm{NAD}^{+}+\mathrm{O}_{2} \rightarrow \mathrm{ROH}+\mathrm{Pyruvate}^{+} \mathrm{NADP}^{+} / \mathrm{NADH}+\mathrm{H}_{2} \mathrm{O}$$$
\Delta_{\mathrm{r}} G^{\prime \mathrm{O}}{ }_{\mathrm{aq}}=-\mathbf{3 7 5} \mathrm{kJ} / \mathrm{mol} ; \mathrm{K}_{\mathrm{eq}} \sim \mathbf{1 0}^{67}
$$

This reaction has higher yields and is also kinetically favored because of the coupling mediated by DRS. That is, in the forward reaction cycle, LDH need not be a strict anaerobic enzyme. It would be assisted in its activity by the high mixed function oxidase activity in the liver. Since blood does not have mitochondria, it is understandable that the lactate formed therein must be moved to liver. Both pyruvate and lactate are 3-carbon molecules (anions) with a unit negative charge and three H-bond accepting moieties. Also, they are monocarboxylic acids with similar dimensions (Stokes radii of $\sim 2.3 \AA$ ), diffusivity $\left(1.06 \times 10^{-3} \pm 0.06 \mathrm{~mm}^{2} / \mathrm{s}\right)$, polar surface area $\left(58.5 \pm 1.5 \AA^{2}\right)$ and $\log \mathrm{D}(-4.35 \pm 0.25)$ values. Therefore, they are expected to have similar transport features across phospholipid membranes. If we assume Cori cycle as an unquestionable fact, it would imply that transport of lactate across the mitochondrial membranes in muscle cells is disadvantaged in some way. In this regard, it is known that the diffusion of lactate in fatigued muscles is at least an order lower than in normal cells (Hill, 1928). Since mass transfer is dependent on surface area, we envisage that the lactate movement across the sarcolemma (into blood) may be greater than movement into mitochondria. Also, facilitated lactate/pyruvate/acetate transfer into mitochondria (as exemplified by monocarboxylic acid transporters) may be coupled to oxygen-dependent homeostatic processes across the mitochondrial membranes. These considerations could explain why significant amount of lactate formed in the cytoplasm of muscle cells are moved to liver when their own mitochondrial LDH could effectively oxidize it via murburn scheme. We can now see that the physiological strategy is for the effective downhill recycle using the DROS in the vicinity of endoplasmic reticulum in cytoplasm.

Cancer cells are characterized by the enhanced capacity of using nutrients for cellular growth and multiplication. The high lactate concentration (during hypoxia) that is routinely observed in cancerous tissues supposedly is attributed to glycolytic switch (aka Warburg effect) and the 
lower flux of metabolites in the TCA cycle (Deberardinis and Chandel, 2020). Amongst the LDH types, LDHA is considered to be the major enzyme which regulates the Warburg effect and hence, it is a key pharmacological target in almost all cancers (Kim et al., 2019). Another intriguing fact is that lactate was found to stimulate mitochondrial energy metabolism through the lactate oxidizing activity of membrane-bound mitochondrial LDH (Young et al., 2020). Besides, lactate is known to be a major "fulcrum of metabolism" because it is: (a) an energy source for mitochondrial respiration, (b) a key gluconeogenic precursor, and (c) a potent signaling molecule (Brooks, 2020). In this regard, while cytoplasmic glycolysis is fast (but energetically inefficient), mitochondrial respiration (substrate-level and murburn phosphorylations) is both fast and efficient. In order to grow at high rates, cancer cells must outcompete other cells and use both mechanisms effectively. However, transport of the glycolytic product to mitochondria and Krebs cycle / murburn phosphorylations thereafter is a relatively slower process due to the involvement of multiple interfacial phenomena (as compared to purely aqueous phase processes of the cytoplasmic glycolytic enzymes). This predicament (and not the murburn process, per se!) leads to the low temporal efficiency of production of ATP in mitochondria. Via aerobic lactic acid fermentation in cancer cells, the process of glycolysis is speeded up due to the alleviation of end-product (pyruvate) inhibition by the pyruvate to lactate conversion by LDH, failing which acidity also sets in. Acidity is deleterious to glycolysis (Nishimura and Minakam, 1975). ATP is also known to give feedback inhibition of the glycolytic cascade. Further, since the nicotinamide cofactor is limiting, the nicotinamide nucleotide must be recycled for the efficacy of $6^{\text {th }}$ step of glycolysis. Therefore, the murburn perspective proposes that cancer cells temporally minimize the effective pyruvate concentration in cells by the continuous backward reaction of $\mathrm{LDH}$ (leading to the formation of lactate). The lactate formed is subjected to murburn in cytoplasm itself, due to the higher dynamics of DROS in cancer cells (quite like the liver cells!). That is- while the fast backward reaction (Pyruvate $\rightarrow$ Lactate) is mediated using NADH by LDH, the relatively non-specific fast forward reaction (Lactate $\rightarrow$ Pyruvate/Acetate $+\mathrm{CO}_{2}$ /other products) is mediated using DROS by LDH, outside the active site (Figures 3 and 4). In the cancer cells, as the energetically inefficient glycolysis chugs on fast, the small amount of pyruvate/acetate formed can get converted to acetyl-CoA and go through the mitochondrial routine, rendering the overall reaction both kinetically viable and energetically efficient. Therefore, the current insight could aid in resolving 
some outstanding questions regarding Warburg effect (Liberti and Locasale, 2017) and permits a new therapeutic approach towards cancer therapy, in conjunction to the existing approaches (Li et al, 2014). We could "restrict cell-division and facilitate implosive burn-out" by enhancing DROS-mediated apoptosis/autophagy (He et al., 2017) of cancer cells (in contrast to "restricting cell division and limiting nutrient supply").

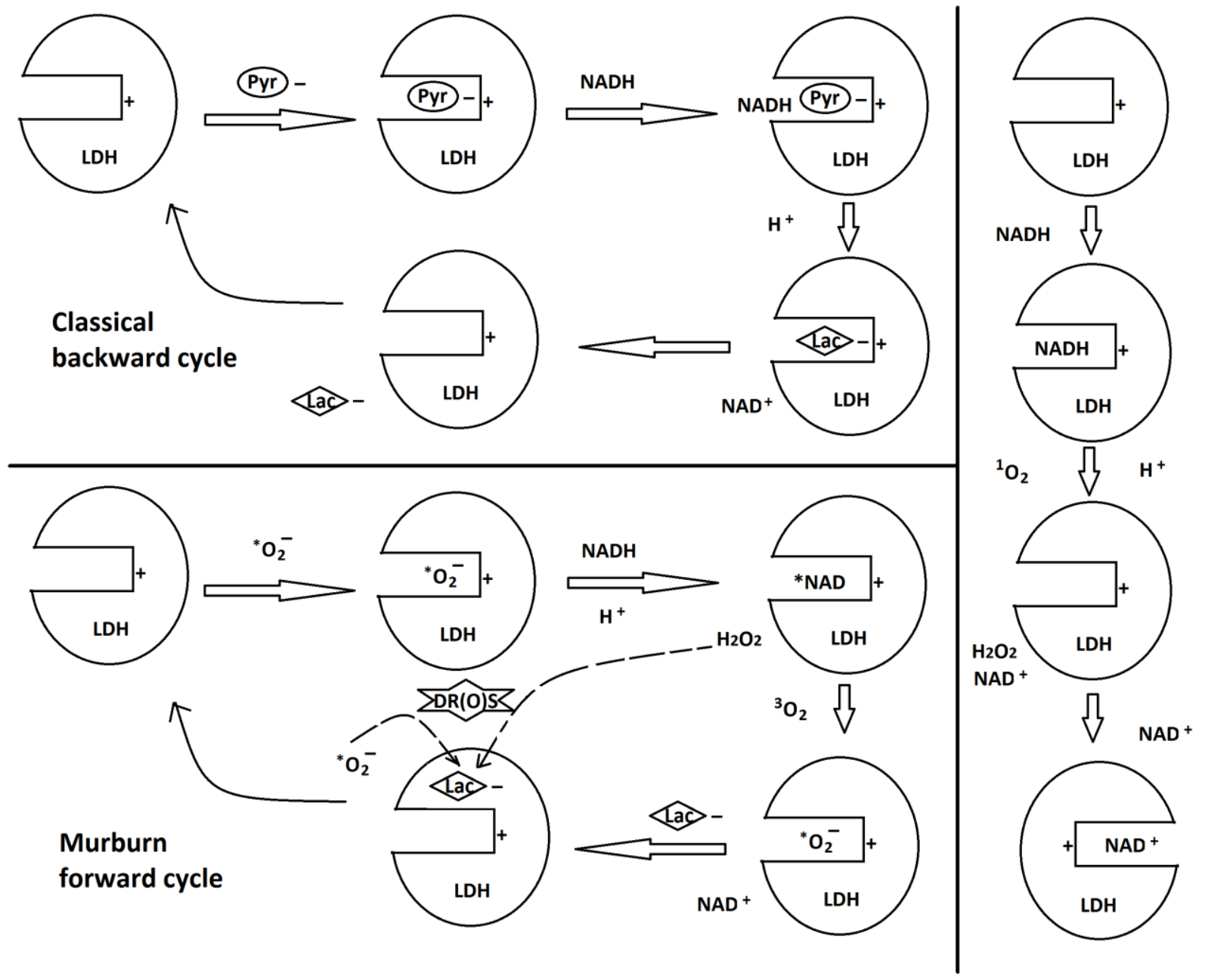

Figure 3. Revis(it)ing the reaction mechanism of lactate dehydrogenase (LDH). In the top-left panel, a reinterpretation of the classcical backward reaction is shown, taking into account the known crystal structure of LDH. Since binding of NADH first would block the access of pyruvate to the active site, the latter must bind first. Therefore, $\mathrm{LDH}$ should be more aptly called as pyruvate reductase as an enzyme derives its name from the substrate it works on or has higher affinity for. (The scheme is discussed in greater details within a later section of the manuscript.) In the bottom left panels, the involvement of DROS is the salient aspect, which leads to the conversion of lactate (the product(s) is not shown).The murburn model is depicted in an ordered fashion for ease in comprehension. The actual sequence of reaction can have multiple routes for achieving similar outcomes. For example- DROS may attack free lactate in solution, NADH could bind LDH before superoxide; oxygen may react outside the active site with *NAD, etc. Also, the DROS reaction with lactate may give pyruvate, acetate and/or other products. Therefore, the reverse reaction is not expected to be stoichiometric, with respect to the nicotinamide or 3- 
carbon substrate. In the right panel, other possible interactions of reaction components with LDH are depicted. Singlet oxygen can react with NADH to give DROS and the binding of $\mathrm{NAD}^{+}$occurs in opposite direction as compare to that of NADH (within the active site). This may enable it to scavenge milieu electrons and get reduced.

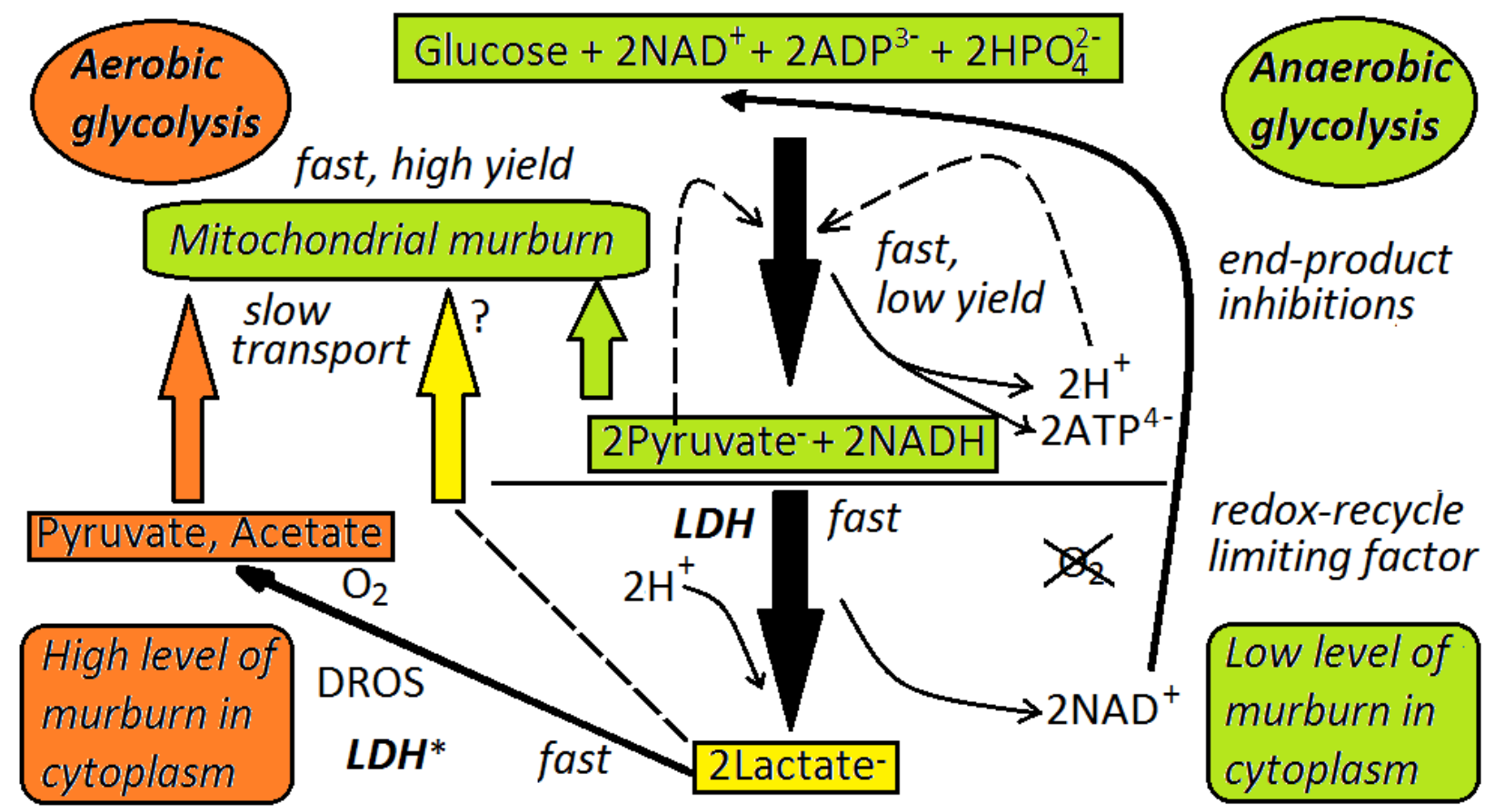

Figure 4: The metabolic scheme for lactate in normal (green, right side) and cancer/liver cells (red, left side).

\subsection{What about other alpha-hydroxyacid oxidations?}

$\mathrm{MDH}$ (malate dehydrogenase) reaction half cell reactions are:

$\mathrm{NAD}^{+}+2 \mathrm{H}^{+}+2 \mathrm{e}^{-} \rightarrow \mathrm{NADH}+\mathrm{H}^{+}\left(\mathrm{E}_{0}^{\prime}=-320 \mathrm{mV}\right)$

Malate $+2 \mathrm{H}^{+}+2 \mathrm{e}^{-} \rightarrow$ Oxaloacetate $\left(\mathrm{E}_{0}^{\prime}=-166 \mathrm{mV}\right)$

For $\mathrm{MDH} ;-166-(-320)=156 \mathrm{mV} ; \Delta \mathrm{G}^{\circ}$ corresponds to $30 \mathrm{~kJ} / \mathrm{mol}$ (Lehninger, 2004). The experimental delta $\mathrm{G}$ from equilibrium constant gives a value of $68.4 \mathrm{~kJ} / \mathrm{mol}\left(\mathrm{Keq}=10^{-12}\right.$ ) (Burton \& Wilson, 1953). This is when the corrected value with approach 1 gives $481 \mathrm{~kJ} / \mathrm{mol}$. Therefore, in the context of the alpha-hydroxyl acid dehydrogenase reactions, the thermodynamic yield is analyzed in Table 2. For the traditional enzyme catalyzed reaction (A), the transformed Gibbs (standard) free energy of reaction corresponds to $~ 445$ (lowest positive value) to $\sim 495$ (highest positive value) $\mathrm{kJ} / \mathrm{mol}$, translating to equilibrium constants of $10^{-80}$ to $10^{-87}$. For a simple oxidation alternative proposed in (B), Transformed Gibbs (standard) free 
energy of reaction corresponds to $\sim-88$ (lowest negative value) to $\sim-137$ (highest negative value) $\mathrm{kJ} / \mathrm{mol}$, translating to equilibrium constants of $10^{15}$ to $10^{24}$. In the murburn coupled reaction $(\mathrm{C})$, the yield is significantly higher, from -356 to $-376 \mathrm{~kJ} / \mathrm{mol}$, corresponding to $\mathrm{K}_{\mathrm{eq}}$ values of $10^{63}$ to $10^{67}$. Therefore, the newly proposed murburn coupling reaction strategy affords a high displacement of equilibrium to the right, by a magnitude of $10^{143}$ to $10^{154}$, when compared to the purely (de)hydrogenase enzyme catalyzed reaction!

Table 2: Calculation of overall free energy change in water, for the generic reactions given below:

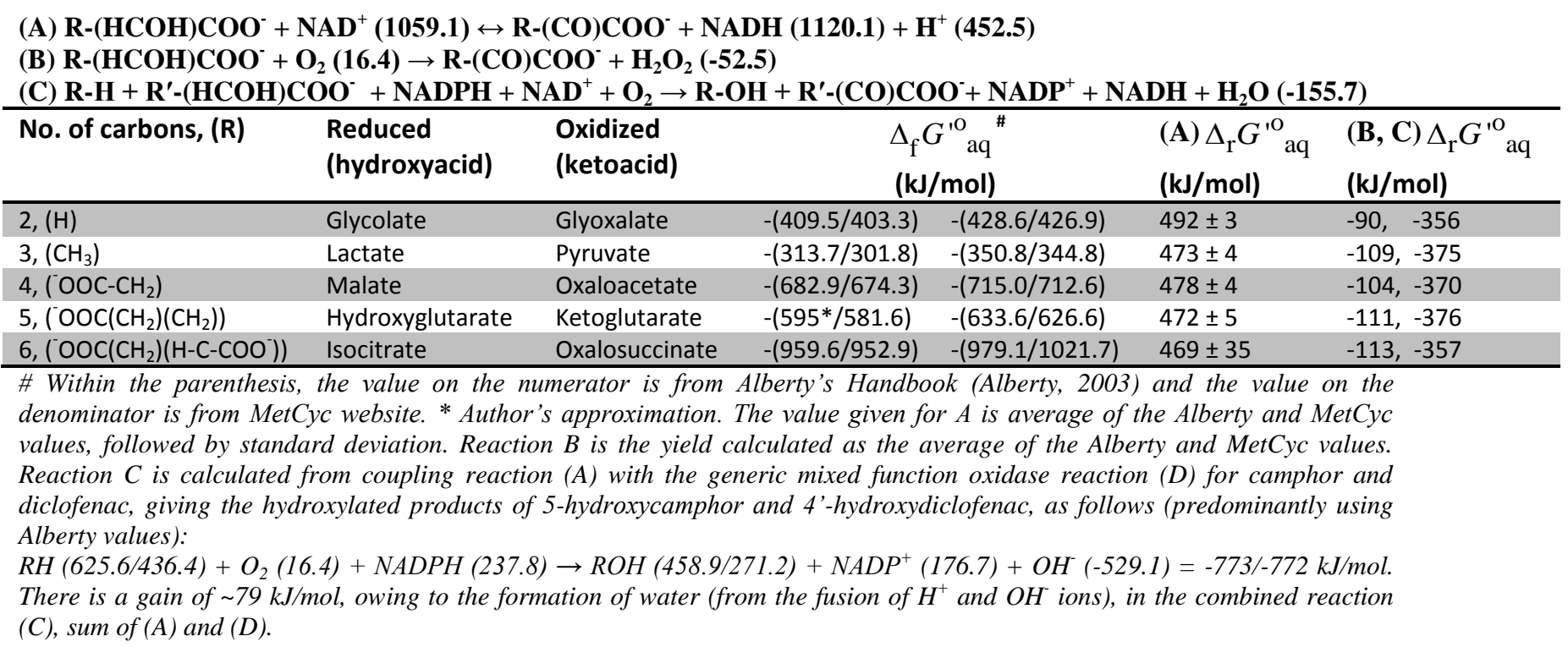

\subsection{Understanding pH dynamics in glycolysis, and factors leading to 'lactic acidosis'}

From Figure 2, it is evident that until the formation of lactate from glucose, there are only two reactions that directly involve protons, and both are at the 3-carbon stage. In the highly complex reaction catalyzed by glyceraldehyde-3-phosphate dehydrogenase (GAPDH, reaction 6), the enzyme phosphorylates its substrate and also reduces $\mathrm{NAD}^{+}$in the process, leading to the production of diphosphorylated product and NADH; and also liberating a proton. Now, LDH (via reaction 11) is supposed to replenish the nicotinamide pool by oxidizing the NADH generated and in this process, also consumes the excess proton released in step 6, thereby serving as a $\mathrm{pH}$ stat. However, as we pointed out in the introduction, lactic acid production or $\mathrm{LDH}$ activity is associated with or without acidosis. The reason could lie in the negative charges formed on the intermediates, $\mathrm{pKa}$ of inorganic phosphate, and the overall dynamics of the four 
phosphorylation/kinase activities in the glycolytic scheme. On a meticulous analysis (excluding reactions $7 \mathrm{a} / 7 \mathrm{~b}$ ), it is noted that there are essentially four types of phosphate bond formation mechanisms in the reactions 1 to 11 (which are presented in a simplified mass-charge balanced format below):

(i) Reactions 1 and 3 at the 6-carbon stage, which involves the phosphorylation of an $-\mathrm{OH}$ moiety of a sugar, thereby imparting two negative charges to the intermediate, and releasing a proton in the process.

$\mathrm{R}-\mathrm{OH}+\mathrm{ATP}^{4-} \rightarrow \mathrm{R}-\mathrm{O}-\left(\mathrm{PO}_{3}\right)^{2-}+\mathrm{ADP}^{3-}+\mathrm{H}^{+}$

(ii) Reaction 7 at the 3-carbon stage, which has a substrate level phosphorylation of ADP, and this does not involve protons.

${ }^{2-}(\mathrm{R})-(\mathrm{C}=\mathrm{O})-\mathrm{O}-\left(\mathrm{PO}_{3}\right)^{2-}+\mathrm{ADP}^{3-} \rightarrow{ }^{2-}(\mathrm{R})-(\mathrm{C}=\mathrm{O})-\mathrm{O}^{-}+\mathrm{ATP}^{4-}$

(iii) Reaction 10 at the 3-carbon stage, which is a substrate level phosphorylation of ADP that consumes protons from milieu.

${ }^{-}(\mathrm{R})-\left(\mathrm{C}=\mathrm{CH}_{2}\right)-\mathrm{O}-\left(\mathrm{PO}_{3}\right)^{2-}+\mathrm{ADP}^{3-}+\mathrm{H}^{+} \rightarrow{ }^{-}(\mathrm{R})-\left(\mathrm{C}-\mathrm{CH}_{3}\right)=\mathrm{O}+\mathrm{ATP}^{4-}$

(iv) Reaction 6 at the 3-carbon stage, a complicated multi-molecular step, which may produce one or two protons, as shown below:

${ }^{2-}(\mathrm{R})-(\mathrm{HCOH})-(\mathrm{C}=\mathrm{O}) \mathrm{H}+\mathrm{NAD}^{+}+\mathrm{HPO}_{4}{ }^{2-} \rightarrow{ }^{2-}(\mathrm{R})-(\mathrm{HCOH})-(\mathrm{C}=\mathrm{O})-\mathrm{O}-\left(\mathrm{PO}_{3}\right)^{2-}+\mathrm{NADH}+\mathrm{H}^{+}$

${ }^{2-}(\mathrm{R})-(\mathrm{HCOH})-(\mathrm{C}=\mathrm{O}) \mathrm{H}+\mathrm{NAD}^{+}+\mathrm{H}_{2} \mathrm{PO}_{4}{ }^{-} \rightarrow{ }^{2-}(\mathrm{R})-(\mathrm{HCOH})-(\mathrm{C}=\mathrm{O})-\mathrm{O}-\left(\mathrm{PO}_{3}\right)^{2-}+\mathrm{NADH}+2 \mathrm{H}^{+}$

We find this multi-molecular reaction step to be very interesting, in energetic terms. The Gibbs free energy of formation (in the transformed scale) of the first species of inorganic phosphate is $1058.5 \mathrm{~kJ} / \mathrm{mol}$ and the value for proton is $-452.5 \mathrm{~kJ} / \mathrm{mol}$. The oxidized and reduced forms of nicotinamide nucleotide have 1059.1 and $1120.1 \mathrm{~kJ} / \mathrm{mol}$, respectively. Substituting the values of glyceraldehyde-3-phosphate (-1088) and bisphosphoglycerate (-2207.3), we get the free energy yield of the first reaction as $\sim 453 \mathrm{~kJ} / \mathrm{mol}$. Therefore, production of protons in milieu is a highly unfavorable reaction, and contrary to popular belief, this step cannot be deemed spontaneous in physiology. It becomes feasible in steady-state only in conjunction with the $11^{\text {th }}$ step of lactate formation (Figure 2), which consumes the proton. Now, in the glycolytic scheme, for every 6carbon reaction, there are two 3-carbon equivalents. Therefore (disregarding the routing of 
intermediates in other/parallel schemes), for simplicity, we can equate the stoichiometry of two 6-carbon steps of $1 \& 3$ [mechanism (i)] with the single step of the 3-carbon reaction 10 [mechanism (iii)]. Then, the proton dynamics would be dependent on the interplay of phosphate-

transfer reactions $6,7 \mathrm{a} / 7 \mathrm{~b}$ and the redox reaction 11 . Even in the classical purview, since the reaction 6 is not highly favorable and close to equilibrium (with positive $\Delta \mathrm{G}^{\prime \circ}$ or $\Delta \mathrm{G}^{\circ}$ values of $6.3 \mathrm{~kJ} / \mathrm{mol}$ and $2.5 \mathrm{~kJ} / \mathrm{mol}$, respectively; as seen in Lehninger/Stryer textbooks), and since ATP can be lost/replenished via multiple ways ( $7 \mathrm{a} / 7 \mathrm{~b}$ being a classical example in the charted scheme itself), the interplay of electron and phosphoryl moiety transfers (dynamic murburn equilibriums, as can be gauged from the net charge-fluctuations on the glycolytic intermediates!) in the overall scheme (and not just proton-producing or releasing steps evident in the reaction cycle) affect $\mathrm{pH}$ dynamics of the milieu. Thereby, lactate production may or may not be associated with acidosis (Davenport et al., 1994; Koukourakis et al., 2003; Lewis et al., 2014). Our theoretical analysis does not support the proposal that pyruvate could serve as an alkalizing agent in glycolysis (Wang et al., 2018). Other aspects of $\mathrm{pH}$ dynamics in cells and body fluids can be availed from an elaborate treatment presented by Peter Stewart (Stewart, 1983).

\subsection{LDH mediated conversions of pyruvate-lactate and nicotinamide nucleotides}

\section{5a. Classical structure-function correlations of monomers/multimers of $L D H$}

The functional tetramer of $\mathrm{LDH}$ is composed of two types of monomers- $\mathrm{A} / \mathrm{M}$ or $\mathrm{B} / \mathrm{H}$ types; which differ primarily due to the presence of alanine or glutamine (respectively), although having an otherwise identical active site (Figure 5). The $\mathrm{pK}_{\mathrm{a}}$ governing the $\mathrm{K}_{\mathrm{M}}$ of pyruvate of the $\mathrm{A} / \mathrm{M}$ and $\mathrm{B} / \mathrm{H}$ monomers vary by less than $1 \mathrm{pH}$ unit, perhaps connoting a histidine residue (Read et al., 2001). Researchers believe that the LDH 1/A/M4 isozyme presumably has a higher affinity for pyruvate, catalyzing the backward reaction in anaerobic conditions. LDH 5/B/H4 type is considered to favor the conversion of lactate into pyruvate. Heart \& RBC-specific LDH1/H4 (LDH-B) is a homotetramer of $\mathrm{H}$ protein. RBC and myocardial tissues possess LDH2/H3M1, skeletal muscle \& kidneys contain LDH-3/H2M2 and LDH-4/H1M3. Liver as well as skeletal muscle contain the M4 type (LDH-5/LDH-A). While LDH-A is located in the cytosol (of muscle and liver), LDH-B is localized in cytosol, membrane, mitochondria and mitochondrial inner membrane. The sequence differences/similarities between LDH-A and LDH-B are 
highlighted in Item 3, Supplementary Information. The homo-tetramer of LDH-4M (or LDH5) has a net charge of -6 whereas the homo-tetramer of LDH-4H (or LDH1) has an overall charge of +1 , which is supposed to enable the isozymes to work in the backward or forward directions of pyruvate/NADH $\leftrightarrow$ lactate/NAD ${ }^{+}$, respectively (Read et al., 2001; Farhana \& Lappin, 2021). If the inferences from thermodynamic stature are backed up by in silico investigations indicating the absence of evidence supporting the purported affinities or sequence of actions, the current theory of enzyme action can be questioned. In this regard, the mechanism of LDH action is believed to be through concerted binding of either pyruvate+NADH or lactate+NAD ${ }^{+}$substrates at the active site. This necessitates the presence of two different sub-sites (within the activie site) which can differentiate the two molecules. Acid-base catalysis is known to be the prevailing mechanism of LDH-dependent oxiodoreduction reactions. The active site amino acid residues and the overall topography of the two monomers are given in Figure 5. The shape and organization of tetramer (A4), along with the relative locations of the active sites is given in Figure 6.

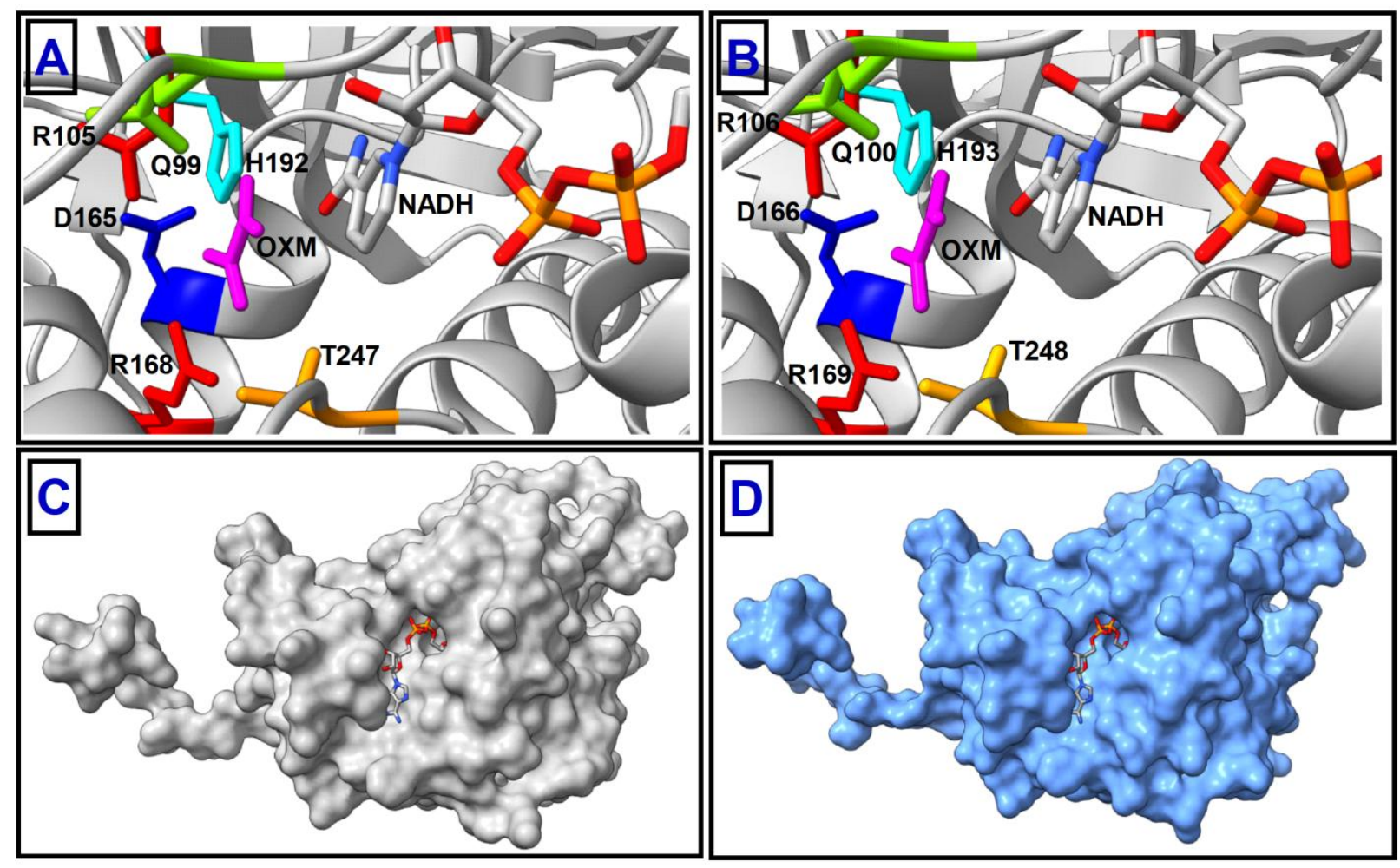

Figure 5: The active site residues and overall topography of $A / M$ and $B / H$ monomers of LDH. Practically, identical active site structures and nicotinamide and oxamate binding can be noted in both monomers, although the surface topography is a bit different. (OXM stands for oxamide.) 


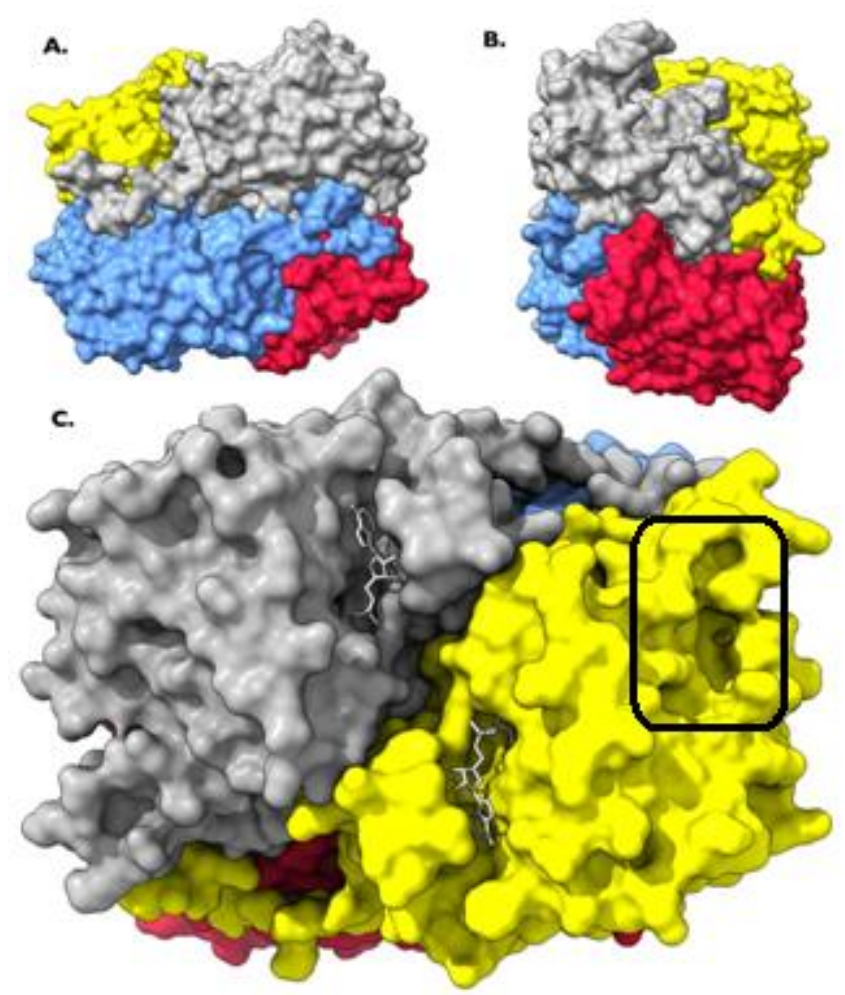

Figure 6: Various views of the tetrameric nature of the predominant LDH1, found in muscle and liver. NADH bound in the active site is shown for two monomers (grey and yellow), in the bottom panel C. The rectangular box depicts a major crypt/groove/pocket on the surface (which shall be discussed at a later juncture).

The accepted mechanism of backward LDH action (occurring in muscles, purportedly catalyzed by the A monomer) involves binding of NADH first to the active site, followed by pyruvate. The five-step reaction sequence, which involves a solvent-proton is (Figure 7):

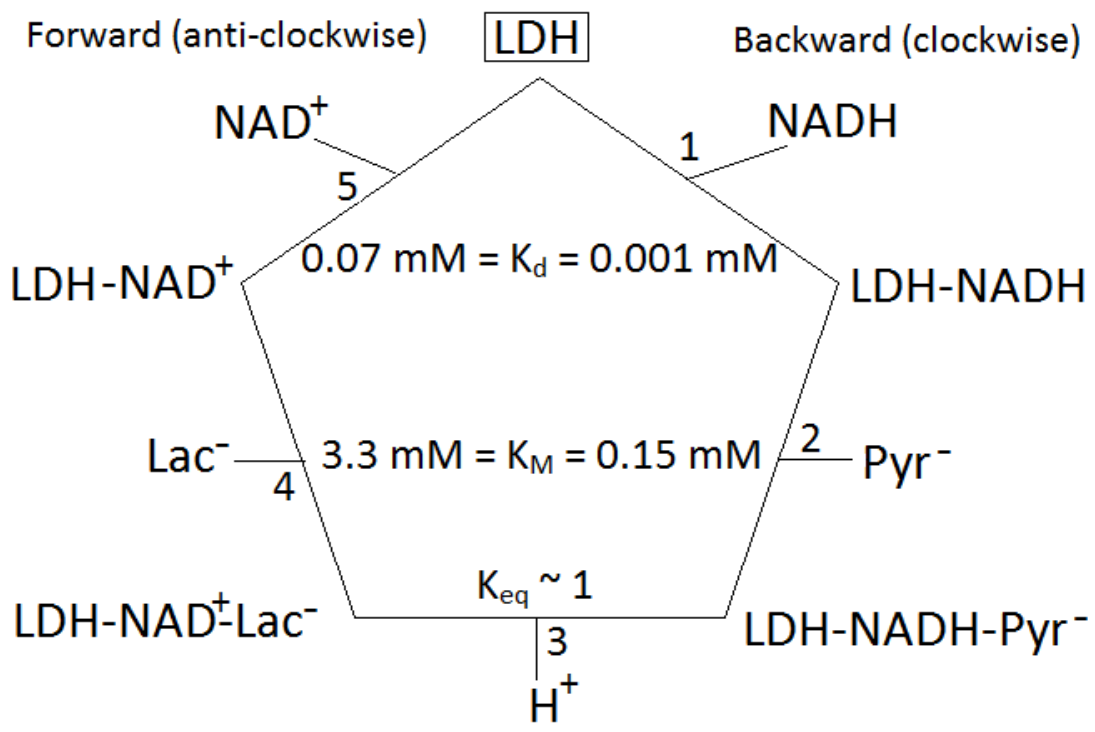


Figure 7: The classical backward reaction of Pyruvate $+\mathrm{NADH}+\mathrm{H}^{+} \rightarrow$ Lactate $+\mathrm{NAD}^{+}$(Shoemark et al., 2007; Zhadin et al., 2008). The classical five-step forward reaction that supposedly occurs in the liver (leading to the thermodynamically unfavorable liberation of a proton) is the sequence of reverse reactions of the above, with the order of $(-5) \rightarrow(-4) \rightarrow(-3) \rightarrow(-2) \rightarrow(-1)$ (Singh and Kanungo, 1968). Therefore, the reaction is deemed to be fully reversible in physiology, with both directions working via the Michaelis-Menten mechanism/kinetics. The big catch is- electron can move from NADH to pyruvate in the LDH active site (in a 1:1 stoichiometric scenario) whereas movement of electrons from lactate to $\mathrm{NAD}^{+}$(in the same 1:1 stoichometry) is unviable.

\section{5 b. Analysis of the classical mechanism for the forward and backward reactions}

In the backward reaction, the resulting ternary complex (NADH-LDH-Pyruvate) is known to undergo a conformational change (a rate-limiting step), during which a desolvated complex is formed by the movement of a specificity loop. The closure of this loop moves R109 in place into the active site and this residue polarizes the ketone group of the reactive carbon and promotes direct hydride transfer and proton transfer from the $\mathrm{C} 4$ carbon of $\mathrm{NADH}$ nicotinamide ring to the secondary substrate, pyruvate. The active site chemistry involves the following highly conserved residues - R109, D168, H195, which participate in substrate recognition and discrimination. Further, other residues like Q102, R171, T246 and R109 together are known to be involved by specific recognition and enclosure of the methyl group of pyruvate. A proton is donated to the carbonyl oxygen atom of pyruvate from the catalytic diad of D168 or H195 and this causes formation of lactate. The imidazole group of $\mathrm{H} 195$ acts as a proton donor/acceptor and ensures proper orientation of pyruvate towards C4 of NADH. D168 stabilizes H195 by maintaining it in the cationic/protonated form via H-bonding between D168 and imidazole ring of H195. R171 is involved in pyruvate binding and I250 provides a hydrophobic environment to facilitate NADH binding (McClendon et al., 2005). Based on multiple sequence alignment results (Item 3, Supplementary Information), it is evident that residues Q100, R107, D166, R169, H193 and T248 are conserved in all mammalian proteins which were taken for the analysis (human, cow, pig, rabbit, cow, mouse and rat). Therefore, the backward reaction seems to be supported by the active site structure.

While the backward LDH reaction is carried out in vitro at $\mathrm{pH} 7.3$ (physiological $\mathrm{pH}$ ), the forward assay is performed in labs at the non-physiological $\mathrm{pH}$ ambience of 8.2-10.0 (wherein $\mathrm{H}^{+}$concentrations is $6.31 \times 10^{-9}$ to $1 \times 10^{-10} \mathrm{~mol} / \mathrm{L}$ ) (Vanderlinde, 1985 ; Kumar et al., 2018). If $\mathrm{pH}$ maintenance occurs spontaneously (and if the reaction did not involve water-based equilibria that incur energy inputs), this necessity would not arise. In the forward reaction (lactate to pyruvate), 
$\mathrm{H}^{+}$is a product; also, electrons from lactate must be driven uphill to $\mathrm{NAD}^{+}$(to be reconverted to $\mathrm{NADH}$ ). (The reaction is feasible in labs only because $\mathrm{OH}^{-}$in the mileu serves as a thermodynamic pull element for proton release in the forward reaction.) The normal blood lactate levels are in the range of $1-2 \mathrm{mM}$ (Tomschi et al., 2018). During 'lactic acidosis', the $\mathrm{pH}$ of the blood (and tissues) drops to $<7.35$ and sometimes, it can reach life-threatening levels of even under 7.0. Hence, the low $\mathrm{H}^{+}\left(10^{-9}\right.$ to $\left.10^{-10} \mathrm{~mol} / \mathrm{L}\right)$ in the routine assay conditions has little functional relevance with respect to the higher $\mathrm{H}^{+}$levels of $\left\langle 10^{-7} \mathrm{M}\right.$ in physiological states wherein lactate is present in excess. Further, high concentrations of diverse redox-active molecules like 2-p-iodophenyl-3-p-nitrophenyl tetrazolium chloride, 1-methoxyphenazine methosulfate, diethanolamine, hydrazine, etc. are included in the LDH assay mixture in the nicotinamide based-assays (Kumar et al., 2018), along with lithium lactate as the assay substrate. Carrying out the forward reaction in such an unrealistic way is no justification for supposing that lactate oxidation occurs in this fashion in routine physiology, within living cells. Also, we have repeatedly stressed that obtaining binding of a ligand in a particular fashion at very high concentrations of the active site and ligands is not justification that such a subinding could have in relevance in physiology (Manoj et al., 2016a).

\section{5 c. In silico explorations of $L D H$}

Substrate/inhibitor binding profiles in human and animal LDHs: As far as we reckon, there are no major differences in the structures of human LDHA (1I10) and LDHB (1IOZ) (Figure 5), other than subtle variations in surface topography. The two monomers were aligned using the MatchMaker tool (Chimera) and they look very similar (75\% identical!). If structural differences are indeed responsible for substrate specificity and catalytic differences (and if this is what dictates the directionality of reaction!), then there must be some clear demarcation between the substrate binding pockets and key residues of LDHA and LDHB monomers. Even the binding of $\mathrm{NADH}$ and the inhibitor oxamate were found to be superimposable in the crystal structures.

LDHB has a narrow active site channel $\sim 10 \AA$ deep, located in the middle of the globular monomer. The active site residues which are known to be involved in catalysis are found at the distal end of the active site (away from the channel opening). The interaction of the monomers and their inhibition/modulation by various substrates/inhibitors are shown in Figure 8. 


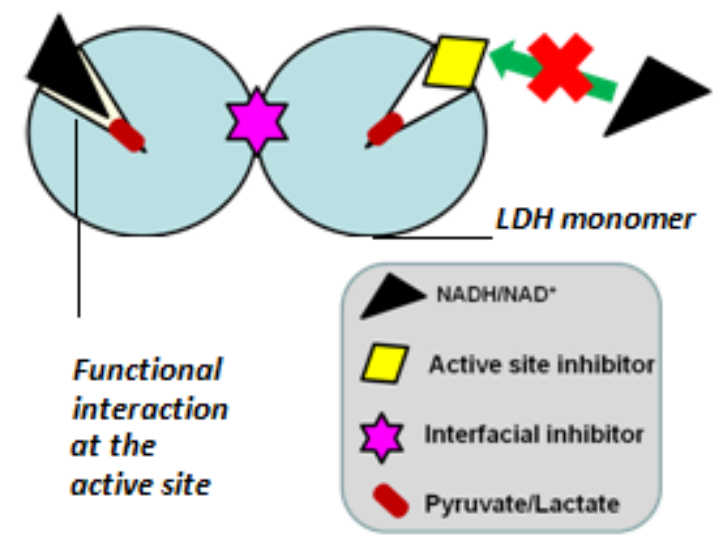

Figure 8: Schema for interaction of substrates and inhibitors with multimeric LDH.

For human LDHs, we checked the difference in docking of its substrates with monomeric and multimeric forms of the two isozymes. (This was done because while some surfaces of the monomer go into complexation, new cusp-surfaces are available for binding in the multimer.) Contrary to the classical perceptions, the docking outcomes for human LDHB did not show any significant specificity/preference for lactate (over pyruvate) or/and NAD ${ }^{+}$(over NADH). (As can be seen from Tables $3 \& 4$, the general trend was that all types of LDH analyzed showed only a slightly higher affinity for pyruvate!) While $\mathrm{NADH}$ binds to the active site in the correct orientation (with the nicotinamide ring towards the distal end, where the catalytic residues are located), $\mathrm{NAD}^{+}$binds in almost the opposite orientation (with the adenine ring inside the pocket and the nicotinamide ring being exposed to the solvent) or binds outside the active site. The details and images are provided in Item 4, Supplementary Information. Such a queer finding was seen again when docking nicotinamide nucleotides to LDHA. This result from the repulsion proffered by the three positively charged arginine residues in the active site, to the positive charge on the oxidized nicotinamide moiety. Docking of the 3-carbon substrates showed lower affinity in LDHA (as compared to LDHB). This in silico finding agrees with the experimental observations that M-dominated LDH isozymes have 3.5-7 times higher $\mathrm{K}_{\mathrm{M}}$ for pyruvate and lactate than their H-dominated counterparts. Also, while the $\mathrm{H} 4$ type is inhibited by pyruvate concentrations of $\sim 0.2 \mathrm{mM}$, the M4 type can handle upto $5 \mathrm{mM}$ pyruvate (Sanz et al., 1990). Once again, highly differentiating enzyme-substrate recognitions were not noted for the 3-carbon substrates (pyruvate over lactate or vice versa!). Therefore, with the same active site and 
equations, the classical scheme cannot explain the bidirectional activity of pyruvate reduction and lactate oxidation.

Table 3. Docking of natural substrates to human LDH [PDB (1110) and (110Z)] and comparison of binding affinities with diverse functional inhibitors

\begin{tabular}{|c|c|c|c|c|c|c|c|}
\hline \multirow[t]{2}{*}{ No. } & \multirow[t]{2}{*}{ Ligand } & \multicolumn{3}{|c|}{ LDH1 or $A / M K_{d}$ or $K_{i}\left(I C_{50}\right)$, } & \multicolumn{3}{|c|}{ LDH5 or $B / H K_{d}$ or $K_{i}\left(I C_{50}\right),(M)$} \\
\hline & & In silico (M) & Exp. (M) & Ref. & In silico & Exp. & Ref. \\
\hline 1 & \multirow[t]{2}{*}{ Lactate } & Out, $5.4 \times 10^{-3}$ & $>10^{-3}$ & (1) & In, $1.0 \times 10^{-4}$ & $>10^{-3}$ & (1) \\
\hline 2 & & Out, $7.4 \times 10^{-4}$ & & & Out, $1.4 \times 10^{-4}$ & & \\
\hline 3 & \multirow{2}{*}{ Pyruvate } & Out, $4.8 \times 10^{-3}$ & $3.9 \times 10^{-3}$ & (2) & In, $4.2 \times 10^{-5}$ & $8 \times 10^{-4}$ & (2) \\
\hline 4 & & $\ln , 2.9 \times 10^{-5}$ & & & In, $6 \times 10^{-5}$ & & \\
\hline 5 & \multirow[t]{2}{*}{$\mathrm{NAD}^{+}$} & Bad, $3.3 \times 10^{-5}$ & $1.6 \times 10^{-4}$ & (2) & Bad, $3.7 \times 10^{-5}$ & $6.2 \times 10^{-5}$ & $(2)$ \\
\hline 6 & & Out, $8.9 \times 10^{-5}$ & & & Out, $5.4 \times 10^{-4}$ & & \\
\hline 7 & \multirow[t]{2}{*}{$\mathrm{NADH}$} & In, $1.8 \times 10^{-4}$ & $5.3 \times 10^{-7}$ & (2) & In, $2.0 \times 10^{-5}$ & $2.0 \times 10^{-4}$ & (2) \\
\hline 8 & & Out, $4.1 \times 10^{-5}$ & & & Out, $1.6 \times 10^{-4}$ & & \\
\hline 9 & Sesamol & In, $1.1 \times 10^{-4}$ & NA & NA & In, $3.8 \times 10^{-4}$ & NA & NA \\
\hline 10 & Machilin A & $\ln , 5.0 \times 10^{-7}$ & $2.9 \times 10^{-5}$ & (3) & $\ln , 1.8 \times 10^{-7}$ & NA & NA \\
\hline 11 & Galloflavin & $\ln , 2.5 \times 10^{-6}$ & $5.4 \times 10^{-6}$ & (4) & $\ln , 4.6 \times 10^{-6}$ & $1.5 \times 10^{-5}$ & (4) \\
\hline 12 & CDMIMQABA & $\ln , 2.4 \times 10^{-7}$ & $\left(2.6 \times 10^{-9}\right)$ & (5) & Out, , $3.0 \times 10^{-9}$ & NA & NA \\
\hline 13 & PSTMB & $\ln , 5.9 \times 10^{-5}$ & $\left(1.4 \times 10^{-7}\right)$ & (6) & In, $1.3 \times 10^{-5}$ & NA & NA \\
\hline \multirow[t]{2}{*}{14} & FX11 & In, $2.6 \times 10^{-7}$ & $\begin{array}{l}8.0 \times 10^{-6} ; \\
\left(2.3 \times 10^{-5}\right)\end{array}$ & (7) & In, $7.0 \times 10^{-8}$ & NA & NA \\
\hline & & & $5 \times 10^{-8}$ & (8) & & $1 \times 10^{-6}$ & (8) \\
\hline 15 & EGCG & $\ln , 4.4 \times 10^{-7}$ & $\left(6.8 \times 10^{-5}\right)$ & (9) & In, $1.3 \times 10^{-7}$ & NA & (9) \\
\hline 16 & Gossypol & Out, $4.1 \times 10^{-6}$ & $1.9 \times 10^{-6}$ & (10) & In, $1.0 \times 10^{-5}$ & $1.4 \times 10^{-6}$ & (10) \\
\hline 17 & $\begin{array}{c}\mathrm{N} \text {-acylhydrazone } \\
\text { derivative }\end{array}$ & In, $3.0 \times 10^{-8}$ & $\left(3.7 \times 10^{-5}\right)$ & (11) & $\ln , 6.0 \times 10^{-8}$ & NA & NA \\
\hline 18 & $\begin{array}{l}\text { Genetech } \\
\text { inhibitor }\end{array}$ & $\begin{array}{c}\text { Partly in, } 2.0 \times \\
10^{-8}\end{array}$ & $\left(3.0 \times 10^{-8}\right)$ & (11) & In, $8.0 \times 10^{-8}$ & NA & NA \\
\hline 19 & $\begin{array}{l}\text { Glaxosmithkline } \\
\text { inhibitor }\end{array}$ & Out, $5.0 \times 10^{-7}$ & $\begin{array}{l}4.8 \times 10^{-9} ; \\
\left(1.6 \times 10^{-8}\right)\end{array}$ & (11) & At mouth, $1.0 \times 10^{-7}$ & NA & NA \\
\hline 20 & Methylmalonate & Out, $1.0 \times 10^{-5}$ & NA & NA & Out, $4.1 \times 10^{-6}$ & $3.0 \times 10^{-3}$ & (12) \\
\hline 21 & $\begin{array}{l}\text { Penta-O-galloyl } \\
\text { glucose (PGG, } \\
\text { gallotannin) }\end{array}$ & Out, $2.1 \times 10^{-2}$ & $\left(2.7 \times 10^{-8}\right)$ & (13) & At mouth, $1.2 \times 10^{-1}$ & NA & NA \\
\hline 22 & $\begin{array}{l}\text { Purinedione } \\
\text { derivative }\end{array}$ & Out, $3.1 \times 10^{-6}$ & $\left(2.5 \times 10^{-7}\right)$ & (11) & Out, $3.3 \times 10^{-6}$ & NA & NA \\
\hline 23 & AXKO-0046 & Out, $2.9 \times 10^{-7}$ & NA & (14) & Partly in, $2.3 \times 10^{-6}$ & $\left(4.2 \times 10^{-10}\right)$ & (14) \\
\hline 24 & Malonate & Out, $6.9 \times 10^{-6}$ & NA & $\begin{array}{l}(12, \\
15)\end{array}$ & Out, $8.0 \times 10^{-6}$ & NA & NA \\
\hline 25 & Oxalate & Out, $3.4 \times 10^{-5}$ & NA & $\begin{array}{l}(12 \\
15)\end{array}$ & In, $2.4 \times 10^{-5}$ & NA & NA \\
\hline 26 & Oxamate & $\begin{array}{c}\text { Partly in, } 6.6 \times \\
110^{-5}\end{array}$ & $\begin{array}{l}8.7 \times 10^{-6} ; \\
1.8 \times 10^{-3}\end{array}$ & $\begin{array}{l}(2, \\
16)\end{array}$ & In, $9.6 \times 10^{-5}$ & NA & NA \\
\hline
\end{tabular}

$\mathrm{K}_{\mathrm{d}}$ or $\mathrm{K}_{\mathrm{i}}$ values are given as such while $\mathrm{IC}_{50}$ values are given in braces. NA- not applicable or not available; Bad connotes an incorrect orientation of the nicotinamide moiety when docked inside the active site.

Table references: (1) Holbrook \& Gutfreund, 1973; (2) Hewitt et al., 1999; (3) Chung et al., 2019; (4) Manerba et al., 2012; (5) Billiard et al., 2013; (6) Kim et al., 2019; (7) Le et al., 2010; (8) Fauber et al., 2013; (9) Xu et al., 2011; (10) 
Gupta et al., 1988; (11) Di Stefano et al., 2016; (12) Saad et al., 2006; (13) Deiab et al., 2015; (14) Sogabe et al., 2020; (15) Beutler et al., 1987 and (16) Volpato et al., 2008.

Table 4. Binding of ligands to LDH from animals.

\begin{tabular}{|c|c|c|c|c|c|}
\hline No. & Ligands & Rabbit A (3H3F) & Rat A (5ES3) & Pig A (5LDH) & Pig B (5YTA) \\
\hline 1 & Lactate & 190,0 & 150,0 & 1100,1 & 96,0 \\
\hline 2 & Pyruvate & 80,0 & 63,0 & 770,1 & 43,0 \\
\hline 3 & $\mathrm{NAD}^{+}$ & 9.7, I(bad) & 26, I(bad) & 990, I(bad) & 320, I(bad) \\
\hline 4 & $\mathrm{NADH}$ & 820,1 & $160, I$ & 280,1 & 850,1 \\
\hline 5 & Sesamol & 132,0 & 238,0 & $157, I$ & 83,1 \\
\hline 6 & Machilin A & $6.6,0$ & $2.8,0$ & $0.180,0$ & $0.26,1$ \\
\hline 7 & Galloflavin & 51,0 & $8.4,1$ & $3.0,1$ & $3.0,1$ \\
\hline 8 & CDMIMQABA & $0.13,0$ & $0.32,0$ & $0.51,0$ & $0.2,0$ \\
\hline 9 & PSTMB & 218,1 & 132,1 & $14.4,1$ & $52.7,1$ \\
\hline 10 & FX11 & $6.0,0$ & $2.9,0$ & $4.36,0$ & $0.52,1$ \\
\hline 11 & EGCG & $7.0,0$ & $3.0,0$ & $0.30,1$ & $6.6,0$ \\
\hline 12 & Gossypol & $0.68,0$ & $2.6,0$ & $0.71,0$ & 12,0 \\
\hline 13 & Oxamic acid & 440,0 & 213,0 & 1050,0 & $167, \mathrm{I}$ \\
\hline 14 & Citric acid & 31,0 & 68,0 & 1160,0 & 31,0 \\
\hline
\end{tabular}

Key: $\mathrm{K}_{\mathrm{d}} / \mathrm{K}_{\mathrm{i}}$ in $\mu \mathrm{M}$, inside (I) or outside (O) active site; bad indicates a binding within the active site but poor orientation (opposite from that of the required)

In both directions of the classical purview (Figure 7), it can be seen that the binding of nicotinamide is the first step and the dissociation of same is the last and rate-limiting step. That is: according to the classical mechanism, the nicotinamide nucleotide must bind first to the active site pocket, which is followed by the binding of the 3-carbon substrate. Perhaps, the low efficiency of direct binding of 3-carbon substrate (Holbrook and Gutfreund, 1963) and its inhibition effects (whereby the 3-carbon substrate could bind and block the release of products) (Ezes et al., 1996) could have prompted the earlier researchers to moot the first binding of nicotinamide nucleotide (from the Michaelis-Menten perspective). In this regard, we have shown in a diverse array of redox-active heme proteins that substrate inhibitions are common when oneelectron mechanism involving diffusible species (murburn concept) is operative (Manoj et al., 2010; Manoj et al., 2016). The Arg109-containing loop is supposed to be mobile (which is supposed to make way for the 3-C substrate), but that movement would destabilize the priorbound NADH then (which would dissociate!). Further, a key observation is that the active site channel is only about $\sim 4-5 \AA$ across. This is inadequate to allow a kinetically viable inward or outward movement of the 3-carbon metabolite post nicotinamide binding. While it is facile to imagine NADH's entry and docking at the active site after the binding event of pyruvate, it is 
difficult to envisage the binding events in the reverse manner. Looking at all the 2D mechanistic depictions in literature of how pyruvate sits in the active site (interacting with Asp168, His195, Arg109 and Arg171), and considering the thermodynamic logic of the overall reaction, it is quite possible that there may be a different mechanism by which LDH may function for the forward reaction of lactate oxidation. Regarding the forward reaction, it needs to be first ascertained if the physiological reaction does make NADH in the liver. In the animal LDH proteins studied herein, the binding of pyruvate is slightly favored over lactate, as expected of muscle LDH (which converts the thermodynamically viable reaction of pyruvate to lactate).

On the affects/effects of inhibitors of LDH activity: The action of LDH inhibitors is based on different mechanisms: (a) competition with lactate/pyruvate (pyruvate/lactate analogs), (b) competition for binding to the NADH binding site (nicotinamide coenzyme analogs), (c) competition for binding to either lactate/pyruvate and/or NADH docking site, and (d) allosteric mechanisms (such as, binding to the oligomerization interface) (Thabault et al., 2021). For example: penta O-galloyl glucose or PGG is supposed to compete with NADH-binding site whereas oxamate, oxalate and methylmalonate supposedly compete with the 3-carbon substratebinding site (Deiab et al., 2015). When SiRNA mediated suppression of LDH protein expression or administration of FX11 (an active-site competitive inhibitor of LDH-A) was carried out in P493 or pancreatic cancer cells, suppression of LDH activity was noted (Le et al., 2010). The effect of active-site binding in this molecule is clearly traced with in silico exploration, as the docking also gave high binding energy (Table 3).

Several of the LDH inhibitors explored herein (Tables $3 \& 4$ ) are compounds that have antioxidant properties. (Please refer Item 5, Supplementary Information for the structural details of the molecules studied. These are just representative compounds, and the list is by no means exhaustive.) For example, sesamol (a phenol derivative obtained from sesame seeds) is known to have antioxidant and pleiotropic biological effects (Bosebabu et al., 2020). Even though sesamol does not have a low $\mathrm{K}_{\mathrm{d}}$ value for $\mathrm{LDH}$, it is still known to inhibit $\mathrm{LDH}$ reactions. Moreover, several derivatives of 1,3-benzodioxole and sesamol have been synthesized and characterized to be inhibitors of LDH (Annas et al., 2020). Similarly, the natural compounds - machilin A, galloflavin, gossypol and EGCG are known to be inhibitors of several redox enzymes, not just 
LDH alone. They are known to bind to and inhibit numerous cellular proteins and their functions in diverse pathophysiological conditions like inflammation, cancer and diabetes. Machilin A is known to bind to the interface between two subunits of LDHA and the inhibition is not kowing to any competitive interaction with the nicotinamide cofactor (Sogabe et al., 2020). Another such "interfacial inhibitor" touted to cause inhibition of LDH is the synthetic compound, AXKO0046, which is considered to be a highly selective inhibitor of LDHB (Sogabe et al., 2020). How does inhibitor-binding at a location far away from the actual active-site cause such drastic inhibition of enzyme activity? Most of the currently known/clinically useful LDH inhibitors are "modest" in their ability to inhibit the enzyme and have "low potency" and this makes it “challenging to correlate the observed cellular effects to LDHA inhibition" (Billiard et al., 2013). The exact mechanism by which these inhibitors powerfully inhibit LDH (judging from the very low $\mathrm{IC}_{50}$ and $\mathrm{K}_{\mathrm{i}}$ values) is unclear from the perspective of Michaelis-Menten or allosteric inhibition kinetics. For example, AXKO-0046 was shown to inhibit the enzyme at close to nM ranges. Several phenylpropanoids and flavonoids isolated from natural sources were found to inhibit LDH (Bader et al., 2015). Most of the well-known LDH inhibitors are considered to be selective inhibitors of LDHA and very few molecules (such as AXKO-0046) are known to selectively inhibit LDHB. Since LDH is an oxidoreductase and because NADH can yield hydrogen peroxide, the ROS in situ (and the ROS dynamics encountered in such a system) could be modulated by the antioxidant properties of enzymatic inhibitors which can scavenge the ROS and thereby, inhibit enzymatic activity. This is why murburn reaction chemistry explains the outcomes in such milieu. Hence, antioxidants such as machilin A, gossypol, galloflavin, sesamol and EGCG are able to inhibit LDH by modulating ROS dynamics and not strictly through binding-based mechanisms.

Comparison of Figure(s) 5/6 and the structure/dimenions of inhibitors (Item 5, Supplementary Information) suggests that some LDH inhibitors are too large to possibly even enter the active site. A classic example is the extremely large penta O-galloyl glucose molecule. In our docking studies, it is evident that PGG may not even bind to the active site, since it has in silico $\mathrm{K}_{\mathrm{i}}$ values in supra-mM ranges (close to even 0.1 M!); but, interestingly, this compound was found to yield a very low $\mathrm{IC}_{50}$ value of $2.7 \times 10^{-8} \mathrm{M}$ for the pure enzyme. We question the inferences drawn for such molecules' affects earlier (Deiab et al., 2015), as the molecule docks outside with poor 
efficiency, for both LDH-H (LDHB) and LDH-M (LDHA). Another such compound with large dimensions is the Glaxosmithkline LDH inhibitor (Di Stefano et al., 2016).

The findings above are better explained by the murburn purview for the forward reaction. The conversion of lactate to pyruvate via a one-electron route (with DROS+LDH) is a feasible reaction, and this theory is supported with EPR spectroscopic evidence (Chan and Bielski, 1974; Petrat et al., 2005). Lactate is shown to bind to a surface site (that includes V240, K244, T247, S248, W249, A250; as marked in Figure 6; within the vicinity of positively charged residues such as R168, R170, H180, K244, R268, and H270 that could aid ROS dynamics) and the inhibitors specific to LDH A were found to inhibit this very cavity on the surface of the enzyme (Figure 9). This is a signature outcome expected if/when murburn principles are operative in the enzyme. Therefore, the forward activity of LDH is actually a murzyme function (wherein the active site housing the redox cofactor and the final substrate binding site are different) (Manoj, 2018). Further, the positively charged polar residues at the mouth of the active site (for e.g. R98 in LDHA) could aid ROS dynamics. Our earlier works have shown that such features are seen in other enzymes that involve ROS utilization/stabilization (Gideon et al., 2021). Our findings are corroborated by the exploration of active structure and surface topographies of other mammalian LDH isozymes (Figure 10). Rat LDH-A has an open active site that is completely solvent accessible. A similar fully open active site can be seen in rabbit LDH-A too. At such instances, the idea of water molecules' extrusion from the active site through closure of a loop is unthinkable because the deep crevice forms the canonical active site. When the docking of gossypol was checked in both rat and rabbit LDH-A, differential sites of binding were discovered. In the rat LDH-A, gossypol was stabilized at the canonical active site; but, in LDH-A of rabbit, the binding was found to occur away from the canonical site. In pig LDH-A, CDMIMQABA binding was found to occur much further away from the canonical active site (marked by a red circle), which had two crevices leading to a common cavity inside the protein. However, CDMIMQABA had bound to a region containing predominantly positively charged amino acid residues. In pig LDH-B, EGCG had bound to the alternative site (where most of the surface binding occurred in Figure 9 for selected LDH-inhibitor combinations, which we can call "alternative site"). The pig LDH-B protein had an active site that was structurally similar to human LDH-A and LHD-B active sites. In many other cases of LDHA/B-drug combinations (not 
shown), binding did not occur exclusively to the canonical active site and this strongly emphasizes that inhibition of LDH activity involves mechanisms other than mere active site binding/blockage.

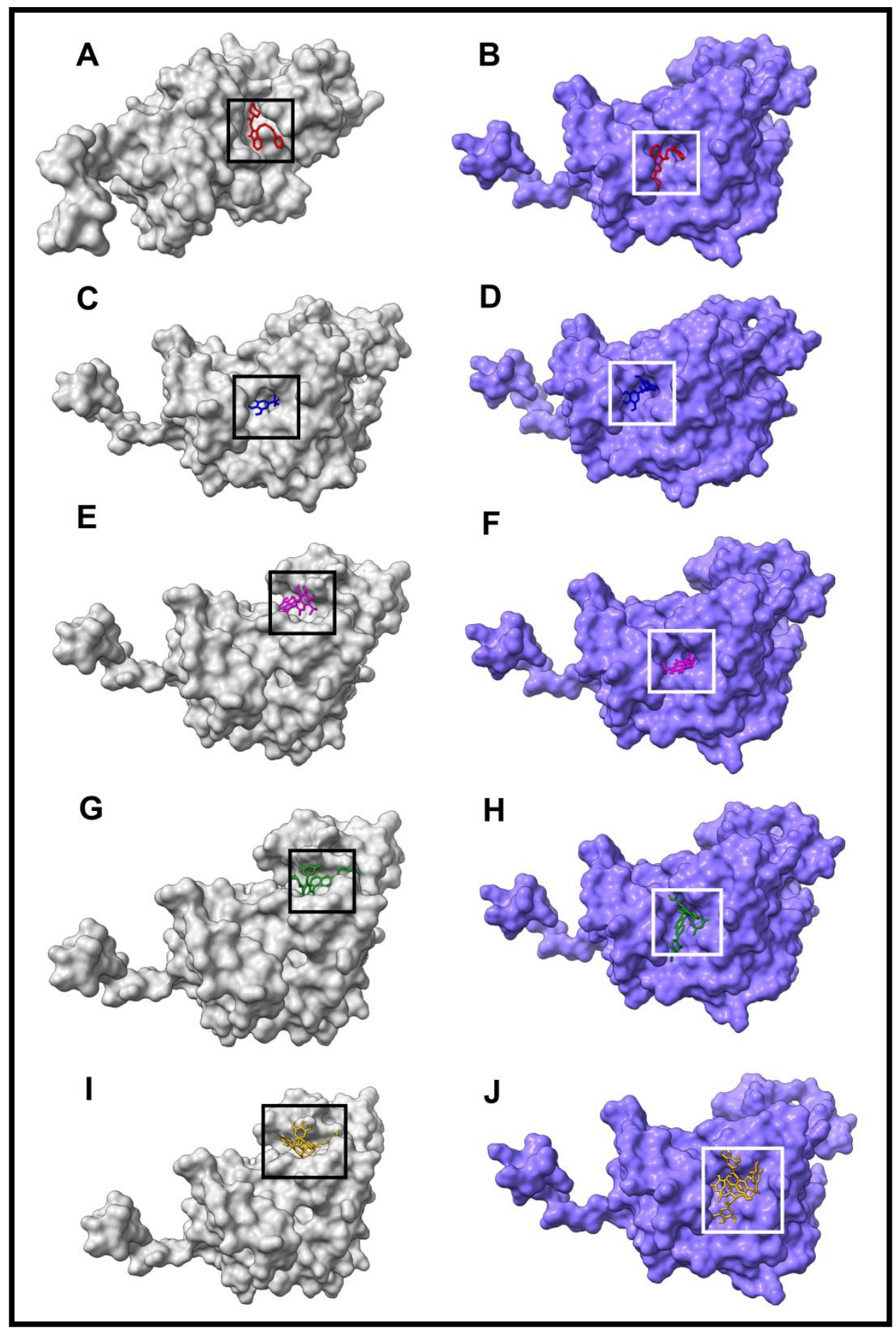


Figure 9: Docking of large inhibitor molecules to human LDH: All left panels (coloured gray) are human LDHA protein (1I10) and right panels are human LDHB protein (coloured violet). Panels A \& B: AXKO-0046 (different sites/modes); panels C \& D: EGCG (same site, slightly different mode); panels E \& F: Gossypol (different sites/modes); panels G \& H: Glaxosmithkline inhibitor (different sites/modes) and panels I \& J: PGG (different sites/modes). It can be clearly discerned that the inhibitors specific to LDH A (E, G and I) bind to the lactate binding site of LDHA; whereas LDH B binds the specific inhibitor (A) at the mouth of its active site. The non-specific ligand of EGCG binds in a similar mode, with both isozyme monomers.

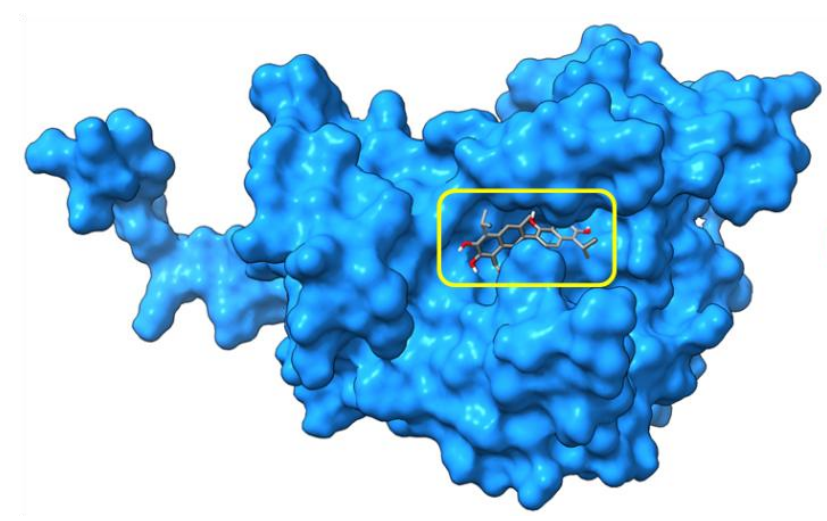

Rat LDH-A (5ES3) with gossypol

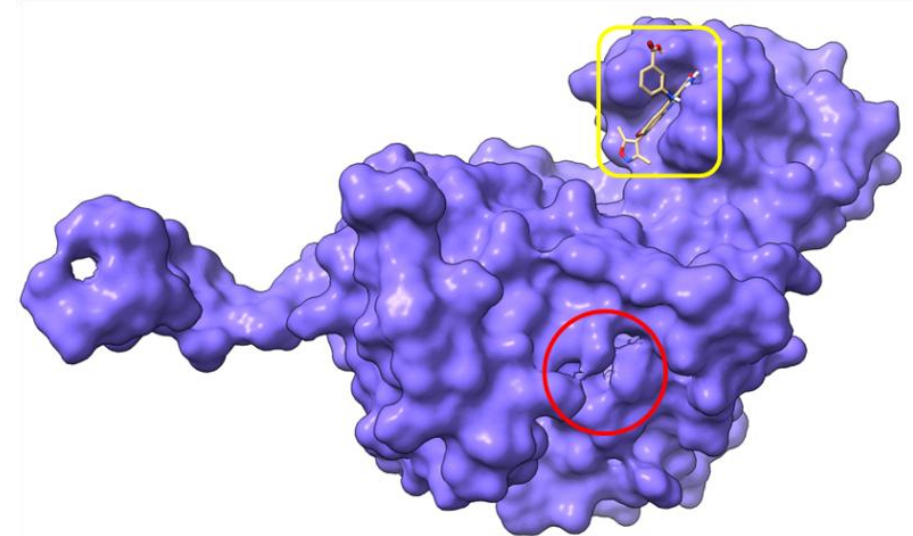

Pig LDH-A (5LDH) with CDMIMQABA

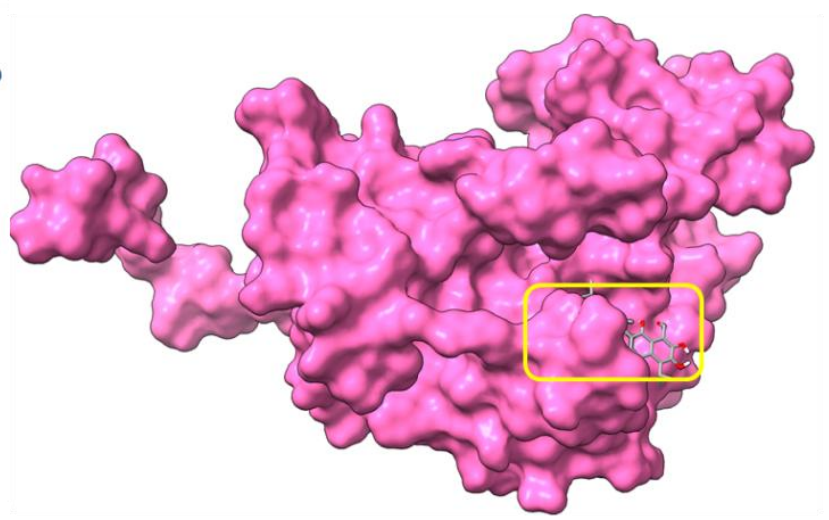

Rabbit LDH-A (3H3F) with gossypol

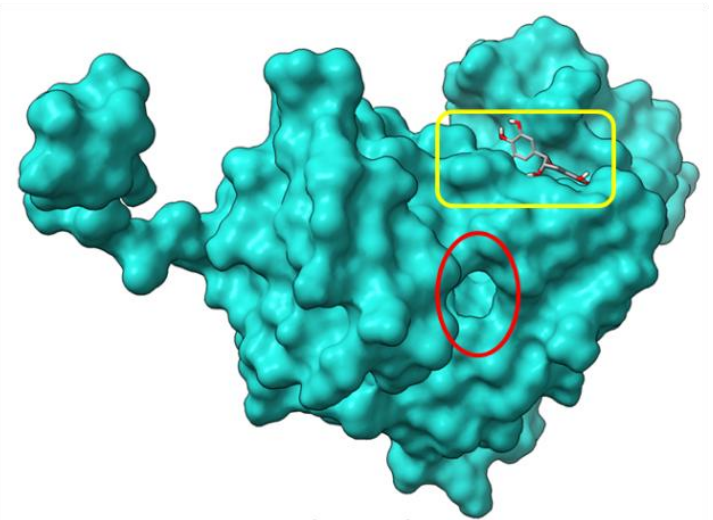

Pig LDH-B (5YTA) with EGCG

Figure 10: Structure of some mammalian LDH isozymes and the location of the principal active site and the binding loci of inhibitors on the surface.

Regarding the prevalence/delination of LDHA and LDHB, we have no concrete rationale yet, other than the one based on surface topographical differences. The physiological difference of binding of diverse molecular cues to the surface could enable metabolic modifications of these molecules (rather than proffer allosteric modulations!). Although the difference in surface topography and the surface groove with moderate affinity for lactate could be one reason. We speculate that the intermediary distribution of isozymes is based on chance, depending upon the 
relative expression of the monomers in the cells. That is- when there is a high ratio of monomer A expressed, we may observe LDH1/LDH2/LDH3 in such cells whereas if the cell has higher expression of monomer B, then more of LDH5/LDH4/LDH3 may be found.

\section{5. d. Predictability and validation of the new proposals}

We have already cited several rationale for supporting the new ideas and murburn functioning of LDH. The following are a compilation of arguments excluding the ones already cited.

The non-specificity and complications in assays of LDH can be partly reasoned by the involvement of DRS. The presence of LDH in mitochondria, where it is known to convert lactate to pyruvate (Passarella \& Schurr, 2018) is yet another support of our hypothesis. Also, the fact that LDH is a multimer (tetramer) is another support for this protein being a murzyme (which utilizes diffusible reactive species). The multimeric nature of the protein enables a greater probabilistic efficiency in function (Manoj \& Bazhin, 2021; Parashar \& Manoj, 2021). Also, this proposal suggests that the reverse reaction would not be stoichiometric (with respect to NADH production) and we might observe complicated (multiphasic) kinetics owing to the involvement of $\mathrm{DR}(\mathrm{O}) \mathrm{S}$.

Lactate and partial pressure of oxygen was directly found to modulate superoxide levels in cardiomyocytes (Mohazzeb-H et al., 1997).

While suppression of LDH activity (at protein expression level or via active site inhibition) is known to lead to enhanced oxygen consumption and DROS in milieu (Let et al., 2010), LDH activity can enhance ROS production (Wu et al., 2021). Superoxide generated in mitochondria is known to modulate the rate of peroxide generation by the enzyme (Wu et al., 2021). This is quite like the paradigm in cytochrome $\mathrm{P} 450$ mediated metabolism in the endoplasmic reticulum, which we had reasoned out with murburn concept (Manoj et al., 2016; Parashar et al., 2021). ROS is also known to regulate LDH activity (Rossi et al., 2016). Pyruvate is known to protect various types of cells/organelles from peroxide by direct reaction, giving lactate like products (Desagher et al., 1997; Wang et al., 2007; Guarino et al., 2019). Lactate can both react with hydroxyl radical and its presence can induce the production of more hydroxyl radicals in milieu (Ali and 
Konishi, 1998). Both pyruvate and lactate are known to react with singlet oxygen, superoxide, peroxide and hydroxyl radical (Martin et al. , 2009; Groussard et al., 2000; Ray, 1924). The oxoacid dehydrogenases (do they have any heme/flavin cofactors? If so, they are irrelevant here!) in mitochondria are known to produce more ROS than Complex I (Quinlan et al., 2014). It is facile to see from the reaction chemistry that even diffusible species can mediate the lactate to pyruvate conversions (Collin, 2019). In the light of such awareness, we propose the mechanistic outlay for the forward reaction of $\mathrm{LDH}$, as given in Figure 3.

Concentration dependent outcomes were seen with pyruvate-peroxide interactions in physiology (Desagher et al, 1997). That is $1 \mathrm{mM}$ peroxide gave favorable outcomes whereas $10 \mathrm{mM}$ did not. Such kind of outcomes are expected in the murburn paradigm.

In a rat brain/astrocyte LDH assay (O'Brien et al., 2007), researchers observed $\mathrm{K}_{\mathrm{M}}$ of $30-84 \mu \mathrm{M}$ (for pyruvate) in the backward reaction. However, the forward reaction exhibited biphasic kinetic profile in which, two different $\mathrm{K}_{\mathrm{M}}$ values were obtained for lactate - of $\sim 1.6 \mathrm{mM}$ and $\sim 8 \mathrm{mM}$, respectively. Such a behavior is a classical manifestation of the involvement of DRS, as we have shown in our earlier works with heme enzymes (Manoj et al., PLos One, 2010).

The murburn explanation for Warburg effect posits that cancer cells would have low pyruvate levels (versus normal cells) and this is in fact the case (Zhang et al., 2019)! Further, formation of acetate from pyruvate has been recently proposed as a viable metabolic routing in cells (Liu et al., 2018).

Talaizadeh et al. (2015) examined the differences in kinetic constants for normal vs. breast cancer tissue samples. In a normal tissue sample, $\mathrm{LDH}$ backward reaction was found to have $\mathrm{K}_{\mathrm{M}}$ values of pyruvate $=0.63 \mathrm{mM} \pm 0.03 \mathrm{mM}$ and $\mathrm{NADH}=0.33 \pm 0.01 \mathrm{mM}$. In tumour cells, the corresponding $\mathrm{K}_{\mathrm{M}}\left(\mathrm{S}_{0.5}\right)$ values were $0.78 \pm 0.07$ and $0.3 \pm 0.03 \mathrm{mM}$ for pyruvate and NADH, respectively. Similarly, the $\mathrm{V}_{\max }$ values for pyruvate and NADH was only marginally increased in $\mathrm{LDH}$ of cancerous tissue. To us, the changes in these values are only marginal and appear to be well within experimental variability. Therefore, it is not the altered specific activity of the 
enzyme per se that is responsible for the outcomes in cancer cells, but the overall dynamics of metabolism.

This can be envisaged to be achieved by: (i) enhancing the expression of flavin/heme enzymes and LDH in cytoplasm so as to increase the production/utilization of DROS; (ii) lowering the expression of DROS dismutating enzymes such as SOD/catalase in cytoplasm; (iii) enhance mitochondrial transport of glycolytic product to minimize end-product inhibition by pyruvate (Williamson \& Jones, 1964) and enhance mitochondrial ATP production.

It would be worth seeing the effects of mutating select surface residues where lactate binds, to see the effect on the outcome of reactions.

\section{Conclusions}

1. We fully agree with the recent insightful mini-review titled "Misconceptions regarding basic thermodynamics and enzyme kinetics have led to erroneous conclusions regarding the metabolic importance of lactate dehydrogenase isoenzyme expression" (Bak and Schousboe, 2017), wherein the learned authors point out the misconceptions regarding LDH's functioning in the field of neuroscience research. We restate that an enzyme merely helps the system achieve equilibrium; it cannot change the position of the same. Having different isozymes with altering $\mathrm{K}_{\mathrm{M}}$ or $\mathrm{V}_{\max }$ cannot help in reversing the direction of the reaction. In this regard, we have presented a viable murburn concept based alternative for the forward reaction of LDH. It is now opportune to correct the erroneous concepts in the textbooks, in this regard.

2. This is the first instance of an acid-base catalyst enzyme serving as a murzyme in the freesolution. The earlier examples were membrane-bound enzymes and those with redox cofactors like metal ions and heme/flavin groups. We see that polar and soluble redox-active agents affect the dynamics here, in contrast to the interfacial active species showing impact in the earlier case. We calculate that since the backward reaction has a yield of $-476 \mathrm{~kJ} / \mathrm{mol}$, the forward reaction forming free protons would not be thermodynamically facile (owing to a highly displaced equilibrium). The heme/flavin combo of cytochrome P450s (CYPs) and their reductase (CPR) in 
the liver activate oxygen to give DROS. This reaction can be coupled with the LDH reaction to give: Lactate $+\mathrm{RH}+\left(\mathrm{NAD}^{+} / \mathrm{NADPH}\right)+\mathrm{O}_{2} \rightarrow$ Pyruvate $+\mathrm{ROH}+\left(\mathrm{NADH} / \mathrm{NADP}{ }^{+}\right)+\mathrm{H}_{2} \mathrm{O}$. Thus, the metabolic thermodynamics and redox homeostasis of Cori cycle is explained better within the murburn purview.

3. The newly proposed scheme affords a tangible explanation for $\mathrm{pH}$ dynamics, Cori cycle and Warburg effect associated with lactate metabolism. The murburn proposal provides a tangible explanation for the variations in surface topographies of different mammalian isozymes.

4. Further, the analyses conducted in this study suggest that the tetra-molecular reaction within glycolysis mediated by glyceraldehydes-3-phosphate dehydrogenase is a murzyme type process. This is corroborated by the finding that the enzyme activity is inhibited by cyanide and reversed by peroxide (DROS) (Pena et al., 2015). Also, in the light of murburn equilibriums determining the ultimate redox dynamics within cell, biochemistry must be traced and taught with thoroughly mass and charge balanced treatments. Else, the steady state dynamics cannot be grasped and the situation leads to confusions.

\section{Declarations:}

The author has no conflicts of interests to declare. The work was powered by Satyamjayatu: The Science \& Ethics Foundation. KMM thanks Prof. Nikolai Bazhin (Russian Academy of Sciences) for discussions. KMM conceived/compiled the problems/solutions and wrote the first draft of the paper. DAG originally suggested that enzymes like LDH/COX could be associated with DROS-murburn activity, initiated the exploration of inhibition aspects, traced several relevant published works and helped in writing the paper. AP, VN and JE carried out in silico works.

\section{References:}

Alberty, R. A. (2005). Thermodynamics of biochemical reactions. John Wiley \& Sons.

Ali, M. A., \& Konishi, T. (1998). Enhancement of hydroxyl radical generation in the fenton reaction by alpha-hydroxy acid. IUBMB Life, 46(1), 137-145. 
Ali, M. A., Yasui, F., Matsugo, S., \& Konishi, T. (2000). The lactate-dependent enhancement of hydroxyl radical generation by the Fenton reaction. Free radical research, 32(5), 429-438.

Annas, D., Cheon, S. Y., Yusuf, M., Bae, S. J., Ha, K. T., \& Park, K. H. (2020). Synthesis and initial screening of lactate dehydrogenase inhibitor activity of 1,3-benzodioxole derivatives. Scientific reports, 10(1), 1-9.

Bader, A., Tuccinardi, T., Granchi, C., Martinelli, A., Macchia, M., Minutolo, F., ... \& Braca, A. (2015). Phenylpropanoids and flavonoids from Phlomis kurdica as inhibitors of human lactate dehydrogenase. Phytochemistry, 116, 262-268.

Bak, L. K., \& Schousboe, A. (2017). Misconceptions regarding basic thermodynamics and enzyme kinetics have led to erroneous conclusions regarding the metabolic importance of lactate dehydrogenase isoenzyme expression. Journal of neuroscience research, 95(11), 2098-2102.

Bakker, J., Nijsten, M. W., \& Jansen, T. C. (2013). Clinical use of lactate monitoring in critically ill patients. Annals of intensive care, 3(1), 12. https://doi.org/10.1186/2110-5820-3-12

Berg, J. M., Tymoczko, J. L., \& Stryer, L. (2002). Protein structure and function. Biochemistry, 262, 159-173.

Beutler, E., Forman, L., \& West, C. (1987). Effect of oxalate and malonate on red cell metabolism. Blood 70: 1389-1393.

Billiard, J., Dennison, J. B., Briand, J., Annan, R. S., Chai, D., Colón, M., ... \& Duffy, K. J. (2013). Quinoline 3-sulfonamides inhibit lactate dehydrogenase $A$ and reverse aerobic glycolysis in cancer cells. Cancer \& metabolism, 1(1), 1-17.

Borgmann, U., Laidler, K. J., \& Moon, T. W. (1975). Kinetics and thermodynamics of lactate dehydrogenases from beef heart, beef muscle, and flounder muscle. Canadian journal of biochemistry, 53(11), 1196-1206.

Bosebabu, B., Cheruku, S. P., Chamallamudi, M. R., Nampoothiri, M., Shenoy, R. R., Nandakumar, K., ... \& Kumar, N. (2020). An Appraisal of current pharmacological perspectives of sesamol: a review. Mini reviews in medicinal chemistry, 20(11), 988-1000. https://doi.org/10.2174/1389557520666200313120419

Brooks, G. A. (2020). Lactate as a fulcrum of metabolism. Redox biology, 35, 101454.

Burton, K., \& Wilson, T. H. (1953). The free-energy changes for the reduction of diphosphopyridine nucleotide and the dehydrogenation of L-malate and L-glycerol 1-phosphate. Biochemical Journal, 54(1), 86.

Chan, P. C., \& Bielski, H. J. (1974). Enzyme-catalyzed Free Radical Reactions with Nicotinamide Adenine Nucleotides: II. Lactate dehydrogenase-catalyzed oxidation of reduced nicotinamide adenine dinucleotide by superoxide radicals generated by xanthine oxidase. Journal of Biological Chemistry, 249(4), 1317-1319.

Chin, K. K., Trevithick-Sutton, C. C., McCallum, J., Jockusch, S., Turro, N. J., Scaiano, J. C., ... \& GarciaGaribay, M. A. (2008). Quantitative determination of singlet oxygen generated by excited state 
aromatic amino acids, proteins, and immunoglobulins. Journal of the American Chemical Society, 130(22), 6912-6913.

Chung, T. W., Kim, E. Y., Han, C. W., Park, S. Y., Jeong, M. S., Yoon, D., ... \& Ha, K. T. (2019). Machilin a inhibits tumor growth and macrophage $\mathrm{m} 2$ polarization through the reduction of lactic acid. Cancers, 11(7), 963.

Collin, F. (2019). Chemical basis of reactive oxygen species reactivity and involvement in neurodegenerative diseases. International journal of molecular sciences, 20(10), 2407.

Davenport, A., Will, E. J., \& Davison, A. M. (1991). Hyperlactataemia and metabolic acidosis during haemofiltration using lactate-buffered fluids. Nephron, 59(3), 461-465.

de la Cruz-López, D., Griselda, K., Castro-Muñoz, L. J., Reyes-Hernández, D. O., García-Carrancá, A., \& Manzo Merino, J. (2019). Lactate in the regulation of tumor microenvironment and therapeutic approaches. Frontiers in Oncology, 9, 1143.

DeBerardinis, R. J., \& Chandel, N. S. (2020). We need to talk about the Warburg effect. Nature Metabolism, 2(2), 127-129. https://doi.org/10.1038/s42255-020-0172-2

Deiab, S., Mazzio, E., Eyunni, S., McTier, O., Mateeva, N., Elshami, F., \& Soliman, K. F. (2015). 1, 2, 3, 4, 6-Penta-O-galloylglucose within Galla Chinensis inhibits human LDH-A and attenuates cell proliferation in MDA-MB-231 breast cancer cells. Evidence-Based Complementary and Alternative Medicine, 2015.

Desagher, S., Glowinski, J., \& Prémont, J. (1997). Pyruvate protects neurons against hydrogen peroxide-induced toxicity. Journal of Neuroscience, 17(23), 9060-9067.

Di Stefano, G., Manerba, M., Di lanni, L., \& Fiume, L. (2016). Lactate dehydrogenase inhibition: exploring possible applications beyond cancer treatment. Future medicinal chemistry, 8(6), 713-725.

Farhana, A., \& Lappin, S. L. (2021). Biochemistry, Lactate Dehydrogenase.[Updated 2020 May 17]. StatPearls [Internet]. Treasure Island (FL): StatPearls Publishing.

Eszes, C. M., Sessions, R. B., Clarke, A. R., Moreton, K. M., \& Holbrook, J. J. (1996). Removal of substrate inhibition in a lactate dehydrogenase from human muscle by a single residue change. FEBS letters, 399(3), 193-197.

Farkas, R., Daniš, P., Medved'ová, L., Mechler, B. M., \& Knopp, J. (2002). Regulation of cytosolic malate dehydrogenase by juvenile hormone in Drosophila melanogaster. Cell biochemistry and biophysics, 37(1), 37-52.

Fauber, B. P., Dragovich, P. S., Chen, J., Corson, L. B., Ding, C. Z., Eigenbrot, C., ... \& Yue, Q. (2013). Identification of 2-amino-5-aryl-pyrazines as inhibitors of human lactate dehydrogenase. Bioorganic \& medicinal chemistry letters, 23(20), 5533-5539.

Forest, V., Figarol, A., Boudard, D., Cottier, M., Grosseau, P., \& Pourchez, J. (2015). Adsorption of lactate dehydrogenase enzyme on carbon nanotubes: How to get accurate results for the cytotoxicity of these nanomaterials. Langmuir, 31(12), 3635-3643. https://doi.org/10.1021/acs.langmuir.5b00631 
Foucher, C. D., \& Tubben, R. E. (2020). Lactic acidosis. StatPearls. Retrieved November 9, 2020.

Fountain JA, Parks ME, Dickey A, McKee RW. (1970). Lactate dehydrogenase isoenzymes in tissues of normal and Ehrlich-Lettré ascites tumor-bearing Swiss mice. Cancer Research 30(4):998-1002.

Gideon, D. A., Nirusimhan, V., \& Manoj, K. M. (2020). Are plastocyanin and ferredoxin specific electron carriers or generic redox capacitors? Classical and murburn perspectives on two photosynthetic proteins.Journal of Biomolecular Structure and Dynamics, 1-15. https://doi.org/10.1080/07391102.2020.1835715

Gideon, D. A., Nirusimhan, V., Jesucastin, E., Sudarsha, K., \& Manoj, K. M. (2021). Mechanism of electron transfers mediated by cytochromes $\mathrm{c}$ and $\mathrm{b} 5$ in mitochondria and endoplasmic reticulum: classical and murburn perspectives. Journal of Biomolecular Structure and Dynamics, 1-18. https://doi.org/10.1080/07391102.2021.1925154

Glancy B., Kane D. A., Kavazis A. N., Goodwin M. L., Willis W. T., Gladden, L. B. (2021). Mitochondrial lactate metabolism: history and implications for exercise and disease. Journal of Physiology Feb;599(3):863-888. doi: 10.1113/JP278930.

Groussard, C., Morel, I., Chevanne, M., Monnier, M., Cillard, J., \& Delamarche, A. (2000). Free radical scavenging and antioxidant effects of lactate ion: an in vitro study. Journal of applied physiology, 89(1), 169-175.

Granchi, C., Bertini, S., Macchia, M., \& Minutolo, F. (2010). Inhibitors of lactate dehydrogenase isoforms and their therapeutic potentials. Current medicinal chemistry, 17(7), 672-697.

Guarino, V. A., Oldham, W. M., Loscalzo, J., \& Zhang, Y. Y. (2019). Reaction rate of pyruvate and hydrogen peroxide: assessing antioxidant capacity of pyruvate under biological conditions. Scientific reports, 9(1), 1-9.

Gupta, G. S., Kapur, S., \& Kinsky, R. G. (1988). Inhibition kinetics of lactate dehydrogenase isoenzymes by gossypol acetic acid. Biochemistry international, 17(1), 25-34.

Hakala, M. T., Glaid, A. J., \& Schwert, G. W. (1956). Lactic dehydrogenase II. Variation of kinetic and equilibrium constants with temperature. Journal of Biological Chemistry, 221(1), 191-210.

He L, He T, Farrar S, Ji L, Liu T, Ma X. Antioxidants Maintain Cellular Redox Homeostasis by Elimination of Reactive Oxygen Species. Cell Physiol Biochem. 2017;44(2):532-553. doi: 10.1159/000485089.r

Heck, H., Mader, A., Hess, G., Mücke, S., Müller, R., \& Hollmann, W. (1985). Justification of the 4$\mathrm{mmol} / \mathrm{l}$ lactate threshold. International journal of sports medicine, 6(03), 117-130.

Hewitt, C. O., Eszes, C. M., Sessions, R. B., Moreton, K. M., Dafforn, T. R., Takei, J., ... \& Holbrook, J. J. (1999). A general method for relieving substrate inhibition in lactate dehydrogenases. Protein Engineering, 12(6), 491-496.

Hill, A. V. (1928). The Diffusion of Oxygen and Lactic Acid through Tissues. Proceedings of the Royal Society of London. Series B, Containing Papers of a Biological Character. Vol. 104, No. 728 (Dec. 1, 1928), pp. 39-96. 
Holbrook, J. J., \& Gutfreund, H. (1973). Approaches to the study of enzyme mechanisms lactate dehydrogenase. FEBS Lett. 31(2):157-169. doi: 10.1016/0014-5793(73)80095-x.

Jacob, V. D., \& Manoj, K. M. (2019). Are adipocytes and ROS villains, or are they protagonists in the drama of life? The murburn perspective. Adipobiology, 10, 7-16. http://dx.doi.org/10.14748/adipo.v10.6534

Kim, E. Y., Chung, T. W., Han, C. W., Park, S. Y., Park, K. H., Jang, S. B., \& Ha, K. T. (2019). A novel lactate dehydrogenase inhibitor, 1-(phenylseleno)-4-(trifluoromethyl) benzene, suppresses tumor growth through apoptotic cell death. Scientific reports, 9(1), 1-12.

Koukourakis, M. I., Giatromanolaki, A., Sivridis, E., Bougioukas, G., Didilis, V., Gatter, K. C., \& Harris, A. L. (2003). Lactate dehydrogenase-5 (LDH-5) overexpression in non-small-cell lung cancer tissues is linked to tumour hypoxia, angiogenic factor production and poor prognosis. British journal of cancer, 89(5), 877-885.

Kumar, P., Nagarajan, A., \& Uchil, P. D. (2018). Analysis of cell viability by the lactate dehydrogenase assay. Cold Spring Harbor Protocols, 2018(6), pdb-prot095497. https://doi.org/10.1101/pdb.prot095497

Le, A., Cooper, C. R., Gouw, A. M., Dinavahi, R., Maitra, A., Deck, L. M., ... \& Dang, C. V. (2010). Inhibition of lactate dehydrogenase $A$ induces oxidative stress and inhibits tumor progression. Proceedings of the National Academy of Sciences, 107(5), 2037-2042.

Lehninger, A. L., Nelson, D. L., Cox, M. M., \& Cox, M. M. (2005). Lehninger principles of biochemistry. Macmillan.

Lewis, L. M., Ferguson, I., House, S. L., Aubuchon, K., Schneider, J., Johnson, K., \& Matsuda, K. (2014). Albuterol administration is commonly associated with increases in serum lactate in patients with asthma treated for acute exacerbation of asthma. Chest, 145(1), 53-59.

Li XB, Gu JD, Zhou QH. Review of aerobic glycolysis and its key enzymes - new targets for lung cancer therapy. Thorac Cancer. 2015 Jan;6(1):17-24. doi: 10.1111/1759-7714.12148.

Liberti, M. V., \& Locasale, J. W. (2016). The Warburg Effect: How Does it Benefit Cancer Cells?. Trends in biochemical sciences, 41(3), 211-218. https://doi.org/10.1016/j.tibs.2015.12.001

Liu, X., et al., (2018). Acetate production from glucose and coupling to mitochondrial metabolism in mammals. Cell 175, 502e513, 2018.

Martin, L. R., Mezyk, S. P., \& Mincher, B. J. (2009). Determination of arrhenius and thermodynamic parameters for the aqueous reaction of the hydroxyl radical with lactic acid. The Journal of Physical Chemistry A, 113(1), 141-145.

Manchester, K. L. (1977). Kinetics of lactate dehydrogenase: A textbook problem. Biochemical Education, 5(1), 15-15.

Manerba, M., Vettraino, M., Fiume, L., Di Stefano, G., Sartini, A., Giacomini, E., ... \& Recanatini, M. (2012). Galloflavin (CAS 568-80-9): a novel inhibitor of lactate dehydrogenase. ChemMedChem, 7(2), 311-317. 
Manoj, K. M. (2018). Aerobic respiration: Criticism of the proton-centric explanation involving rotary adenosine triphosphate synthesis, chemiosmosis principle, proton pumps and electron transport chain. Biochemistry insights, 11, 1178626418818442

Manoj, K. M. (2018). Debunking chemiosmosis and proposing murburn concept as the operative principle for cellular respiration. Biomedical Reviews, 28, 31-48. http://dx.doi.org/10.14748/bmr.v28.4450

Manoj, K. M. (2018). The ubiquitous biochemical logic of murburn concept. Biomedical Reviews, 29, 89-97.

Manoj, K. M. (2020a). Murburn concept: a paradigm shift in cellular metabolism and physiology. Biomolecular concepts, 11(1), 7-22. https://doi.org/10.1515/bmc-2020-0002

Manoj, K. M. (2020b). Refutation of the cation-centric torsional ATP synthesis model and advocating murburn scheme for mitochondrial oxidative phosphorylation. Biophysical chemistry, 257, 106278.

Manoj, K. M. (2021). Some living beings speak up against 'electron transport chain-chemiosmosisrotary ATP synthesis' bioenergetics model.

Manoj, K. M., \& Bazhin, N. M. (2021). The murburn precepts for aerobic respiration and redox homeostasis. Progress in Biophysics and Molecular Biology.

Manoj, K. M., \& Jacob, V. D. (2020). The murburn precepts for photoreception. Biomedical Reviews, 31, 67-74.

Manoj, K. M., \& Manekkathodi, A. (2021). Light's interaction with pigments in chloroplasts: The murburn perspective. Journal of Photochemistry and Photobiology, 5, 100015. https://doi.org/10.1016/j.jpap.2020.100015

Manoj, K. M., \& Nikolai, B. (2019). Murburn precepts for aerobic respiration and homeostasis.

Manoj, K. M., Gade, S. K., Venkatachalam, A., \& Gideon, D. A. (2016). Electron transfer amongst flavo-and hemo-proteins: diffusible species effect the relay processes, not protein-protein binding. RSC advances, 6(29), 24121-24129.

Manoj, K. M., Gideon, D. A., \& Jacob, V. D. (2018). Murburn scheme for mitochondrial thermogenesis. Biomedical Reviews, 29, 73-82. http://dx.doi.org/10.14748/bmr.v29.5852

Manoj, K. M., Gideon, D. A., \& Jacob, V. D. (2018). Murburn scheme for mitochondrial thermogenesis. Biomedical Reviews, 29, 73-82.

Manoj, K. M., Gideon, D. A., \& Parashar, A. (2021). What is the role of lipid membrane-embedded quinones in mitochondria and chloroplasts? Chemiosmotic Q-cycle versus murburn reaction perspective. Cell Biochemistry and Biophysics, 79(1), 3-10. https://doi.org/10.1007/s12013-02000945-y

Manoj, K. M., Nikolai, B., Parashar, A., Gideon, D. A., Jacob, V. D., Haarith, D., \& Manekkathodi, A. (2020). Murburn precepts for the light reaction of oxygenic photosynthesis. 
Manoj, K. M., Parashar, A., David Jacob, V., \& Ramasamy, S. (2019a). Aerobic respiration: proof of concept for the oxygen-centric murburn perspective. Journal of Biomolecular Structure and Dynamics, 37(17), 4542-4556.

Manoj, K. M., Parashar, A., Gade, S. K., \& Venkatachalam, A. (2016b). Functioning of microsomal cytochrome P450s: Murburn concept explains the metabolism of xenobiotics in hepatocytes. Frontiers in pharmacology, 7, 161.

Manoj, K. M., Parashar, A., Venkatachalam, A., Goyal, S., Singh, P. G., Gade, S. K., ... \& Gideon, D. A. (2016a). Atypical profiles and modulations of heme-enzymes catalyzed outcomes by low amounts of diverse additives suggest diffusible radicals' obligatory involvement in such redox reactions. Biochimie, 125, 91-111. https://doi.org/10.1016/j.biochi.2016.03.003

Manoj, K. M., Ramasamy, S., Parashar, A., Gideon, D. A., Soman, V., Jacob, V. D., \& Pakshirajan, K. (2020). Acute toxicity of cyanide in aerobic respiration: Theoretical and experimental support for murburn explanation. Biomolecular concepts, 11(1), 32-56. https://doi.org/10.1515/bmc-2020-0004

Manoj, K. M., Soman, V., Jacob, V. D., Parashar, A., Gideon, D. A., Kumar, M., ... \& Bazhin, N. M. (2019b). Chemiosmotic and murburn explanations for aerobic respiration: predictive capabilities, structure-function correlations and chemico-physical logic. Archives of biochemistry and biophysics, 676, 108128. https://doi.org/10.1016/j.abb.2019.108128

Manoj, K. M., Bazhin, N. M., Tamagawa, H. (2021). The murburn precepts for cellular ionic homeostasis and electrophysiology. Journal of Cellular Physiology. doi: 10.1002/jcp.30547

Martin, L. R., Mezyk, S. P., \& Mincher, B. J. (2009). Determination of arrhenius and thermodynamic parameters for the aqueous reaction of the hydroxyl radical with lactic acid. The Journal of Physical Chemistry A, 113(1), 141-145.

McClendon, S., Zhadin, N., \& Callender, R. (2005). The approach to the Michaelis complex in lactate dehydrogenase: the substrate binding pathway. Biophysical journal, 89(3), 2024-2032.

Miller, S. L., \& Smith-Magowan, D. (1990). The thermodynamics of the Krebs cycle and related compounds.Journal of Physical and Chemical Reference Data,19(4), 1049-1073. https://doi.org/10.1063/1.555878

Kamal M. Mohazzab-H. , PhD , Pawel M. Kaminski , MD, PhD , and Michael S. Wolin , PhD Lactate and $\mathrm{Po}_{2}$ Modulate Superoxide Anion Production in Bovine Cardiac Myocytes Circulation.

1997;96:614-620. https://doi.org/10.1161/01.CIR.96.2.614

Nishimura, J., \& Minakami, S. (1975). Effect of hydrogen ion concentration on energy metabolism in pig platelets. Biochimica et Biophysica Acta (BBA)-Bioenergetics, 396(1), 1-10.

O’Brien, J., Kla, K. M., Hopkins, I. B., Malecki, E. A., \& McKenna, M. C. (2007). Kinetic parameters and lactate dehydrogenase isozyme activities support possible lactate utilization by neurons. Neurochemical research, 32(4), 597-607.

Parashar, A., \& Manoj, K. M. (2021). Murburn precepts for cytochrome P450 mediated drug/xenobiotic metabolism and homeostasis. Current Drug Metabolism. 
Parashar, A., Gideon, D. A., \& Manoj, K. M. (2018). Murburn concept: A molecular explanation for hormetic and idiosyncratic dose responses. Dose-Response, 16(2), 1559325818774421.

Parashar, A., Jacob, V. D., Gideon, D. A., \& Manoj, K. M. (2021). Hemoglobin catalyzes ATP-synthesis in human erythrocytes: a murburn model. Journal of Biomolecular Structure and Dynamics, 1-13.

Passarella, S., \& Schurr, A. (2018). I-Lactate transport and metabolism in mitochondria of Hep G2 cells-The Cori cycle revisited. Frontiers in oncology, 8, 120.

Peña A, Norma Silvia Sánchez, Omar González-López, Martha Calahorra, Mechanisms involved in the inhibition of glycolysis by cyanide and antimycin A in Candida albicans and its reversal by hydrogen peroxide. A common feature in Candida species, FEMS Yeast Research, Volume 15, Issue 8, December 2015, fov083, https://doi.org/10.1093/femsyr/fov083

Peng, H. L., Deng, H., Dyer, R. B., \& Callender, R. (2014). Energy landscape of the Michaelis complex of lactate dehydrogenase: relationship to catalytic mechanism. Biochemistry, 53(11), 1849-1857.

Petrat, F., Bramey, T., Kirsch, M., \& De Groot, H. (2005). Initiation of a superoxide-dependent chain oxidation of lactate dehydrogenase-bound NADH by oxidants of low and high reactivity. Free radical research, 39(10), 1043-1057.

Quinlan, C. L., Goncalves, R. L., Hey-Mogensen, M., Yadava, N., Bunik, V. I., \& Brand, M. D. (2014). The 2-oxoacid dehydrogenase complexes in mitochondria can produce superoxide/hydrogen peroxide at much higher rates than complex I. Journal of Biological Chemistry, 289(12), 8312-8325.

Rabinowitz, J. D., \& Enerbäck, S. (2020). Lactate: the ugly duckling of energy metabolism. Nature Metabolism, 2(7), 566-571.

Ray, G. B. (1924). THE effect of cystine and glycocoll on the oxidation of sodium lactate by hydrogen peroxide. The Journal of general physiology, 6(5), 525.

Read, J. A., Winter, V. J., Eszes, C. M., Sessions, R. B., \& Brady, R. L. (2001). Structural basis for altered activity of $\mathrm{M}$-and $\mathrm{H}$-isozyme forms of human lactate dehydrogenase. Proteins: Structure, Function, and Bioinformatics, 43(2), 175-185.

Roberts, K., Alberts, B., Johnson, A., Walter, P., \& Hunt, T. (2002). Molecular biology of the cell. New York: Garland Science.

Rossi, S. P., Windschüttl, S., Matzkin, M. E., Rey-Ares, V., Terradas, C., Ponzio, R., ... \& Frungieri, M. B. (2016). Reactive oxygen species (ROS) production triggered by prostaglandin D2 (PGD2) regulates lactate dehydrogenase (LDH) expression/activity in TM4 Sertoli cells. Molecular and cellular endocrinology, 434, 154-165.

Russell, P., Williams, A., Abbott, A., Chadwick, J., Ehya, F., Flores, R., \& Hardamon, C. (2010). Effect of lithium salts on lactate dehydrogenase, adenylate kinase, and 1-phosphofructokinase activities. Journal of enzyme inhibition and medicinal chemistry, 25(4), 551-556. https://doi.org/10.3109/14756360903357627

Saad, L. O., Mirandola, S. R., Maciel, E. N., \& Castilho, R. F. (2006). Lactate dehydrogenase activity is inhibited by methylmalonate in vitro. Neurochemical research, 31(4), 541-548. 
Sanz, M. C., Sagrista, M. L., \& Lluis, C. (1990). Kinetic behaviour of soluble and mitochondrial bound lactate dehydrogenase. The Italian journal of biochemistry, 39(1), 21-29.

Sattler, U. G., Walenta, S., \& Mueller-Klieser, W. (2007). A bioluminescence technique for quantitative and structure-associated imaging of pyruvate. Laboratory investigation, 87(1), 84-92.

Seheult, J., Fitzpatrick, G., \& Boran, G. (2017). Lactic acidosis: an update. Clinical Chemistry and Laboratory Medicine (CCLM), 55(3), 322-333.

Shoemark, D. K., Cliff, M. J., Sessions, R. B., \& Clarke, A. R. (2007). Enzymatic properties of the lactate dehydrogenase enzyme from Plasmodium falciparum. The FEBS journal, 274(11), 2738-2748.

Sies, H. (2014). Role of metabolic $\mathrm{H} 2 \mathrm{O} 2$ generation: redox signaling and oxidative stress. Journal of Biological Chemistry, 289(13), 8735-8741. https://doi.org/10.1074/jbc.R113.544635

Singh, S. N., \& Kanungo, M. S. (1968). Alterations in lactate dehydrogenase of the brain, heart, skeletal muscle, and liver of rats of various ages. Journal of Biological Chemistry, 243(17), 45264529.

Sogabe, S., Miwa, M., Fujimoto, T., Takakura, N., Naotsuka, A., Kitamura, S., ... \& Soga, T. (2020). Identification of the First Highly Selective Inhibitor of Human Lactate Dehydrogenase B. https://doi.org/10.21203/rs.3.rs-95794/v1

Stewart PA. Modern quantitative acid-base chemistry. Can J Physiol Pharmacol. 1983;3(12):14441461. doi: $10.1139 / \mathrm{y} 83-207$

Świderek, K., \& Paneth, P. (2011). Differences and similarities in binding of pyruvate and L-lactate in the active site of M4 and $\mathrm{H} 4$ isoforms of human lactate dehydrogenase. Archives of biochemistry and biophysics, 505(1), 33-41.

Talaiezadeh, A., Shahriari, A., Tabandeh, M. R., Fathizadeh, P., \& Mansouri, S. (2015). Kinetic characterization of lactate dehydrogenase in normal and malignant human breast tissues. Cancer cell international, 15(1), 1-9.

Tamagawa, H., Mulembo, T., Delalande B., \& Manoj, K. M. (2021). Explaining trans-phase potential differences with membrane theory, association-induction hypothesis and murburn concept. OSF Preprints. May 25. doi:10.31219/osf.io/asrw5.

Thabault, L., Liberelle, M., Koruza, K., Yildiz, E., Joudiou, N., Messens, J., ... \& Frédérick, R. (2021). Discovery of a novel lactate dehydrogenase tetramerization domain using epitope mapping and peptides. Journal of Biological Chemistry, 296, 100422.

Tomschi, F., Bizjak, D. A., Predel, H. G., Bloch, W., \& Grau, M. (2018). Lactate distribution in red blood cells and plasma after a high intensity running exercise in aerobically trained and untrained subjects.

Vanderlinde, R. E. (1985). Measurement of total lactate dehydrogenase activity. Annals of Clinical \& Laboratory Science, 15(1), 13-31. 
Venkatachalam, A., Parashar, A., \& Manoj, K. M. (2016). Functioning of drug-metabolizing microsomal cytochrome P450s: In silico probing of proteins suggests that the distal heme 'active site'pocket plays a relatively 'passive role'in some enzyme-substrate interactions. In silico pharmacology, 4(1), 1-38. https://doi.org/10.1186/s40203-016-0016-7

Voet, D., \& Voet, J. G. (2011). Biochemistry, $4^{\text {th }}$ Edition. NewYork: John Wiley\& Sons Inc, 492.

Volpato, M., Ablain, J., \& Phillips, R. (2008). Inhibition of Lactate Dehydrogenase (LDH-A) potentiates the activity of NQO1 (NAD (P) H: Quinone oxidoreductase-1) by increasing cellular NADH levels. Cancer Research 4358.

von Platen, A., D'Souza, M. A., Rooyackers, O., \& Nowak, G. (2019). Evaluation of Intrahepatic Lactate/Pyruvate Ratio As a Marker for Ischemic Complications Early After Liver Transplantation-A Clinical Study. Transplantation direct, 5(12).

Wang, X., Perez, E., Liu, R., Yan, L. J., Mallet, R. T., \& Yang, S. H. (2007). Pyruvate protects mitochondria from oxidative stress in human neuroblastoma SK-N-SH cells. Brain research, 1132, 19.

Wang, Y., Huang, Y., Yang, J., Zhou, F. Q., Zhao, L., \& Zhou, H. (2018). Pyruvate is a prospective alkalizer to correct hypoxic lactic acidosis. Military Medical Research, 5(1), 1-9.

Williamson, D. H., Lund, P., \& Krebs, H. A. (1967). The redox state of free nicotinamide-adenine dinucleotide in the cytoplasm and mitochondria of rat liver. Biochemical Journal, 103(2), 514. https://dx.doi.org/10.1042\%2Fbj1030514

Williamson, J. R., \& Jones, E. A. (1964). Inhibition of glycolysis by pyruvate in relation to the accumulation of citric acid cycle intermediates in the perfused rat heart. Nature, 203(4950), 11711173.

Wu, H., Wang, Y., Ying, M., Jin, C., Li, J., \& Hu, X. (2021). Lactate dehydrogenases amplify reactive oxygen species in cancer cells in response to oxidative stimuli. Signal Transduction and Targeted Therapy, 6(1), 1-13.

Xu, X., Zhou, X. D., \& Wu, C. D. (2011). The tea catechin epigallocatechin gallate suppresses cariogenic virulence factors of Streptococcus mutans. Antimicrobial agents and chemotherapy, 55(3), 1229-1236.

Young, A., Oldford, C., \& Mailloux, R. J. (2020). Lactate dehydrogenase supports lactate oxidation in mitochondria isolated from different mouse tissues. Redox biology, 28, 101339.

Zhadin, N., Gulotta, M., \& Callender, R. (2008). Probing the role of dynamics in hydride transfer catalyzed by lactate dehydrogenase. Biophysical journal, 95(4), 1974-1984.

Zhang, M., Pan, Y., Tang, D., Dorfman, R. G., Xu, L., Zhou, Q., ... \& Zou, X. (2019). Low levels of pyruvate induced by a positive feedback loop protects cholangiocarcinoma cells from apoptosis. Cell Communication and Signaling, 17(1), 1-14. 


\section{SUPPLEMENTARY INFORMATION}

\section{Item 1}

We present some highly intriguing aspects of lactate dehydrogenase (LDH), a well-studied redox enzyme with immense physiological and clinical significance. We find that the structural features currently available fail to afford a thermodynamically/kinetically viable explanation (with Michaelis-Menten formalization) for physiologically facile bidirectional LDH catalysis.

\subsection{The relevance of murburn concept in redox metabolism and physiology}

Murburn concept is a theory of redox metabolism, which espouses and establishes the role of diffusible reactive (oxygen) species or $\mathrm{DR}(\mathrm{O}) \mathrm{S}$ (DRS/ROS/DROS) as catalytic/driving agents of biological electron/moiety transfer (BET/BMT) reactions. Murburn is an acronym derived from MURed BURNing or Mild UnRestricted BURNing (mechanistically, a stochastic interactive equilibrium of Molecules, Unbound ions and Radicals/Reactive species) which can occur in both aerobic and anaerobic conditions (Manoj, 2018a; Manoj, 2020a,b). The conceptualization of murburn concept stems from Manoj's efforts to reason out the unusual outcomes seen in several heme/flavin redox enzyme catalyzed reactions. Free radicals and DROS were previously labeled as deleterious \& wasteful products. In the murburn perspective, DRS/ROS are generated by murzymes (enzymes that work along the murburn concept) and they serve to mediate a stochastic interaction network within the reaction milieu. While many research and review papers in the past few decades have explored the deleterious outcomes of free radicals and DROS, murburn logic presents a richer and a much more compelling role for these apparently 'chaotic' agents in maintaining the order of life processes. In murburn concept, DROS are not mere cell signaling or pathogen destroying agents; they carry out electron and group transfers between diverse proteins and small molecules. Hence, the perceptions that: (i) BETs/BMTs occur purely through proteinprotein affinity interactions \& (ii) redox enzyme mediated moiety-transfers occurred purely via a Michaelis-Menten type enzyme-substrate complex formation at a unique active site- have been superseded by the larger purview of murburn concept (Manoj et al., 2016a,b; Manoj, 2018b; Manoj, 2020a,b; Gideon et al., 2020, 2021). Murburn models of reaction chemistry have been proposed for microsomal drug metabolism (Venkatachalam et al., 2016; Manoj et al., 2016c; Parashar \& Manoj, 2021), aerobic respiration or mitochondrial oxidative phosphorylation (mOxPhos) (Manoj et al., 2019a,b; Manoj et al., 2020a; Manoj \& Bazhin, 2021), oxygenic photosynthesis or photophosphorylation (PhotoPhos) (Manoj et al., 2020b; Manoj \& Manekkathodi, 2021; Manoj et al., 2021a,b), hormetic/idiosyncratic dose responses (Parashar et al., 2018), photoreception (Manoj \& Jacob, 2020), thermogenesis (Manoj et al., 2018), redox/ionic homeostasis and trans-membrane potential dynamics (Manoj \& Bazhin, 2021; Manoj et al., 2021; Tamagawa et al., 2021). The thermodynamically, kinetically, mechanistically and probabilistically viable physico-chemical logic of murburn concept overwhelms the 'aesthetics' stigma that 'DROS are agents of chaos' (Jacob \& Manoj, 2019). We have explained the structure-function correlations of several key redox enzyme systems in the light of murburn 
concept and herein, we explicate the redox metabolism/physiology of an alpha hydroxyacid exemplified by lactate.

\subsection{Alpha hydroxyacid metabolism: The case of LDH}

Glycolate, lactate, malate, hydroxyglutarate and isocitrate are key alpha-hydroxyacyl metabolic intermediates. They are respectively oxidized to glyoxylate, pyruvate, oxaloacetate, ketoglutarate and oxalosuccinate in cell bioenergetic metabolism. Photorespiration pathways in chloroplasts and plants involving glycolate/glyoxylate; anaerobic glycolysis in muscle and gluconeogenesis in liver; malate shuttle between cytoplasm and mitochondria, etc. and some important steps of Krebs cycle employ enzymes mediating the reversible redox reaction of alpha hydroxyacid to alpha ketoacid. There are usually several isoenzymes involved, which are multimeric and employ the $\mathrm{NAD}^{+} / \mathrm{NADH}$ cofactor system. It is assumed that the differences in the isoenzymes' active sites enable these proteins to work the reaction in the forward or reverse directions. Examples of some common enzymes involved are lactate dehydrogenase (LDH), malate dehydrogenase $(\mathrm{MDH})$, isocitrate dehydrogenase, etc. These enzymes and metabolites serve crucial roles in maintaining the cell metabolic repertoire (Roberts et al., 2002; Berg et al., 2002; Lehninger et al., 2004; Voet \& Voet, 2011). LDH is an oxidoreductase class of enzyme, involved in the interconversion pathways of the 3 -carbon outcomes of pyruvate $\leftrightarrow$ lactate within the anaerobic glycolysis scheme, using the nicotinamide cofactor NAD(H). It is a tetramer which is present as five distinct isozymes (LDH 1-5); these isozymes are comprised of either the same or two different subunits. Present in almost all organisms and tissues, LDH isozymes are particularly found in high concentrations in muscles and liver. Malate dehydrogenase (MDH) is closely related to LDH in structure and is usually present as a homodimer (of 30-35 KDa each), with two isoforms. The isozyme found in mitochondrial matrix is a key mediator of a Krebs cycle step (malate $\rightarrow$ oxaloacetate) whereas the isozyme in cytoplasm aids the malate-aspartate shuttle. LDH is a highly studied enzyme, with significant roles in routine cellular energy metabolism, Cori's cycle and in pathophysiological states like cancer. The dehydrogenase enzymes are thermodynamically mandated by equilibrium dictates towards the utilization of NADH and formation the alpha-hydroxy acid. Therefore, it remains an enigma as to how the reverse reaction is viable in certain types of cells or locales.

\subsection{Viable thermodynamic and kinetic explanation for lactate dynamics in physiology}

Since a catalyst merely helps a reaction mixture attain equilibrium status quickly, the fundamental definition of enzyme activity does not permit it to alter the (equation's) equilibrium status. In physiology, equilibrium status may not exist because a product may be depleted rapidly, keeping the dynamics of the reaction unidirectional. However, in many scenarios, enzyme-catalyzed reactions are essentially irreversible under physiological conditions, and the biological system must avail alternative reaction strategies to achieve the reverse of the given reaction. That is, when the physiological (equilibrium) conditions do not permit reversibility, the system cannot use the same enzyme and the same equation (i.e. reaction components) for the forward and backward processes. This is because such a premise would require the enzyme to be 
intelligently governed (or it must be smart in itself) to deterministically drive outcomes. Since this scenario is highly unlikely, we propose that the tissues/cells/organelles use alternative strategies to achieve the desired outcomes. This was the essential rationale employed to question the ideas of "affinity-binding based electron transport/transfer chain (ETC)" and chemiosmotic rotary ATP synthesis (CRAS)" for oxidative-/photo- phosphorylation (Manoj \& Bazhin, 2021; Manoj et al., 2021a). In the bioenergetic phosphorylation (hydrolase and esterification) processes, two different reactions and enzyme systems are used; i.e. $\left[\mathbf{A T P}+\mathbf{H}_{2} \mathbf{O} \rightarrow \mathbf{A D P}+\mathbf{P i}\right.$ $\left.\left(+\mathbf{H}^{+}\right)\right]$mediated by Complex $\mathrm{V}$ and $\left[\mathbf{N A D H}+\mathbf{H}^{+}+\mathbf{O}_{2}+\mathbf{A D P}+\mathbf{P i} \rightarrow \mathbf{N A D}{ }^{+}+\mathbf{H}_{2} \mathbf{O}_{2}+\mathbf{A T P}+\right.$ $\mathbf{H}_{2} \mathrm{O}$ ] mediated by Complex I, respectively. In the same vein, we propose that if the action of a redox enzyme like LDH $\left[\right.$ Pyruvate $^{-}+\mathbf{N A D H}+\mathbf{H}^{+} \rightarrow$ Lactate $^{-}+\mathbf{N A D}^{+}$] were to be fully reversible in a given cellular locale, the enzyme cannot serve any useful/directional physiological function. If so, the enzyme activity would have to be governed with 'intelligence' or must be 'smart' to make 'independent decisions'. In this regard, theoretical foundations dictate that the presence of isozymes in various tissues with somewhat variable affinities for the substrates (thereby demonstrating higher or lower $\mathrm{K}_{\mathrm{M}} / \mathrm{V}_{\max }$ ) does not change the directionality of the reaction. We project that alpha-hydroxyacid oxidation (like oxidation of lactate to pyruvate, which occurs in liver) can occur with high fecundity aided by murburn mechanism. Reaction milieu driving the redox reactions in metabolically active/versatile organs like liver (which contain high amounts of cytochrome P450, CYP) are rich in DROS and generate hydroxide or consume proton equivalents (Manoj, 2018; Manoj, 2020a; Parashar \& Manoj, 2021).

\section{Item 2}

\subsection{Theoretical and experimental aspects of thermodynamics of redox enzyme reactions}

There are usually three norms of representing free energy changes (and therefore, the dependent variables on the right also have the same corresponding norms): Simple $\Delta \mathrm{G}$ (at any given conditions), Standard $\Delta \mathrm{G}^{\circ}$ (at standard state: $298 \mathrm{~K}, 1$ atmosphere pressure and $1 \mathrm{M}$ concentration of components), Transformed $\Delta \mathrm{G}^{\circ}$ (at physiological state: $\mathrm{pH} 7$ and at a given ionic strength). For electrochemical work, a conventional standard scale is often used, in which $\Delta \mathrm{G}=\Delta \mathrm{H}=\Delta \mathrm{S}=0$ for protons, which gives the values of the redox potentials (wherein proton concentration is taken to be $1 \mathrm{M}$ ). The dissociation constants of acids are given, as a rule, in the conventional scale. Since the $\Delta \mathrm{G}$ of solvation of proton was determined about 25 years back, the considerations need to be revisited. Regarding the theoretical and practical aspects of the free energy change of a reaction, we would like to point out that $\Delta \mathrm{G}$ is dependent on several factors, and can be calculated/determined via many methods, as listed below.

1. From the equation of a given reaction, using the free energy of formation of reactants and products. $\left(\Delta G_{\text {reaction }}=\sum \Delta G_{\text {ofproducts }}-\sum \Delta G_{\text {ofreactants }}\right)$. This can be done either in the standard or transformed scales (but the two sets of values are not to be mixed), and they give the same results.

2. Using the macroscopic properties of overall enthalpy and entropy changes at the given temperature $(\Delta G=\Delta \mathrm{H}-\mathrm{T} \Delta \mathrm{S})$

3. From the equilibrium constant of a given reversible reaction, using the concentrations of left and right hand components of an equilibrium $\left(\Delta G=-\mathrm{RT} \ln \mathrm{K}_{\mathrm{eq}}\right)$ 
4. In a redox reaction/equilibrium, from the half cell potentials of the pertinent redox couples, using the equation $(\Delta G=-n \mathrm{~F} . \Delta \mathrm{E})$

Theoretically/ideally, each of the four methods/approaches should give the same value for a given reaction. Each one of the methods listed above for finding $\Delta G$ has its advantages and pitfalls. For example, in the first one, it is necessary to know the standard free energy of formation of a species in the gas phase, for the calculation and verification of the value of the solvated/aquated species. Confusion can also arise, say, if the values determined for standard is mixed with transformed, while calculating a differential. However, using any scale (whether transformed or standard) for the calculation of free energy change of a reaction gives the same outcomes. In the second, entropy change is not easily/directly determinable quantity. In the third modality, determining equilibrium concentrations of a participant makes sense only if all the dynamic interactions of each component are well-characterized. This might not be feasible if there are intricately woven interactions/equilibriums with the solvent components (e.g. protons). In redox equilibrium, the fourth approach is valid only if simple electron transfers are involved. That said, the simplest and most reliable theoretical/empirical way is to calculate the respective norm of $\Delta \mathrm{G}$ of reaction from the $\Delta \mathrm{G}$ values of formation, using approach 1 (as determined by physical chemists over long periods of experimental and theoretical verification). The method is simple arithmetic and the values can be empirically cross-verified with other similar or different reactions involving the same term. To elaborate with an example of the simple homo- and hetero- lysis of water, with standard $\left(\Delta_{\mathrm{f}} G_{\mathrm{aq}}^{\mathrm{o}}\right) / \operatorname{transformed}\left(\Delta_{\mathrm{f}} G^{\prime \mathrm{o}}\right.$ aq $)$ Gibbs free energy terms are represented by:

$$
\begin{gathered}
\mathrm{H}_{2} \mathrm{O}(-237.2 /-155.7)={ }^{*} \mathrm{H}(223.8 / 264.6)+{ }^{*} \mathrm{OH}(25.8 / 66.6) ; \Delta_{r} G^{\mathrm{o}}=\Delta_{\mathrm{r}} G^{\prime \mathrm{o}}{ }_{\mathrm{aq}}=487 \mathrm{~kJ} / \mathrm{mol} \\
\mathrm{H}_{2} \mathrm{O}(-237.2 /-155.7)=\mathrm{H}^{+}(412.5 / 452.5)+\mathrm{OH}^{-}(-569.9 /-529.1) ; \Delta_{r} G^{\mathrm{o}}=\Delta_{\mathrm{r}} G^{\prime \mathrm{o}}{ }_{\mathrm{aq}}=79 \mathrm{~kJ} / \mathrm{mol}
\end{gathered}
$$

As seen, these reactions are very different, and the energy terms are very different. Regardless of using standard or transformed values, the differential treatment gives the consistent value of Gibbs free energy change for a reaction. This approach allows us to deal with the energetic of reactions that differ marginally, say, by the formation of: $* \mathrm{H}$ or $\mathrm{H}^{+}+\mathrm{e}^{-}$.

$$
\mathrm{H}_{2} \mathrm{O}(-237.2 /-155.7)=\mathrm{H}^{+}(412.5 / 452.5)+\mathrm{e}^{-}(-148.5 /-149.3)+{ }^{*} \mathrm{OH}(25.8 / 66.6) ; \Delta_{r} G^{\mathrm{o}}=\Delta_{\mathrm{r}} G^{\prime \mathrm{o}}{ }_{\mathrm{aq}}=526 \mathrm{~kJ} / \mathrm{mol}
$$

The approach to studying chemical energetics with charge and mass balanced equations makes comprehensive sense for simple reactions, and by extension, they should make sense for biochemical reactions too. We project that it is erroneous to overlook the contribution of protons in bioenergetics. If biochemical reactions occurred with $\mathrm{pH}$ maintenance owing to some unforeseen mechanisms (as is classically assumed), we would not have lactic acidosis (Foucher \& Tubben, 2020) or alkalosis in physiology! This fact-based argument shows that in the physiological realms, unless there is energy input $(\sim 79 \mathrm{~kJ} / \mathrm{mol})$, water does not spontaneously undergo heterolysis to give the precise amount of protons or hydroxide ions to maintain $\mathrm{pH}$. Quoting Le-Chatelier's principle in this context is violating the laws of thermodynamics.

Now, let's consider the incomplete oxidation of NADH to hydrogen peroxide (unlike the complete oxidation that leads to water formation), which is given by the mass-charge balanced equation: $\mathrm{NAD}(\mathrm{P}) \mathrm{H}+\mathrm{H}^{+}+\mathrm{O}_{2} \rightarrow \mathrm{NAD}(\mathrm{P})^{+}+\mathrm{H}_{2} \mathrm{O}_{2}$

With the first approach, we have the correct $\Delta_{\mathrm{f}} G_{\mathrm{aq}}^{\mathrm{o}} / \Delta_{\mathrm{r}} G^{\prime \mathrm{o}}{ }_{\mathrm{aq}}=-582 \mathrm{~kJ} / \mathrm{mol}$ (Manoj \& Bazhin, 2021), indicating the high spontaneity of the reaction. However, using the fourth approach of only seeing electron transfers $(\Delta \mathrm{G}=-n \mathrm{~F} . \Delta \mathrm{E})$, with the half cell reactions given as: 
$\mathrm{NAD}(\mathrm{P})^{+}+\mathrm{H}^{+}+2 \mathrm{e}^{-} \rightarrow \mathrm{NAD}(\mathrm{P}) \mathrm{H}\left(\mathrm{E}_{0}^{\prime}=-0.320 \mathrm{~V}\right)$

$\mathrm{O}_{2}+2 \mathrm{H}^{+}+2 \mathrm{e}^{-} \rightarrow \mathrm{H}_{2} \mathrm{O}_{2}\left(\mathrm{E}_{0}^{\prime}=0.680 \mathrm{~V}\right)$

$\Delta \mathrm{G}^{\circ}=-193 \mathrm{~kJ} / \mathrm{mol}[=-2 \times 96.5 \times(0.680+0.320)]$. This gives significantly low yield for the oxidation of $\mathrm{NAD}(\mathrm{P}) \mathrm{H}$ to peroxide. Therefore, the pitfalls of calculating the free energy change of biological redox reaction using mere half-cell potentials is evident from the analyses above. In this regard, we have repeatedly pointed out that this predicament resulted in biochemistry because the contribution of protons $\left(\Delta_{\mathrm{f}} G^{\prime{ }^{\circ}}\right.$ aq $\left.=452 \mathrm{~kJ} / \mathrm{mol}\right)$ was overlooked (Manoj \& Bazhin, 2021; Manoj et al., 2021a). So, in several bioenergetic reactions that involve solvent protons, their contribution to the free energy change needs to be reassessed.

\section{Item 3}

\section{LDHA}

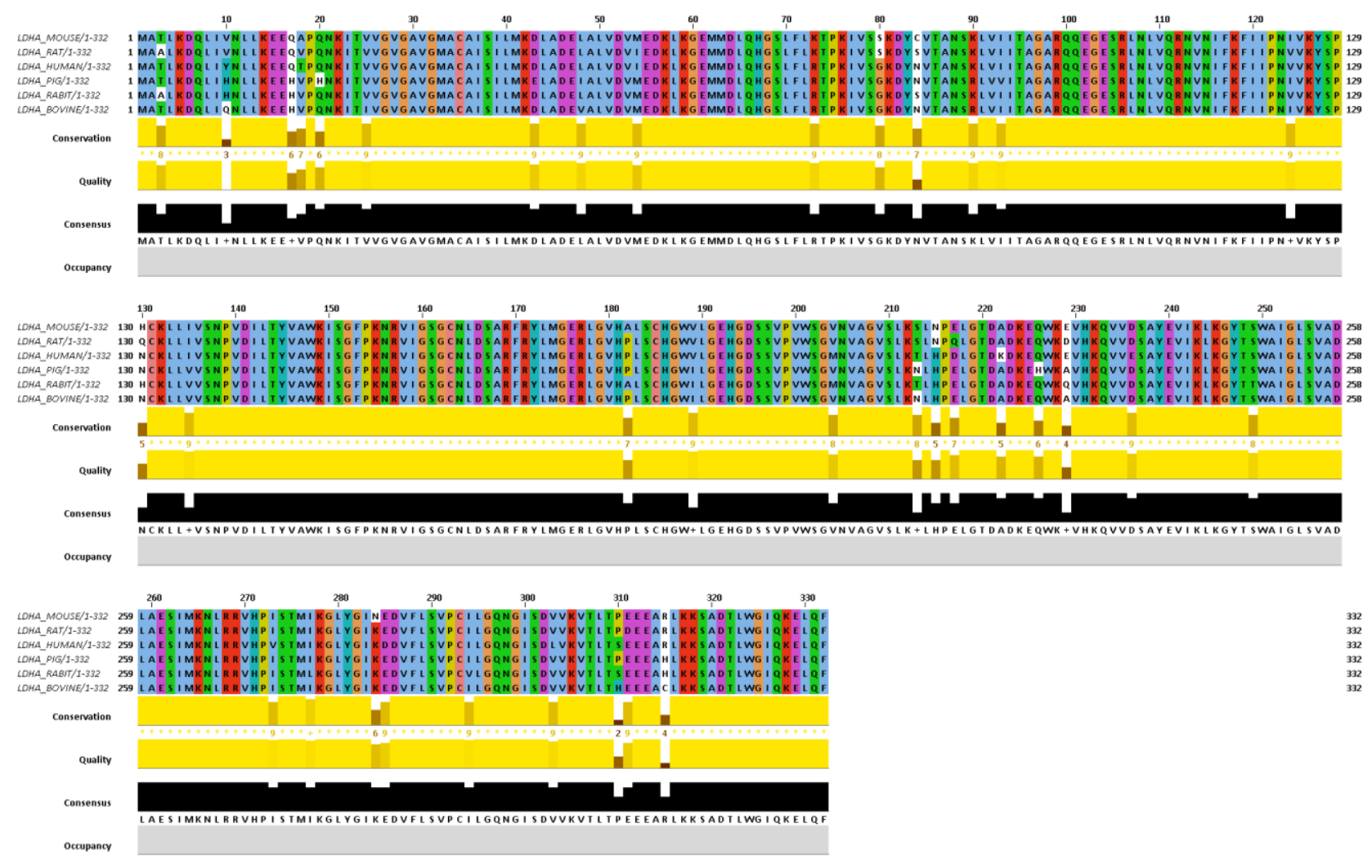

\section{LDHB}




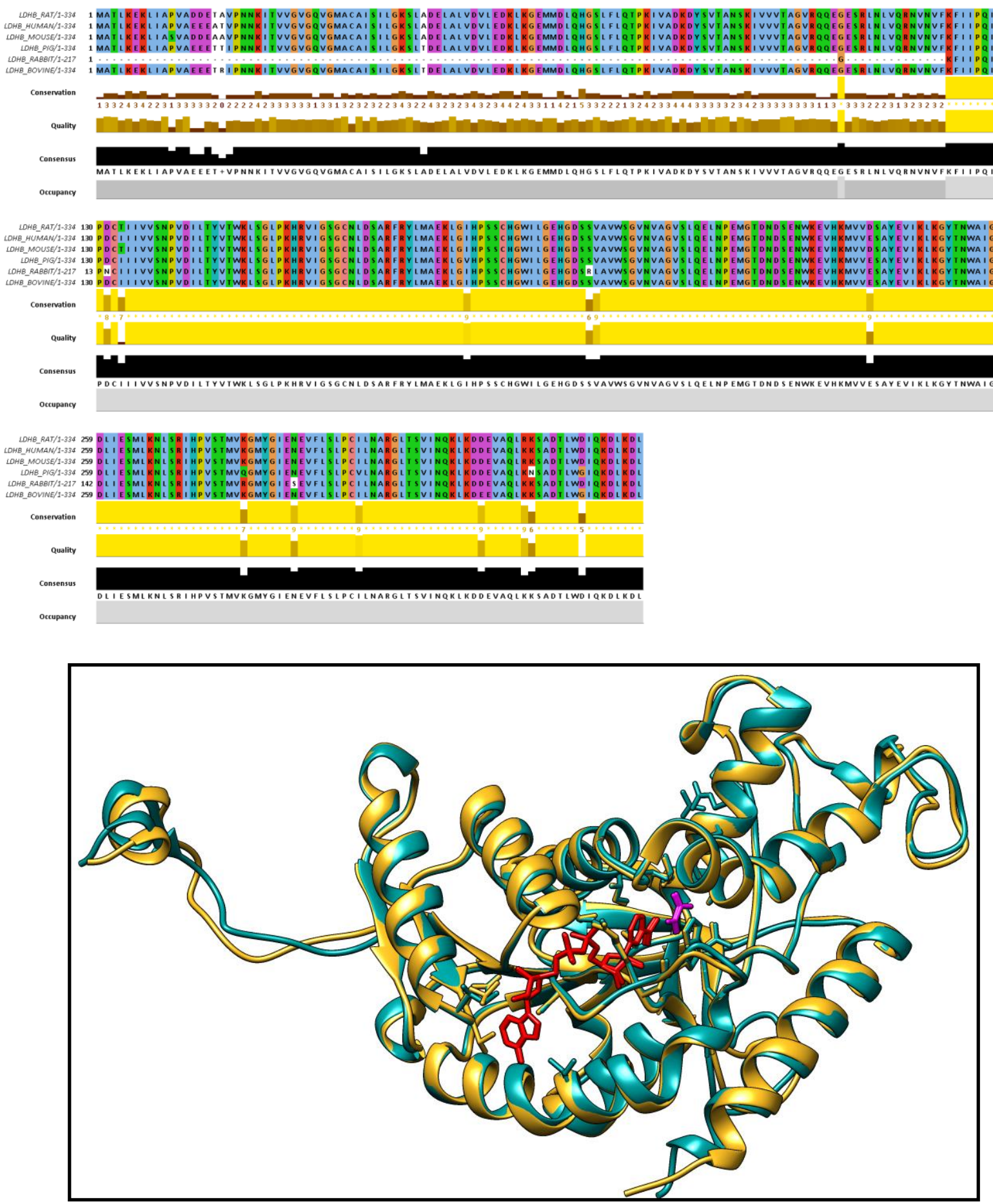

Superimposition of LDH-A and LDH-B: LDH-A is represented in gold and LDH-B is shown in turquoise. NADH is coloured red and oxamate is coloured magenta. 


\section{Item 4}

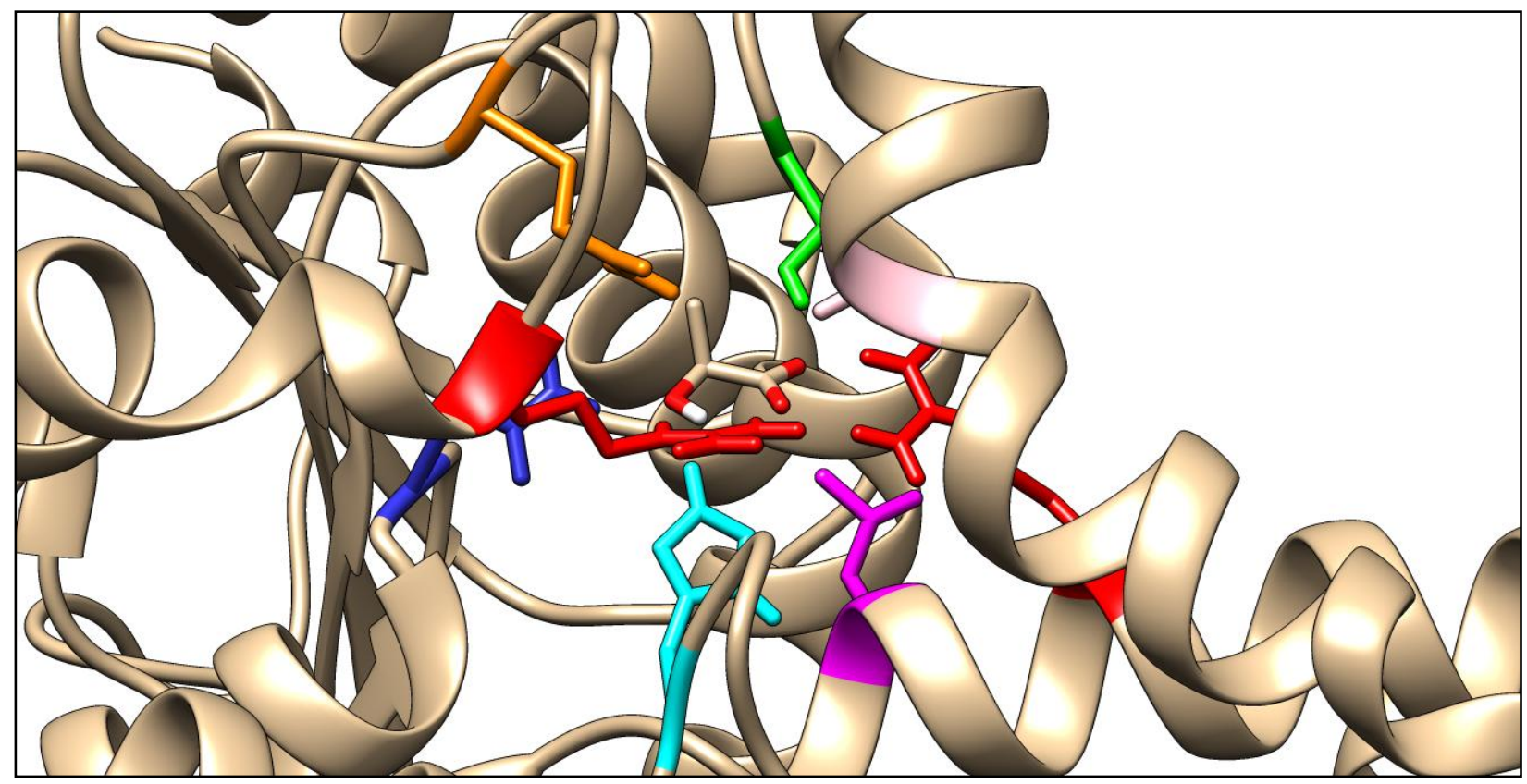

Lactate (supposed substrate) bound to LDHB (1I0Z) - A238-pink, T248-green, R169- red, R106-red, L165-magenta, H193-cyan, N138-deep blue, Q100-orange.

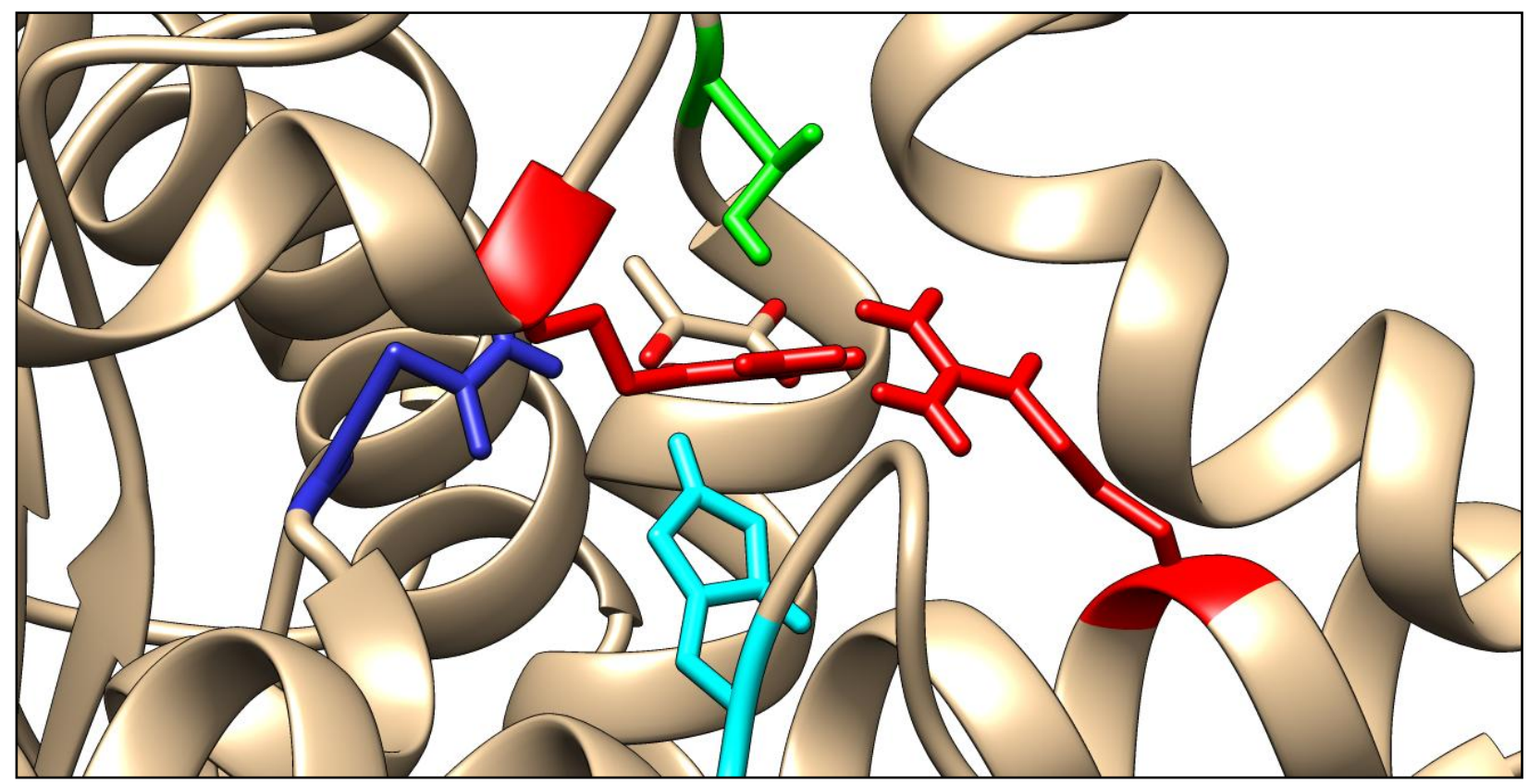

Pyruvate (supposed product) bound to LDHB (1I0Z) -T248-green, R169- red, R106-red, H193cyan, N138-deep blue. 

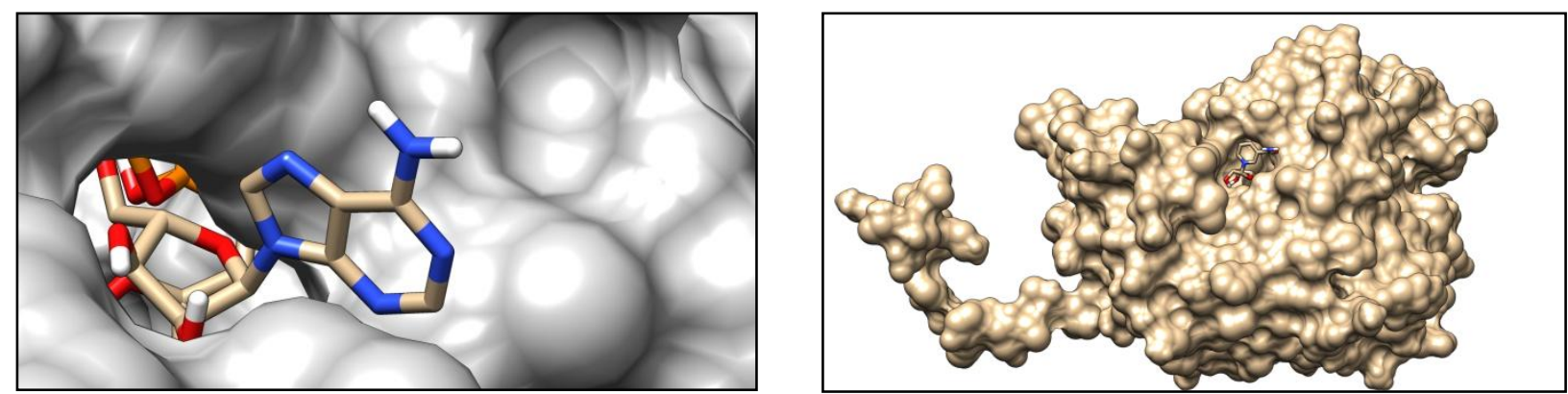

NADH (supposed product) bound to LDHB (1IOZ) - active site channel and adenine ring jutting out
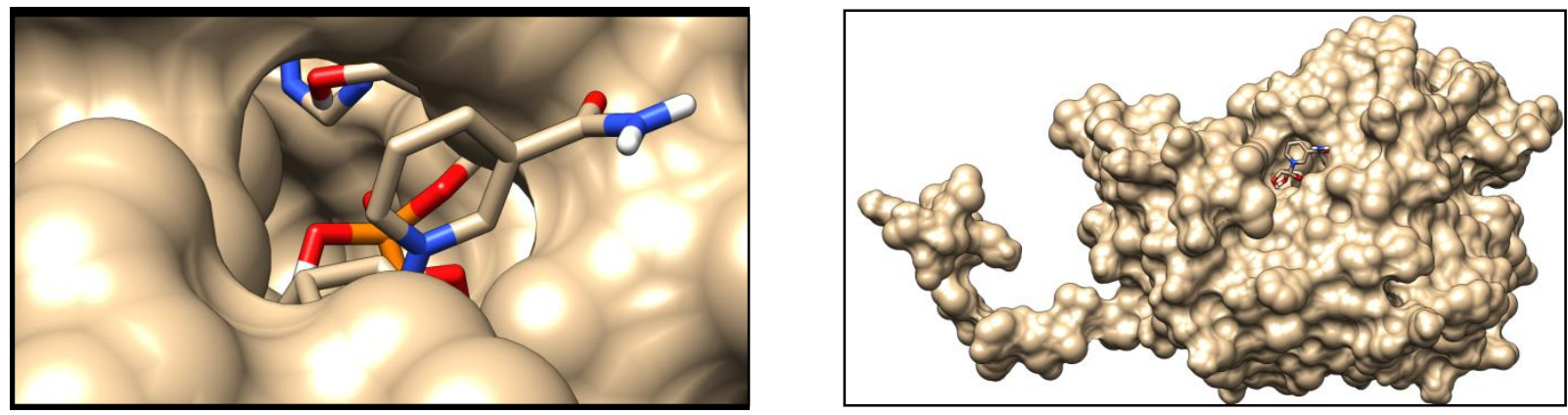

$\mathrm{NAD}^{+}$(supposed substrate) bound to LDHB (1I0Z) - active site channel and nicotinamide ring jutting out!
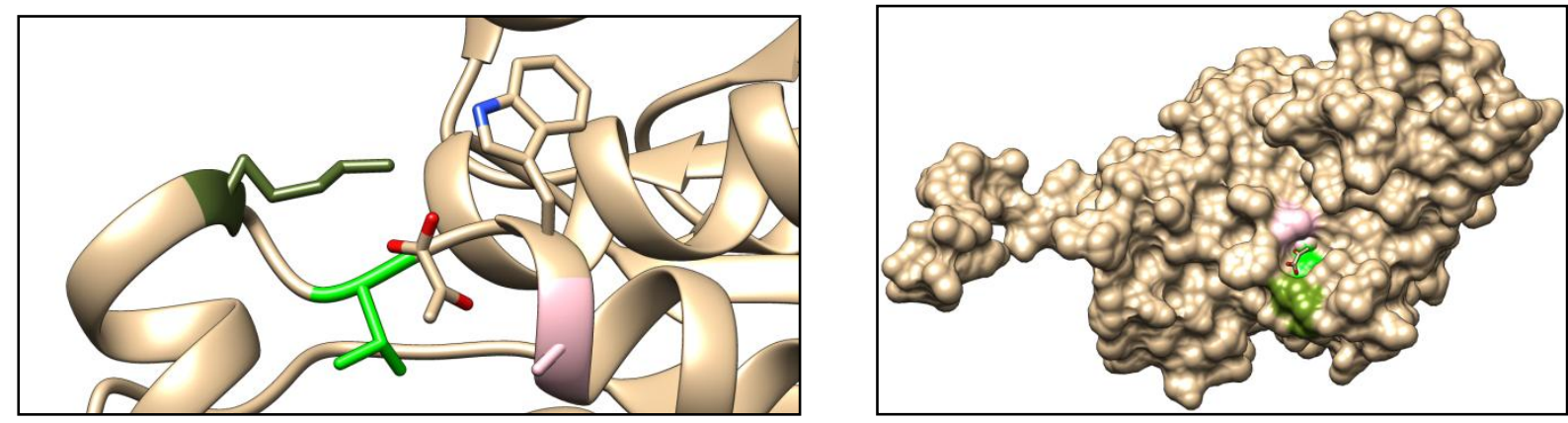

Pyruvate (supposed substrate) bound to LDHA (1I10) -binding to surface rather than active site; k244-olive green, T247-green and A250 - pink
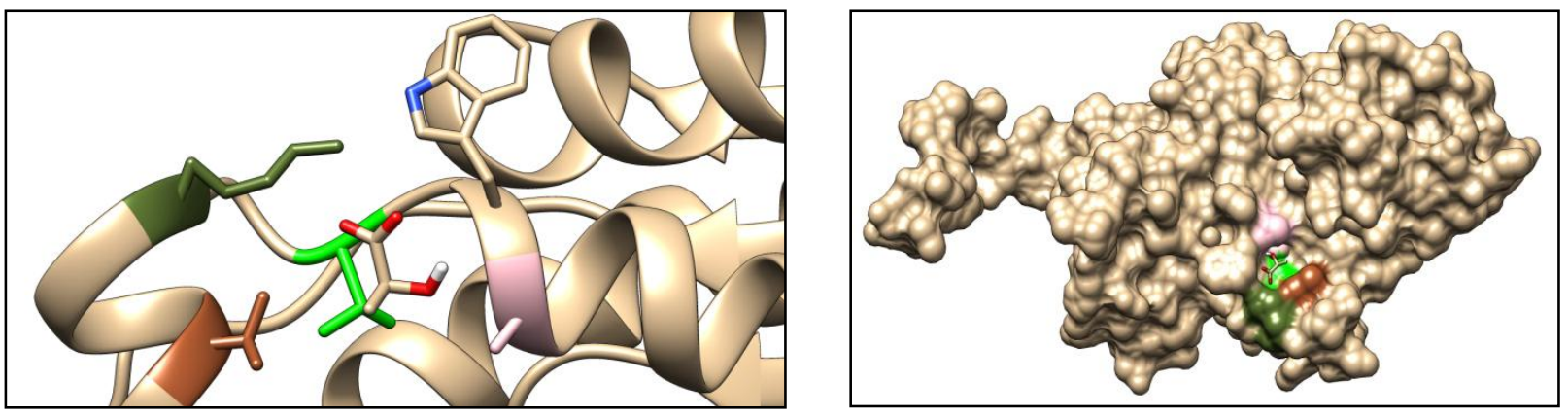
Lactate (supposed product) bound to LDHA (1I10)-binding to the surface rather than active site; k244-olive green, T247-green, V240-brown and A250 - pink
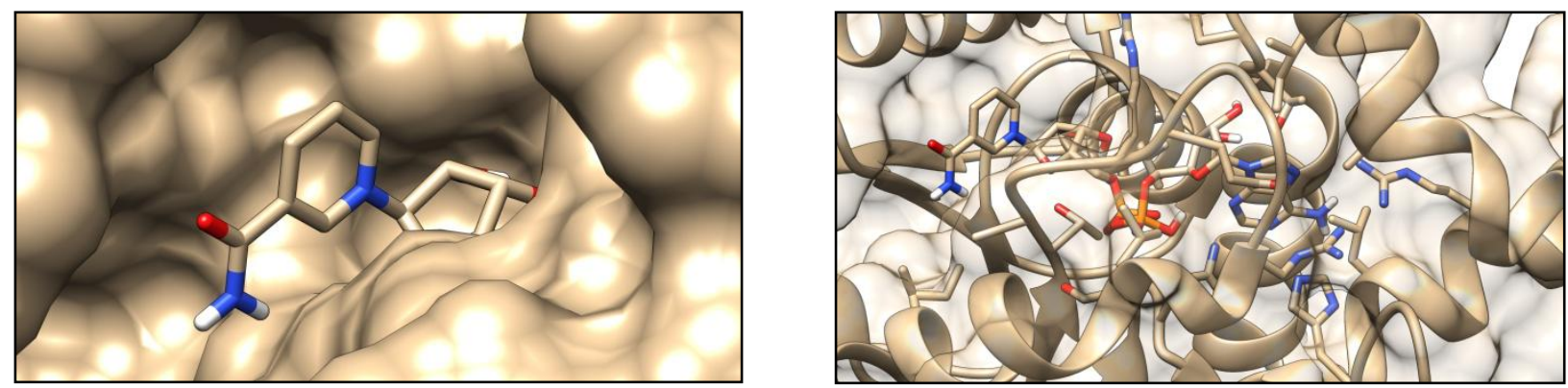

$\mathrm{NAD}^{+}$(supposed substrate in liver) bound to LDHA (1I10)-nicotinamide ring outside! Right transparency view showing contortions of $\mathrm{NAD}^{+}$
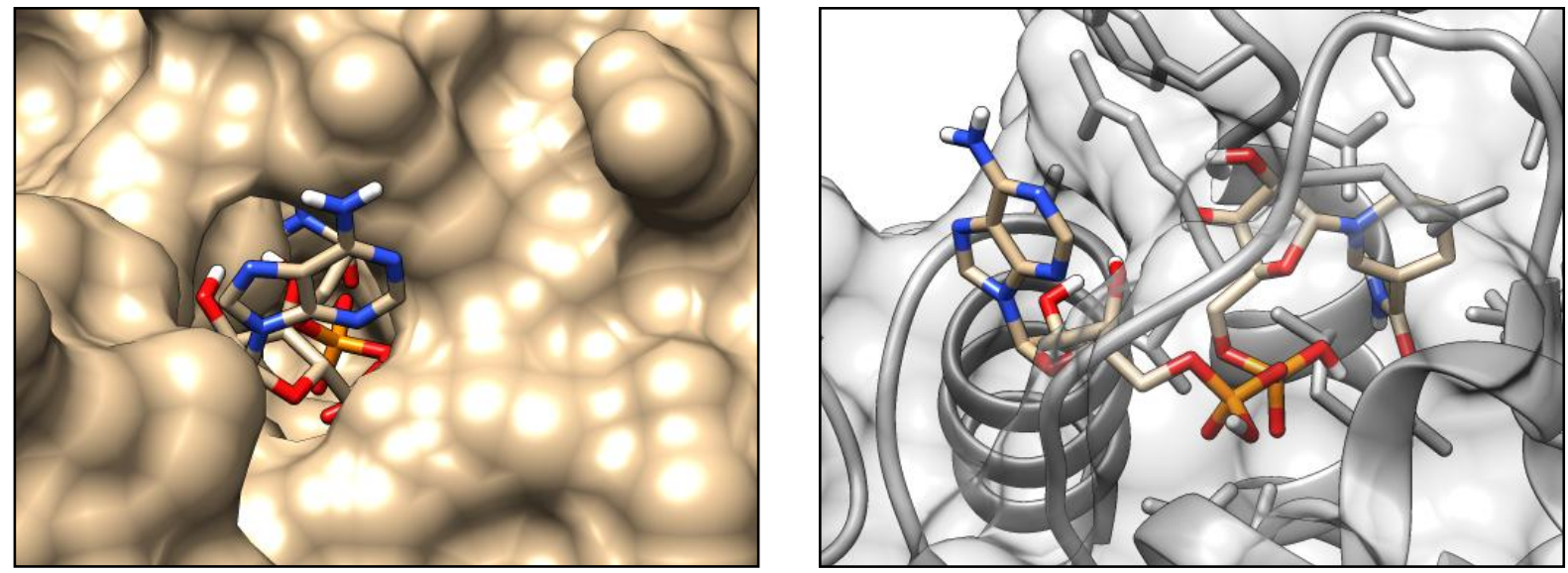

NADH (supposed substrate in muscle) binding to LDHA (1I10)- adenine ring jutting outside and right- highly contorted structure of NADH going all the way into the pocket (surface view) 


\section{Binding of substrate with multimer}

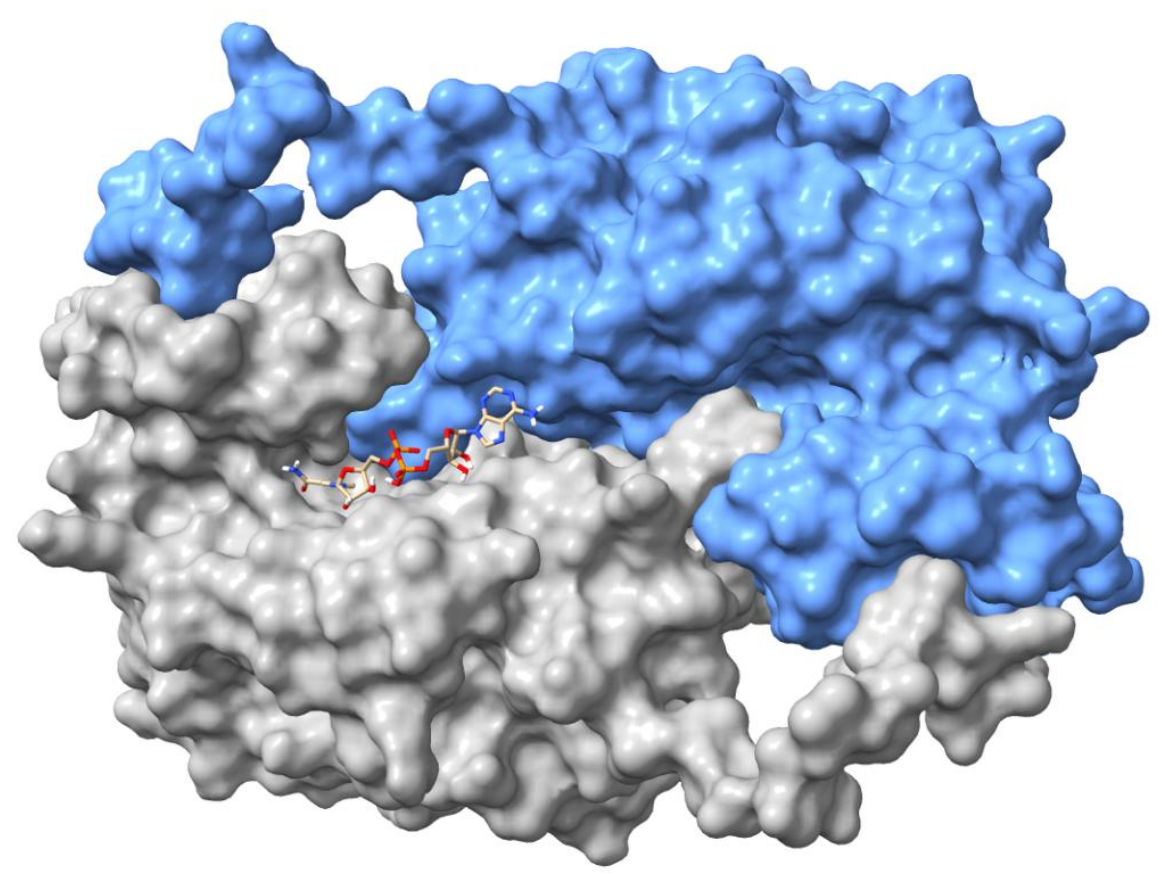

Human LDH B/H (1ioz) with NAD ${ }^{+}(541 \mu \mathrm{M})$

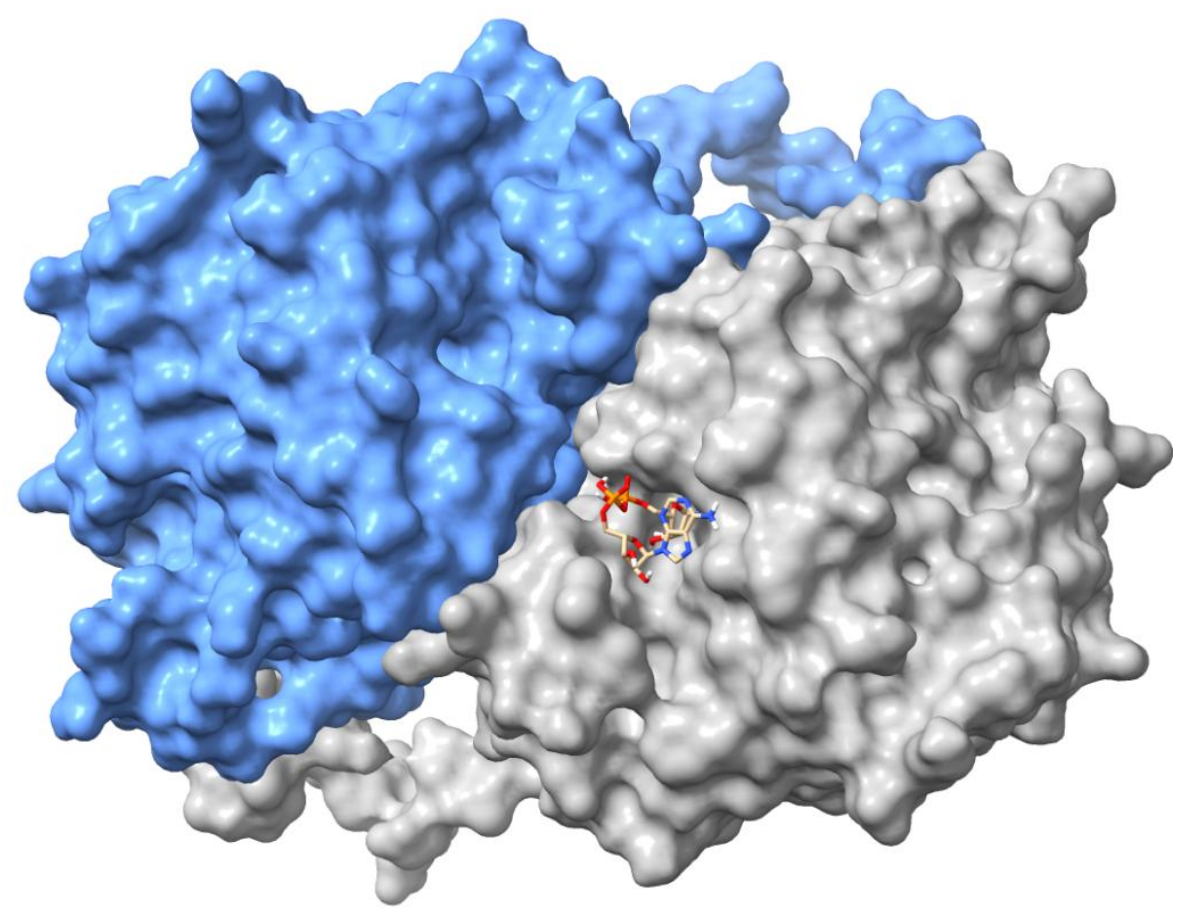

Human LDH B/H (1ioz) with NADH (164 $\mu \mathrm{M})$ 

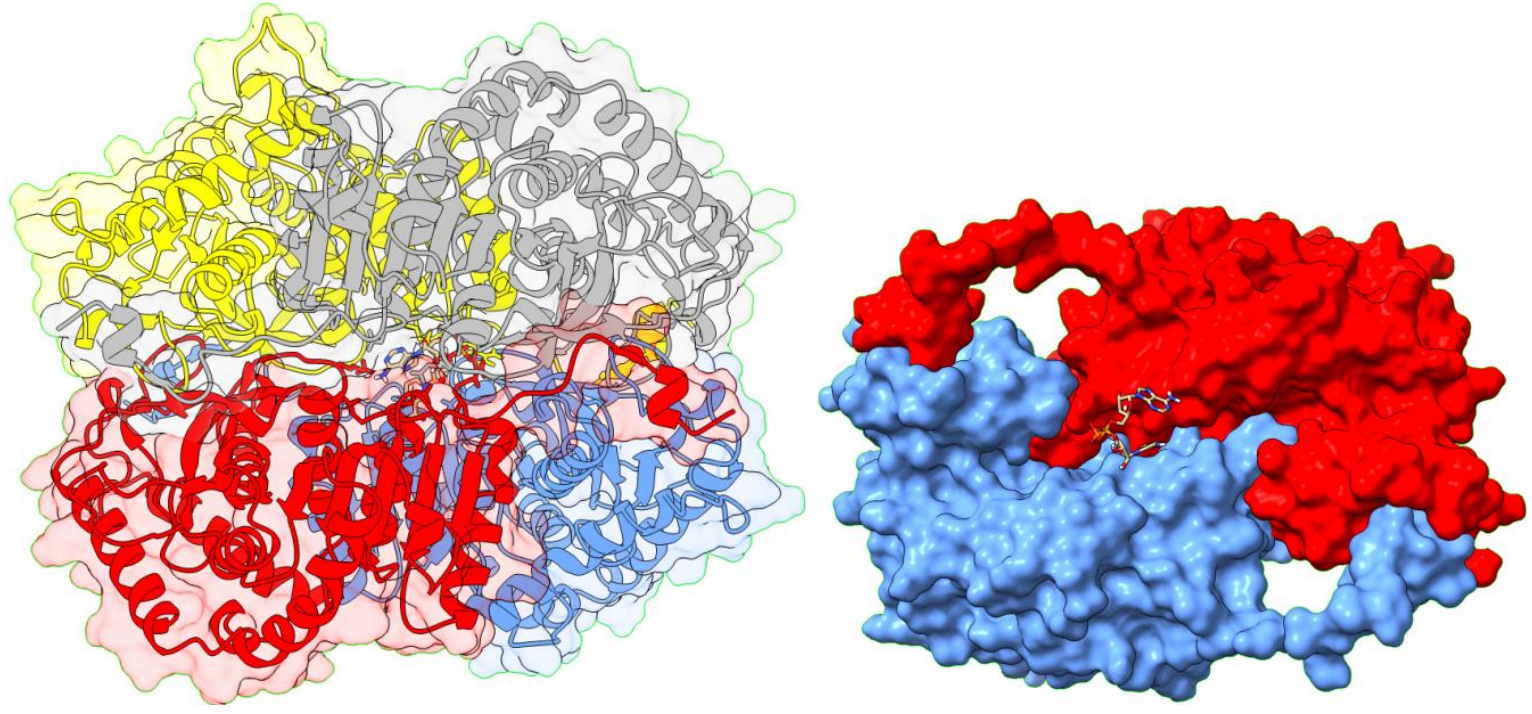

Left- NAD ${ }^{+}$bound in between the four monomers (1i10) $(8.9 \mu \mathrm{M})$ and Right$\mathrm{NAD}^{+}$binding in the crevice between two monomers
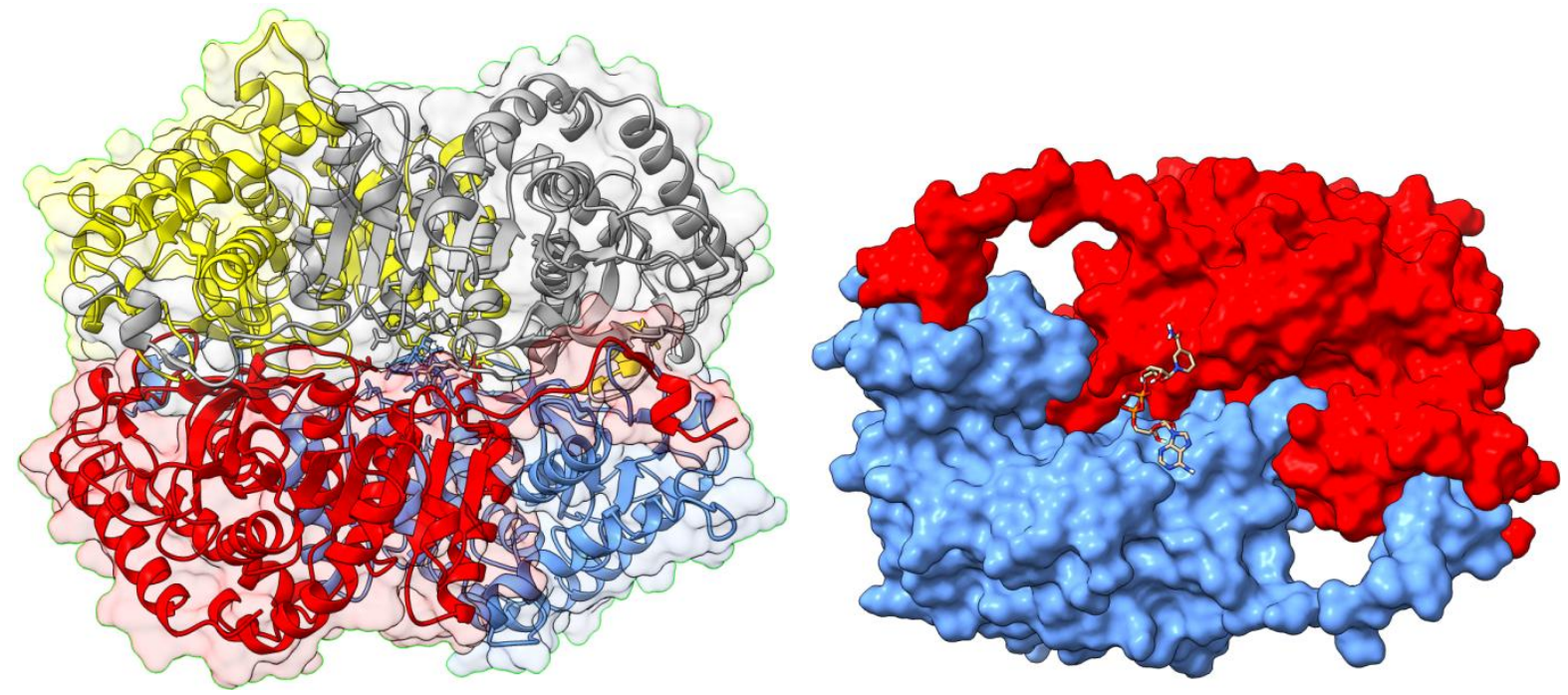

NADH bound in between the four monomers (1i10) $(41.2 \mu \mathrm{M})$ and Right- NADH binding in the crevice between two monomers

Question: If there can be large molecule interfacial inhibitors, why can't NAD ${ }^{+}$or $\mathrm{NADH}$ bind in the region between the monomers? 


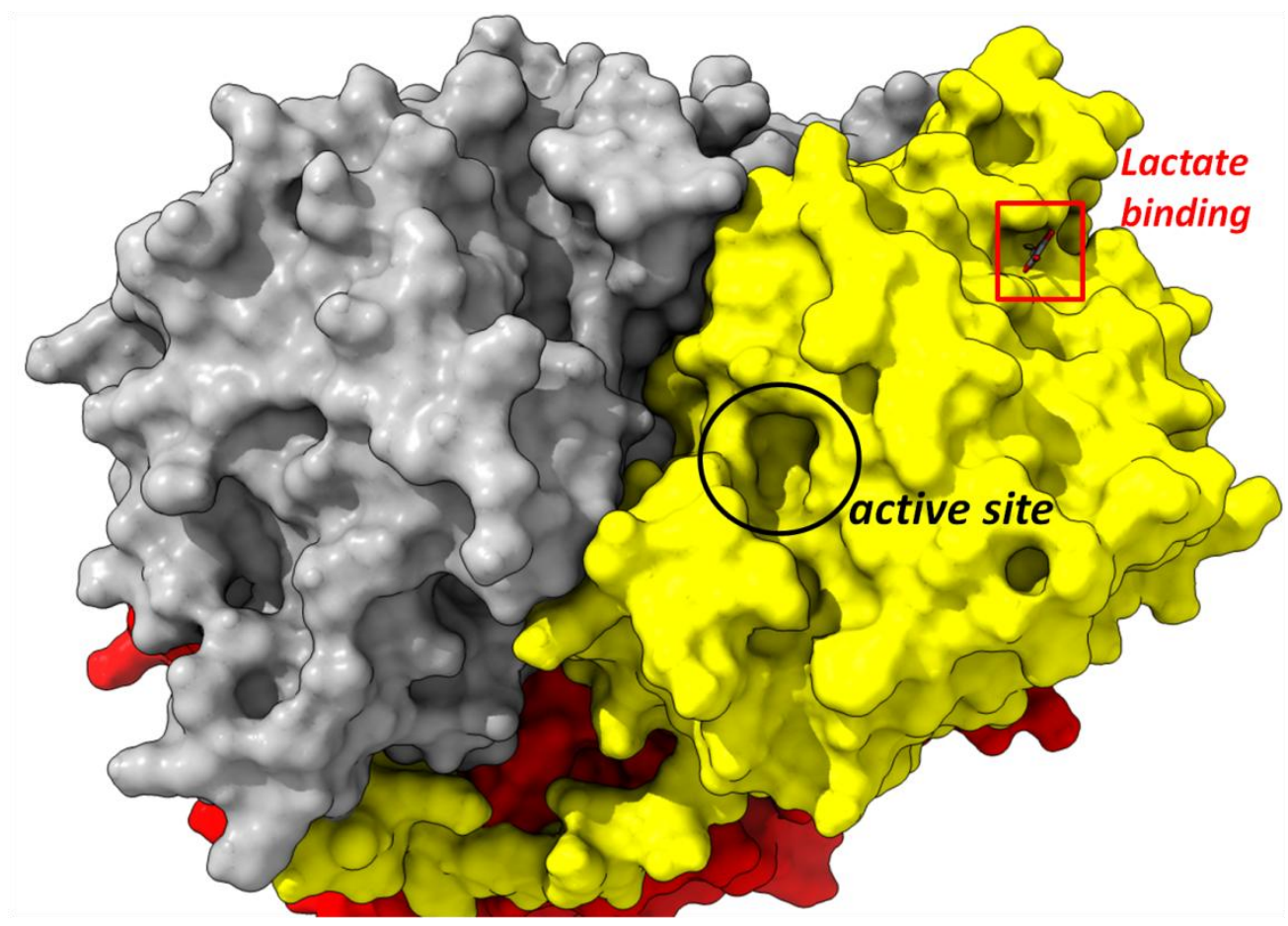

Lactate binding to a different site (other than the active site) of LDHA tetramer (1i10)

\section{POCASA study:}

\begin{tabular}{|c|c|c|c|c|c|c|c|c|}
\hline PDB & SPF & PDF & $\begin{array}{c}\text { No. of } \\
\text { Pockets }\end{array}$ & $\begin{array}{c}\text { Top N } \\
\text { Pockets }\end{array}$ & Pocket & Volume & VD & $\begin{array}{c}\text { Average } \\
\text { VD }\end{array}$ \\
\hline $\begin{array}{c}1110 \\
\text { Human A }\end{array}$ & 16 & 18 & 10 & 5 & 285 & 272 & 1671 & 6.14338 \\
\hline $\begin{array}{c}110 Z \\
\text { Human B }\end{array}$ & 16 & 18 & 13 & 5 & 69 & 368 & 1622 & 4.40942 \\
\hline $\begin{array}{c}3 \mathrm{H} 3 \mathrm{~F} \\
\text { Rabbit A }\end{array}$ & 16 & 18 & 10 & 5 & 164 & 689 & 1853 & 2.6894 \\
\hline $\begin{array}{l}5 E S 3 \\
\text { Rat A }\end{array}$ & 16 & 18 & 13 & 5 & 80 & 407 & 1044 & 2.56593 \\
\hline $\begin{array}{l}\text { 5LDH } \\
\text { Pig A }\end{array}$ & 16 & 18 & 15 & 5 & 348 & 394 & 1697 & 4.3088 \\
\hline $\begin{array}{l}\text { 5YTA } \\
\text { Pig B }\end{array}$ & 16 & 18 & 8 & 5 & 249 & 344 & 1685 & 4.89826 \\
\hline
\end{tabular}

SPF - Single Point Flag; PDF - Protein Depth Flag; VD - Volume Depth. 
Item 5<smiles>Oc1ccc2c(c1)OCCO2</smiles>

01<smiles>CC(Cc1ccc2c(c1)OCO2)C(C)Cc1ccc2c(c1)OCO2</smiles>

02<smiles>FC(F)(F)c1ccc([Se]c2ccccc2)cc1</smiles>

05<smiles>CCCc1c(O)c(O)c(C(=O)O)c2cc(Cc3ccccc3)c(C)cc12</smiles>

06<smiles>O=c1cc2c(=O)oc3cc(O)c(O)oc3c2c(O)c1O</smiles><smiles>O=C(OC1Cc2c(O)cc(O)cc2OC1c1cc(O)c(O)c(O)c1)c1cc(O)c(O)c(O)c1</smiles><smiles>COc1cc2c(Nc3cccc(C(=O)O)c3)c(C(N)=O)cnc2cc1-c1c(C)noc1C</smiles><smiles>Cc1cc2c(C(C)C)c(O)c(O)c(C=O)c2c(O)c1-c1c(C)cc2c(C(C)C)c(O)c(O)c(C=O)c2c1O</smiles><smiles>O=C1OC2(CCCc3c(-c4ccccc4)cccc32)CC(O)=C1Sc1ccccc1Cl</smiles>

12

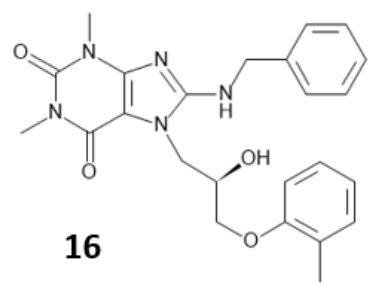

15

13<smiles>O=C(O)CC(O)(CC(=O)O)C(=O)O</smiles>

11
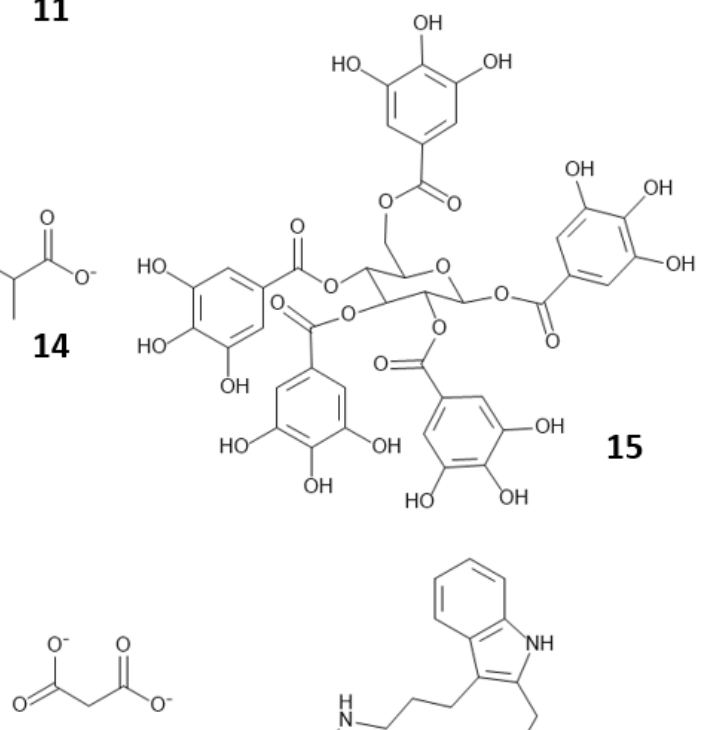

19

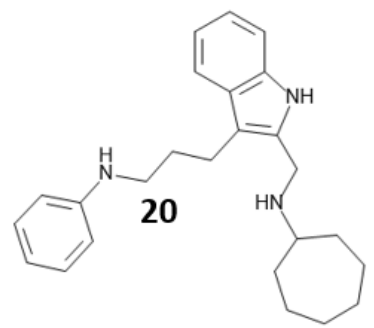

01. Sesamol; 02. Machilin A; 03. Galloflavin; 04. 3-((3-carbamoyl-7-(3,5 dimethylisoxazol-4-yl)-6methoxyquinolin-4-yl) amino) benzoic acid (CDMIMQABA); 05. 1-Phenylseleno-4-trifluoromethylbenzene (PSTMB); 06. FX-11; 07. Epigallocatechin Gallate (EGCG); 08. Gossypol; 09. Oxamic acid; 10. Citric acid; 11. Acylhydrazone derivative; 12. Genetech; 13. GlaxoSmithKline; 14. Methylmalonate; 15. Penta-O-galloylglucose; 16. Purinedione derivative; 17. Oxamate; 18. Oxalate; 19. Malonate; 20. AXKO0046 